\title{
AVTA Federal Fleet PEV Readiness Data Logging and Characterization Study for United States Coast Guard Headquarters
}

Stephen Schey Jim Francfort

November 2014

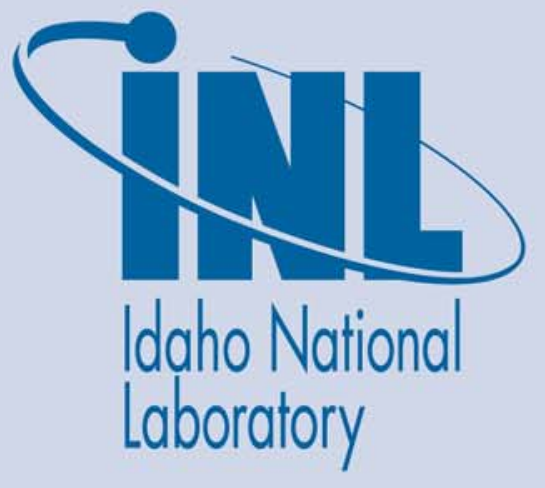

The INL is a U.S. Department of Energy National Laboratory operated by Battelle Energy Alliance 


\section{DISCLAIMER}

This information was prepared as an account of work sponsored by an agency of the U.S. Government. Neither the U.S. Government nor any agency thereof, nor any of their employees, makes any warranty, expressed or implied, or assumes any legal liability or responsibility for the accuracy, completeness, or usefulness, of any information, apparatus, product, or process disclosed, or represents that its use would not infringe privately owned rights. References herein to any specific commercial product, process, or service by trade name, trade mark, manufacturer, or otherwise, does not necessarily constitute or imply its endorsement, recommendation, or favoring by the U.S. Government or any agency thereof. The views and opinions of authors expressed herein do not necessarily state or reflect those of the U.S. Government or any agency thereof. 
INL/EXT-15-34869

\title{
AVTA Federal Fleet PEV Readiness Data Logging and Characterization Study for United States Coast Guard Headquarters
}

\author{
Stephen Schey \\ Jim Francfort ${ }^{2}$ \\ ${ }^{1}$ Project Manager, Infrastructure Planning and Analysis, Intertek Testing Services, North America; \\ Phoenix, Arizona \\ ${ }^{2}$ Vehicle Systems Principal Investigator, Idaho National Laboratory operated by Battelle Energy \\ Alliance, Idaho Falls, Idaho
}

November 2014

\author{
Idaho National Laboratory \\ Idaho Falls, Idaho 83415
}

http://avt.inl.gov

Prepared for the

U.S. Department of Energy

Office of Nuclear Energy

Under DOE Idaho Operations Office

Contract DE-AC07-05ID14517 


\section{ABSTRACT}

Battelle Energy Alliance, LLC, managing and operating contractor for the U.S. Department of Energy's Idaho National Laboratory, is the lead laboratory for U.S. Department of Energy's advanced vehicle testing. Battelle Energy Alliance, LLC contracted with Intertek Testing Services, North America (Intertek) to collect and evaluate data on federal fleet operations as part of the Advanced Vehicle Testing Activity's Federal Fleet Vehicle Data Logging and Characterization Study. The Advanced Vehicle Testing Activity Study seeks to collect and evaluate data to validate the utilization of advanced plug-in electric vehicle (PEV) transportation.

This report focuses on the United States Coast Guard Headquarters (USCG HQ) fleet to identify daily operational characteristics of select vehicles and report findings on vehicle and mission characterizations to support the successful introduction of PEVs into the agency's fleet.

Individual observations of these selected vehicles provide the basis for recommendations related to electric vehicle adoption and whether a battery electric vehicle or plug-in hybrid electric vehicle (collectively referred to as PEVs) can fulfill the mission requirements.

Intertek acknowledges the support of Idaho National Laboratory and USCG HQ personnel for participation in the study. 


\section{EXECUTIVE SUMMARY}

Federal agencies are mandated to purchase alternative fuel vehicles, increase consumption of alternative fuels, and reduce petroleum consumption. Available plug-in electric vehicles (PEVs) provide an attractive option in the selection of alternative fuel vehicles. PEVs, which consist of both battery electric vehicles (BEVs) and plug-in hybrid electric vehicles (PHEVs), have significant advantages over internal combustion engine (ICE) vehicles in terms of energy efficiency, reduced petroleum consumption, and reduced production of greenhouse gas (GHG) emissions, and they provide performance benefits with quieter, smoother operation. This study intended to evaluate the extent to which the United States Coast Guard Headquarters (USCG HQ) could convert part or all of their fleet of vehicles from petroleum-fueled vehicles to PEVs.

It is likely that more fuel-efficient ICE vehicles, including hybrid electric vehicles, exist that may provide improvements for the current fleet; however, this study's focus is on replacing ICE vehicles with suitable PEVs.

$\mathrm{BEVs}$ provide the greatest benefit when it comes to fuel and emissions savings because all motive power is provided by the energy stored in the onboard battery pack. These vehicles use no petroleum and emit no pollutants at their point of use. PHEVs provide similar savings when their battery provides the motive power, but they also have the ability to extend their operating range with an onboard ICE. Because a PHEV can meet all transportation range needs, the adoption of a PHEV will be dependent on its ability to meet other transportation needs such as cargo or passenger carrying. Operation of PHEVs in battery-only mode can be increased with opportunity charging at available charging stations. It should be noted, however, that not all PHEVs have a mode in which the battery provides all motive power at all speeds. This study focuses on the mission requirements of a fleet of vehicles with the objective to identify vehicles that may be replaced with PEVs, with emphasis on BEVs that provide maximum benefit.

The U.S. Coast Guard is one of five branches of the U.S. Armed Forces and it falls under the jurisdiction of the U.S. Department of Homeland Security. The Coast Guard is an adaptable, responsive military force of maritime professionals whose broad legal authorities, capable assets, geographic diversity, and expansive partnerships provide a persistent presence along our rivers, in the ports, littoral regions, and on the high seas. In 2012, it included over 43,000 active duty members, over 8,000 reservists, over 8,800 civilian employees, and over 30,000 volunteer auxiliarists. ${ }^{a}$

At the time of this study, the USCG HQ was located at $21002^{\text {nd }} \mathrm{St}$ SW in Washington D.C. USCG HG was more recently relocated to 2701 Martin Luther King Jr. Ave SE, Washington, D.C. 20032.

Ten vehicles were identified as representative of the entire fleet and instrumented for data collection and analysis. Fleet vehicle mission categories

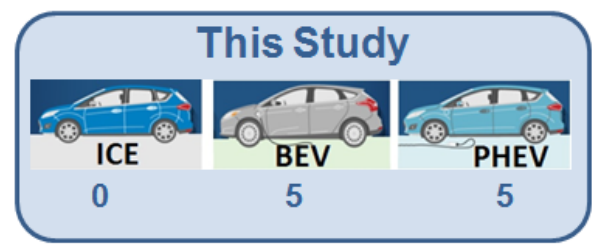

\footnotetext{
${ }^{\mathrm{a}}$ http://www.uscg.mil/top/about// [accessed November 20, 2014].
} 
are defined in Section 4 and, while the USCG HQ vehicles conduct many different missions, the pool mission was selected by agency management to be part of this fleet evaluation.

This report observes that a mix of BEVs and PHEVs are capable of performing most of the required missions and of providing an alternative vehicle for the pool vehicles. This is because, while some vehicles travel long distances, the group could support some BEVs for the short trips and PHEVs for the longer trips. The recommended mix of vehicles will provide sufficient range for individual trips and time is available each day for charging to accommodate multiple trips per day. These charging events could occur at the vehicle's home base. Replacement of vehicles in the current fleet would result in significant reductions in the emission of GHGs and in petroleum

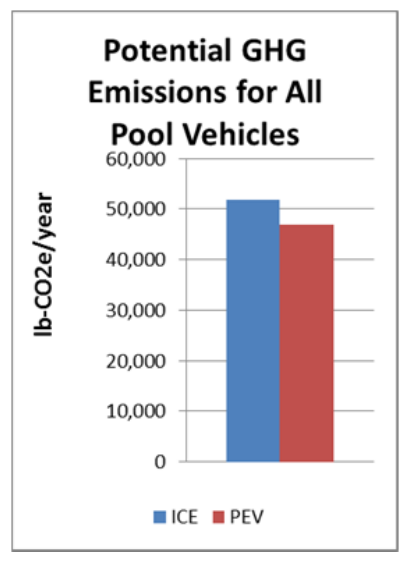
use, as well as reduced fleet operating costs.

Based on the data collected for the monitored vehicles, the 10-vehicle fleet subset could possibly consist of five BEVs and five PHEVs. The replacement of these 10 ICE vehicles with PEVs could result in an annual GHG savings over

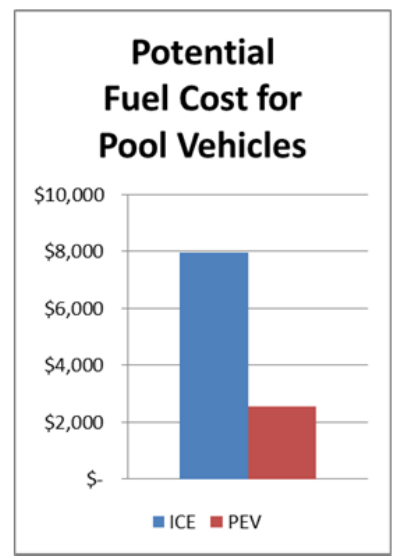
$5,109 \mathrm{lb}-\mathrm{CO}^{2} \mathrm{e}(10 \%$ reduction) and an annual fuel cost savings of $\$ 5,417$ ( $68 \%$ reduction).

PEV charging stations located near USCG HQ could benefit not only USCG HQ's own fleet vehicles but also those in the visiting public and employees who own PEVs.

Intertek suggests USCG HQ may wish to move forward in the near future with the replacement of pool vehicles with PEVs as current budget and vehicle replacement schedules allow. Certainly, the vehicle types studied in this report may be candidates for immediate replacement. 


\section{CONTENTS}

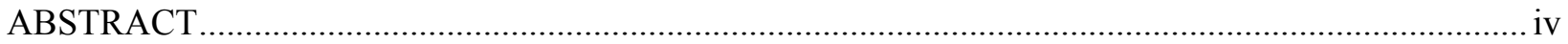

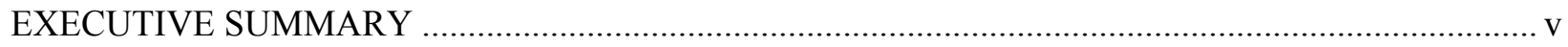

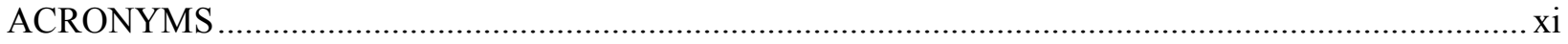

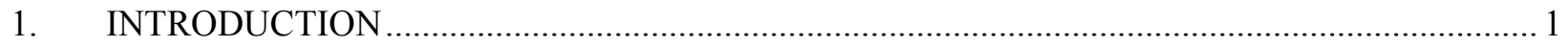

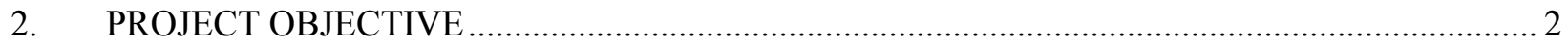

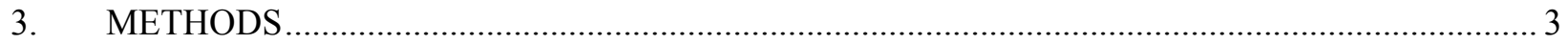

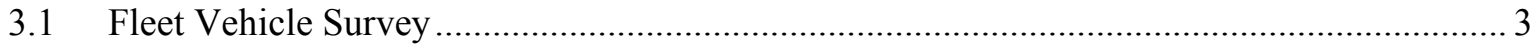

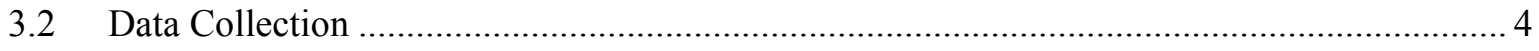

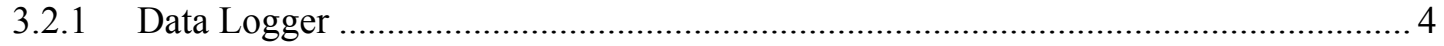

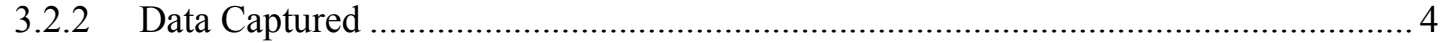

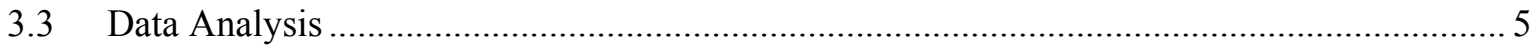

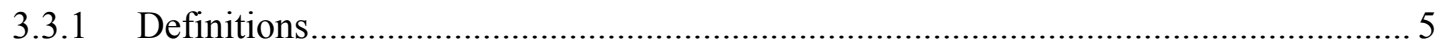

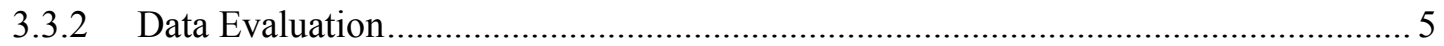

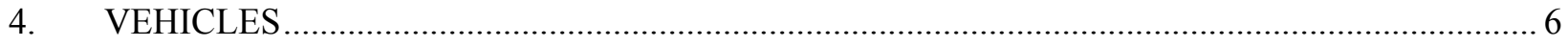

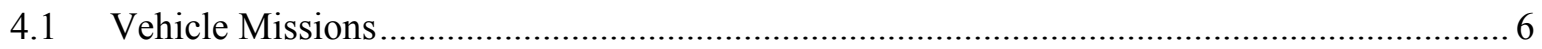

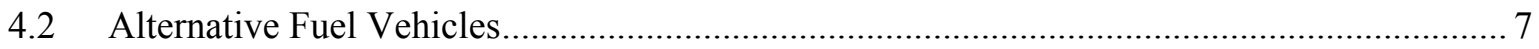

4.3 Battery Electric Vehicle and Plug-In Hybrid Electric Vehicle Benefits/Challenges ............... 7

4.3.1 Battery Electric Vehicle Benefits/Challenges ...................................................... 7

4.3.2 Plug-in Hybrid Electric Vehicle Benefits/Challenges............................................ 8

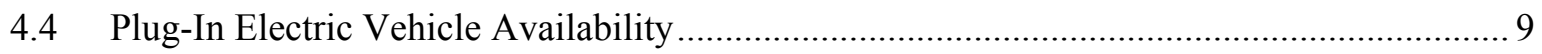

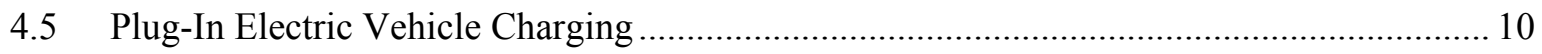

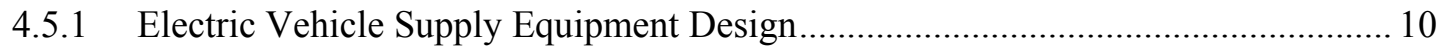

4.5.2 Electric Vehicle Supply Equipment Stations ....................................................... 13

5. U.S. Coast Guard Headquarters Springfield, Ballenger Creek Fleet Evaluation .......................... 15

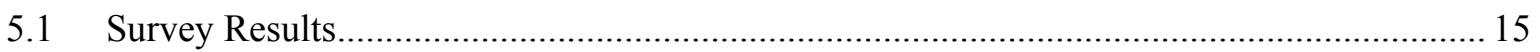

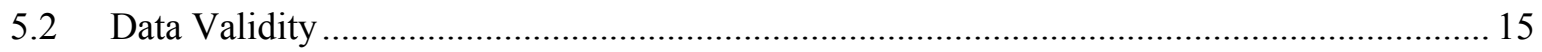

5.3 U.S. Coast Guard Headquarters Pool Vehicles Evaluation................................................ 15 


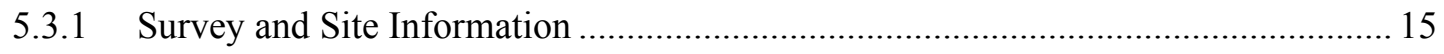

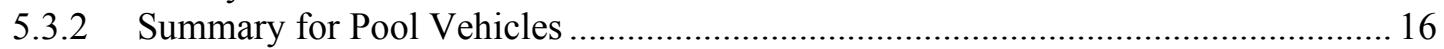

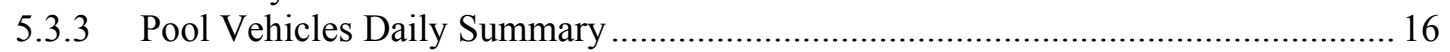

5.3.4 U.S. Coast Guard Headquarters Pool Vehicle Observations/Summary ..................... 18

5.3.5 U.S. Coast Guard Headquarters Pool Vehicle Charging Needs................................ 19

\section{GREENHOUSE GAS EMISSIONS AVOIDED AND FUEL COST REDUCTION}

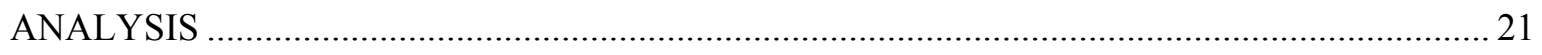

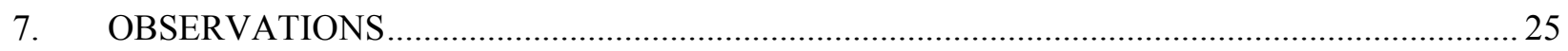

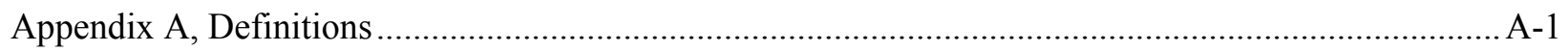

Appendix B, USCG HQ Vehicle Data Sheets .............................................................................. B-1

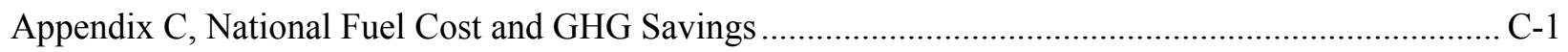

\section{FIGURES}

1. USCG HQ 2012 facilities graphical representation..............................................................2

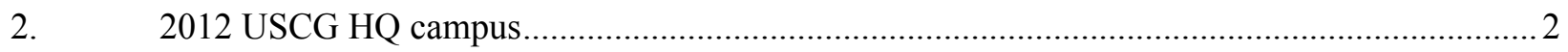

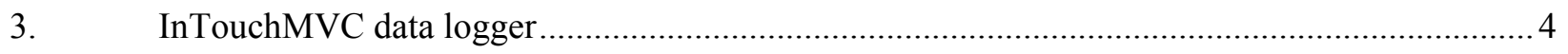

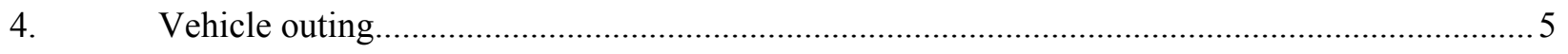

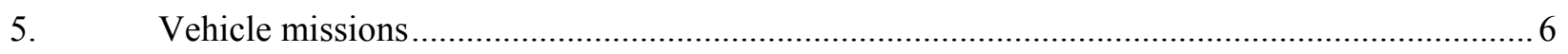

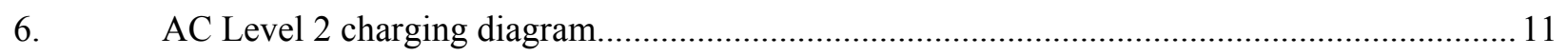

7. Society of Automotive Engineers charging configurations and ratings terminology ................ 12

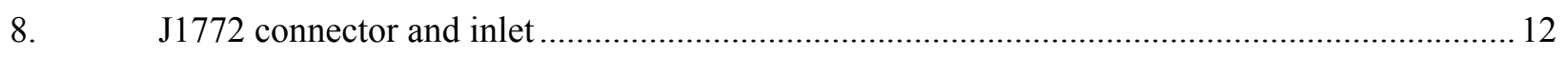

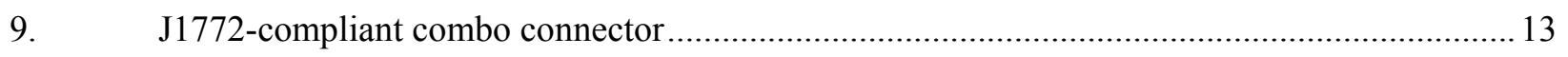

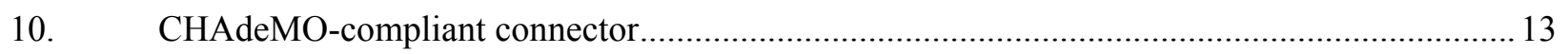

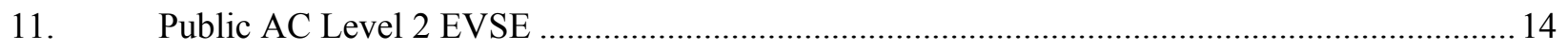

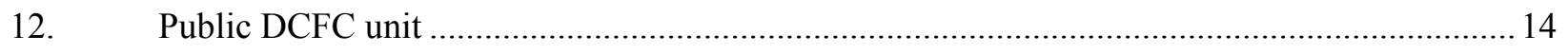

13. USCG HQ pool vehicle daily travel miles and time (all vehicles) ....................................... 16

14. USCG HQ pool vehicle daily travel history (all vehicles) …............................................. 17

15. USCG HQ pool vehicles travel time (all vehicles) ......................................................... 17

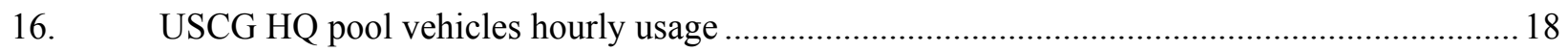




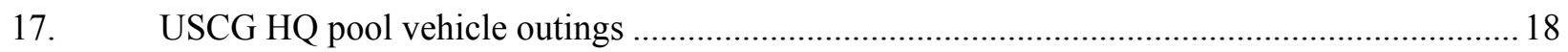

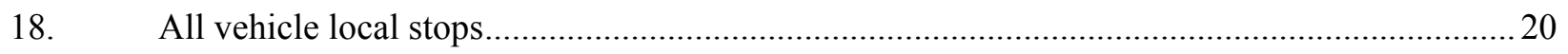

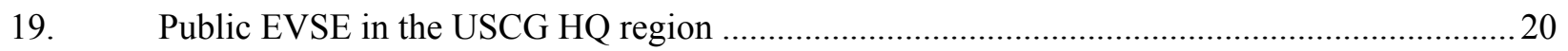

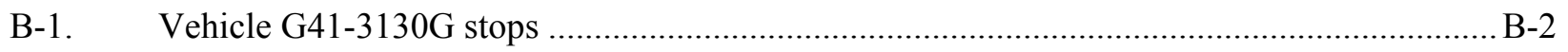

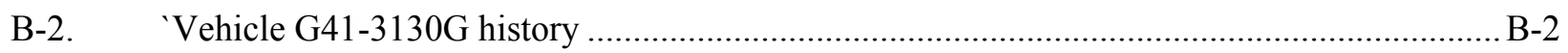

B-3. Vehicle G41-3130G travel graph..................................................................................... B-3

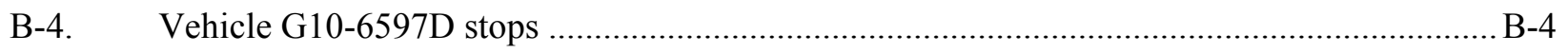

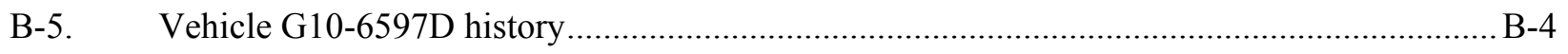

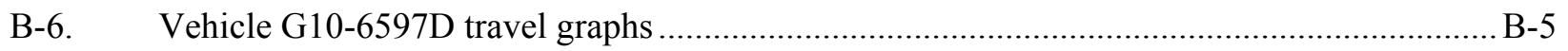

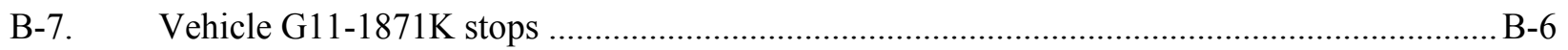

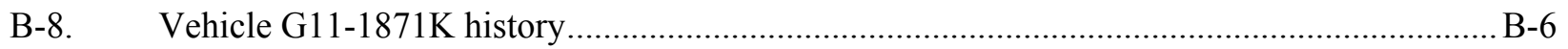

B-9. Vehicle G11-1871K travel graphs ....................................................................................... B-7

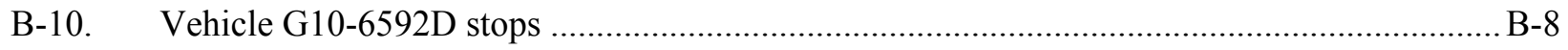

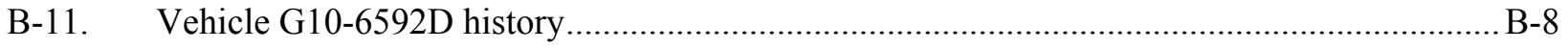

B-12. Vehicle G10-6592D travel graphs ................................................................................. B-9

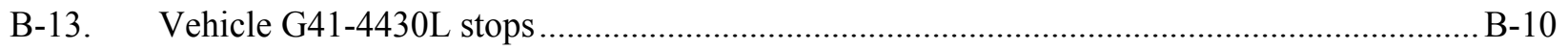

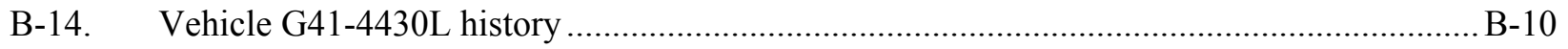

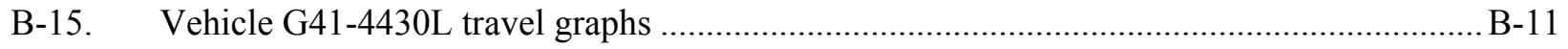

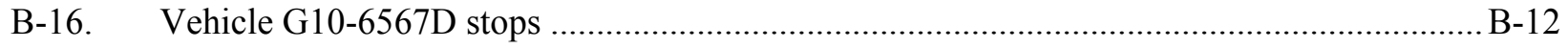

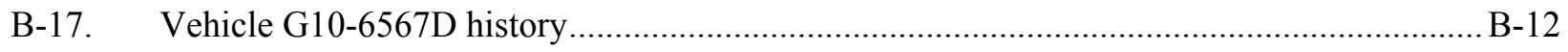

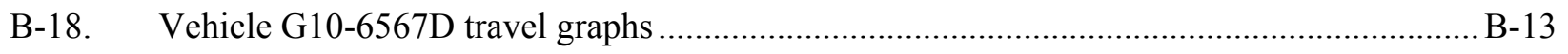

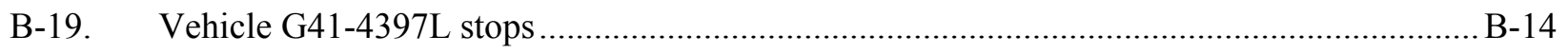

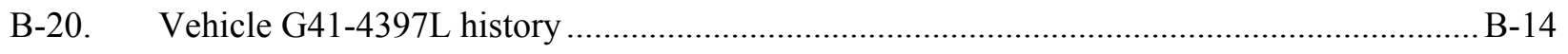

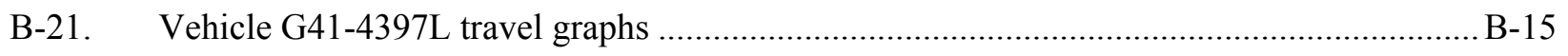

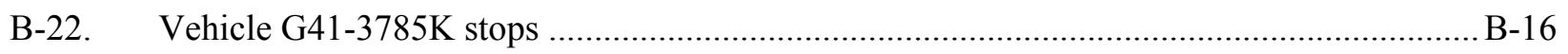

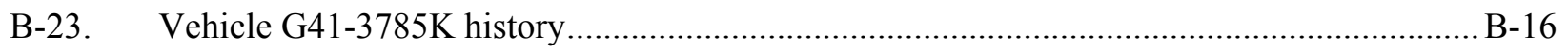




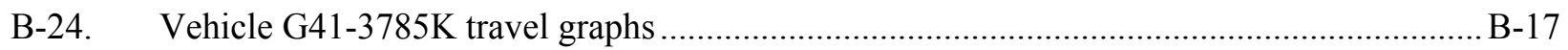

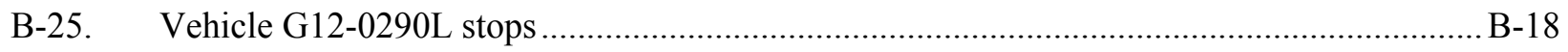

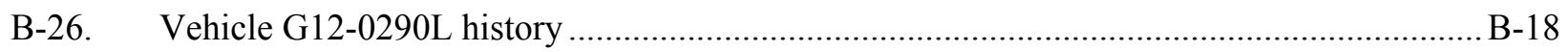

B-27. Vehicle G12-0290L travel graphs ............................................................................... B-19

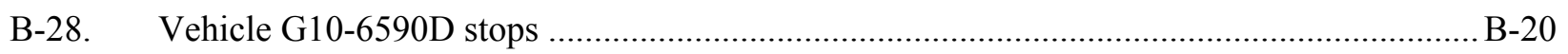

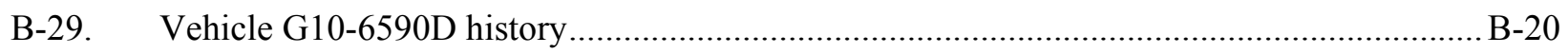

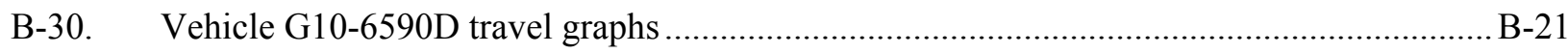

\section{TABLES}

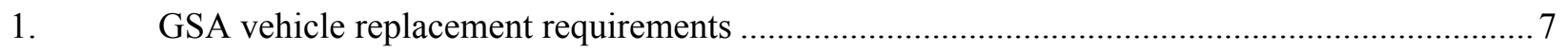

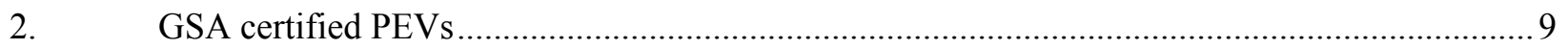

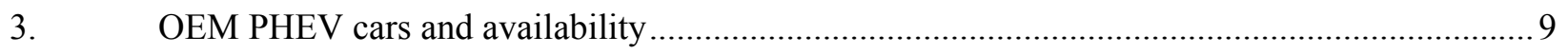

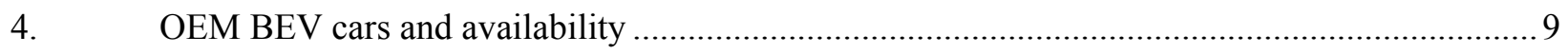

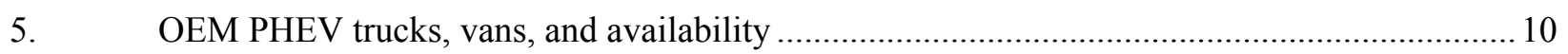

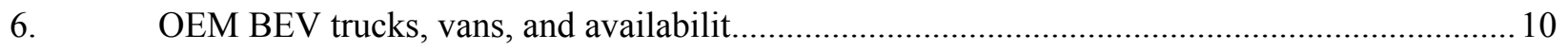

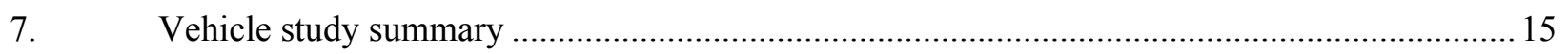

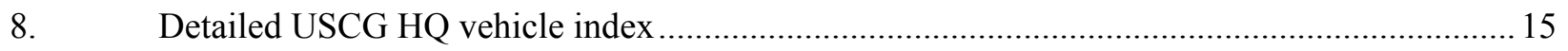

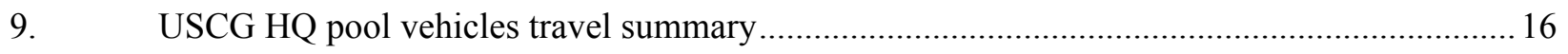

10. U.S. EPA fuel economy ratings of current fleet vehicles ................................................2

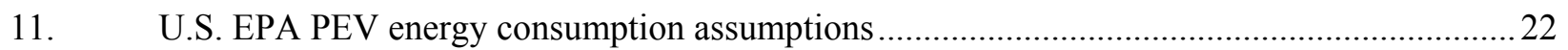

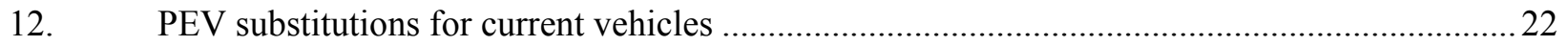

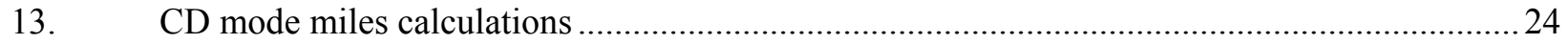

14. Greenhouse gas emissions avoidance and fuel cost reduction analysis summary ....................22

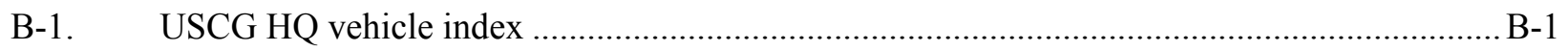

C-1. Fuel cost and GHG savings on a national basis............................................................ 


\section{ACRONYMS}

$\mathrm{AC} \quad$ alternating current

BEV battery electric vehicle

CD charge depleting

CS charge sustaining

DC direct current

EPA U.S. Environmental Protection Agency

EVSE electric vehicle supply equipment

GHG greenhouse gas emissions

GSA General Services Administration

ICE internal combustion engine

Intertek Intertek Testing Services, North America

OEM original equipment manufacturers

PEPCO Potomac Electric Power Company

PEV plug-in electric vehicle (includes BEVs and PHEVs, but not hybrid electric vehicles)

PHEV plug-in hybrid electric vehicle

SUV sport utility vehicle

USCG United States Coast Guard

VIN vehicle identification number 


\section{INTRODUCTION}

Federal agencies are mandated by the Energy Policy Act of $1992,{ }^{2}$ Energy Policy Act of $2005,{ }^{3}$ Executive Order 13423 (President Bush 2007), ${ }^{4}$ Executive Order 13514 (President Obama), ${ }^{5}$ and the Energy Independence and Security Act of $2007^{6}$ to purchase alternative fuel vehicles, increase consumption of alternative fuels, reduce petroleum consumption, and reduce greenhouse gas (GHG) emissions.

Battelle Energy Alliance, LLC, managing and operating contractor for Idaho National Laboratory, is the lead laboratory for the U.S. Department of Energy's advanced vehicle testing and manages the Advanced Vehicle Testing Activity Federal Fleet Vehicle Data Logging and Characterization Study, which promotes utilization of advanced electric drive vehicle transportation technologies. The Advanced Vehicle Testing Activity focuses its testing activities on emerging and newly commercialized plug-in electric vehicle (PEV) technologies, because of the high-energy efficiencies and reduced consumption of petroleum through use of electric-drive vehicles. Battelle Energy Alliance, LLC selected Intertek Testing Services, North America (Intertek) to collect data on federal fleet operations and report the findings on vehicle and mission characterizations to support the successful introduction of PEVs into federal fleets.

It is likely that more fuel efficient internal combustion engine (ICE) vehicles, including hybrid electric vehicles, exist that may provide improvements for the current fleet; however, these vehicles are not the focus of this study.

Because of the large number of vehicles in federal fleets in the United States, these fleets provide a substantial opportunity for the introduction of battery electric vehicles (BEVs) and plug-in hybrid electric vehicles (PHEVs) (collectively referred to as PEVs). However, to assess the scale of this opportunity, additional data are required to characterize the various missions performed by each fleet and to determine which existing vehicles are most suitable for replacement by PEVs.

The U.S. Coast Guard is one of five branches of the U.S. Armed Forces and falls under the jurisdiction of the U.S. Department of Homeland Security. In 2012, it included over 43,000 active duty members, over 8,000 reservists, over 8,800 civilian employees, and over 30,000 volunteer auxiliarists. ${ }^{7}$

At the time of this study, the U.S. Coast Guard Headquarters (USCG HQ) was located at $21002^{\text {nd }} \mathrm{St}$ SW in Washington D.C. However, headquarters was more recently relocated to 2701 Martin Luther King Jr. Ave SE, Washington, D.C. 20032.

USCG HQ is an excellent organization for fleet evaluation because of its size, locations, and travel between this site and other local destinations. USCG HQ has an opportunity to be a leader in the adoption of BEVs and PHEVs for its fleet. In addition, electric vehicle charging stations that may be installed at USCG HQ may be generally available for use by employees and visitors.

\footnotetext{
${ }^{2}$ http://thomas.loc.gov/cgi-bin/query/z?c102:h.r.776.enr [accessed January 10, 2014].

${ }^{3}$ http://www.gpo.gov/fdsys/pkg/BILLS-109hr6enr/pdf/BILLS-109hr6enr.pdf [accessed January 10, 2014].

${ }^{4}$ http://www.gsa.gov/portal/content/102452 [accessed January 10, 2014].

${ }^{5}$ https://www.fedcenter.gov/programs/eo13514/ [accessed September 1, 2014].

${ }^{6}$ http://www.gpo.gov/fdsys/pkg/PLAW-110publ140/pdf/PLAW-110publ140.pdf [accessed January 10, 2014].

${ }^{7}$ http://www.uscg.mil/top/about/ [accessed November 20, 2014].
} 


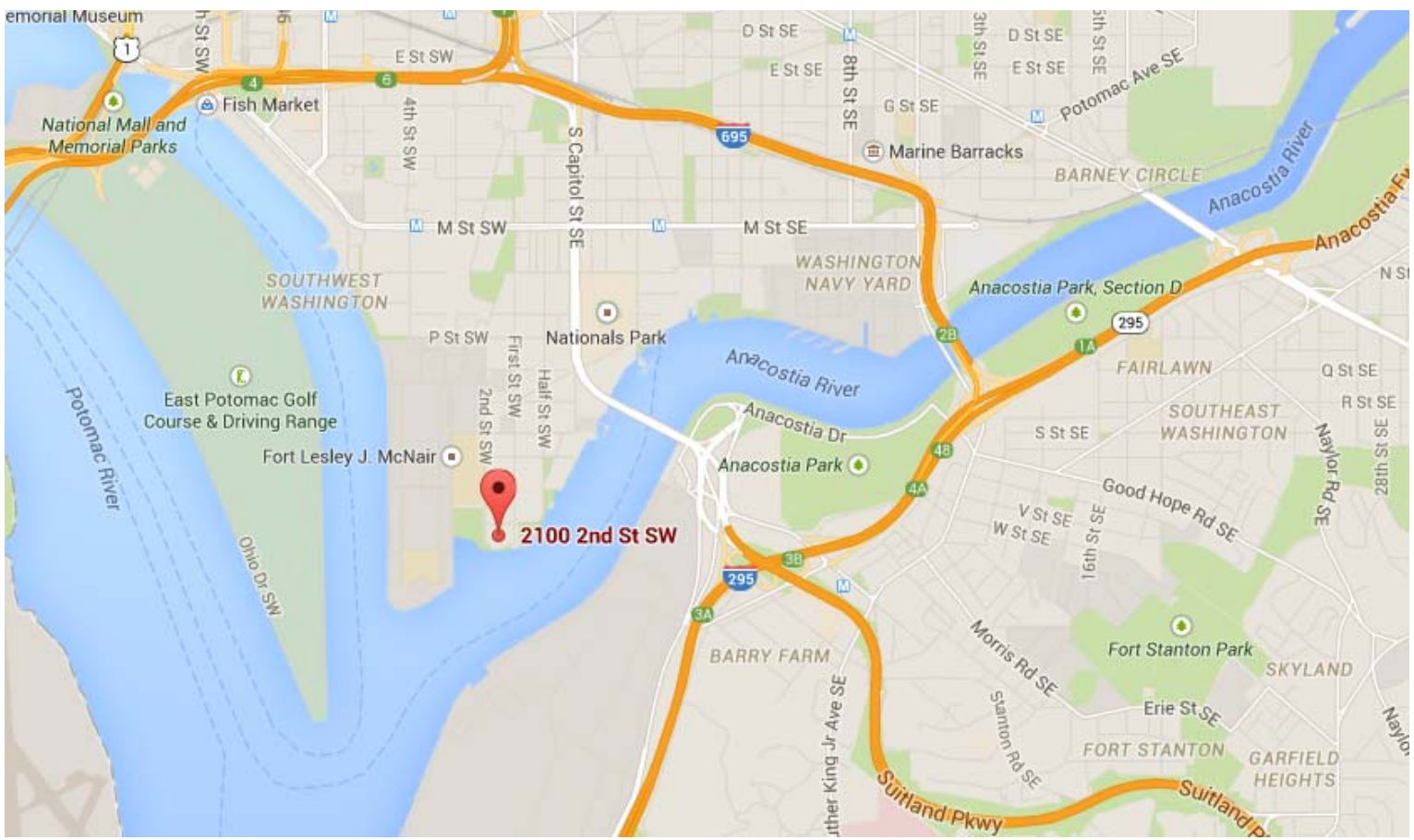

Figure 1. USCG HQ 2012 facilities graphical representation. ${ }^{8}$

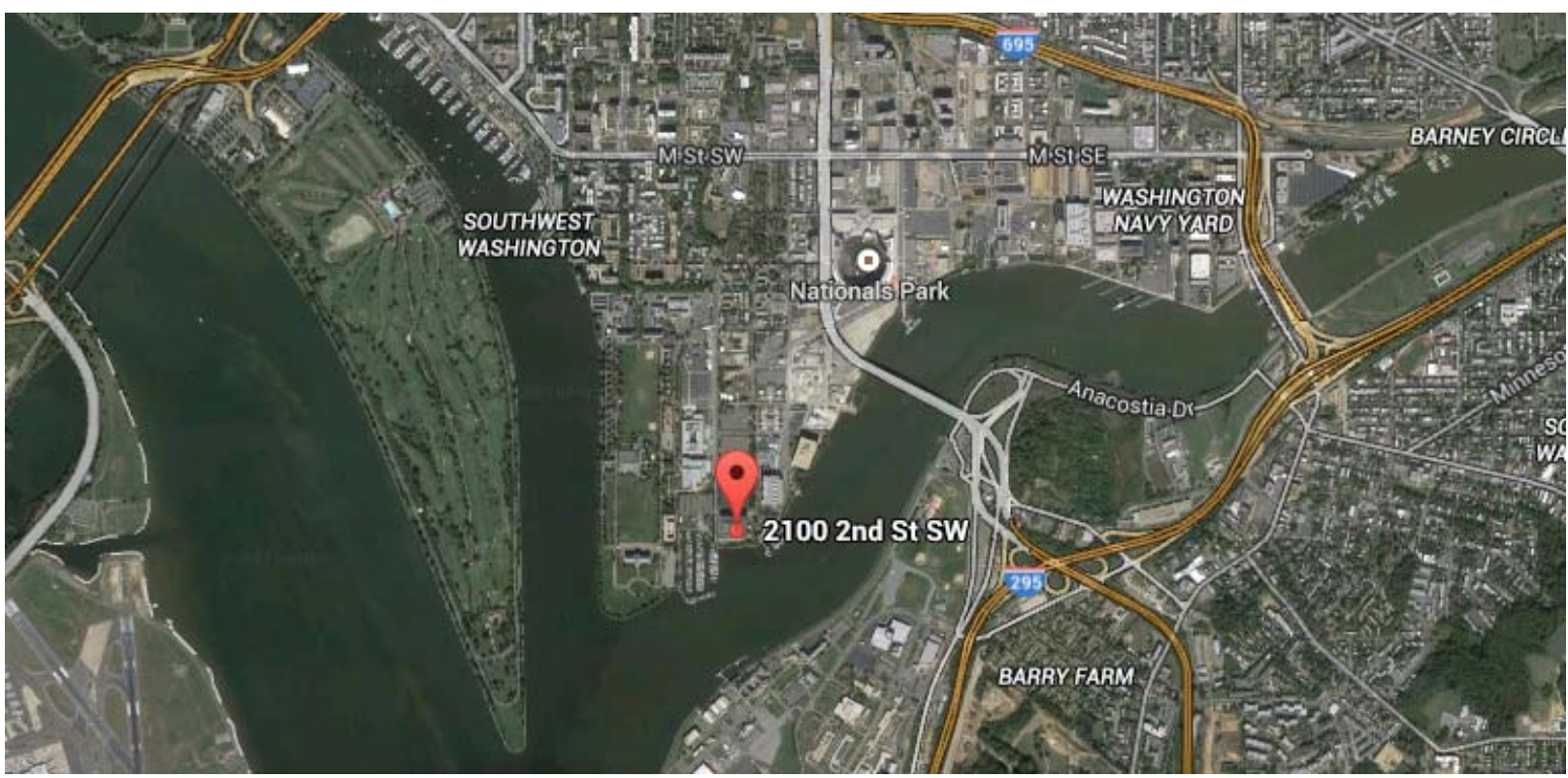

Figure 2. 2012 USCG HQ campus. ${ }^{9}$

\section{PROJECT OBJECTIVE}

This study explores federal fleet vehicles and their usage characteristics, with a primary goal of supporting the goals of Presidential Executive Order 13514, which includes the following:

\footnotetext{
${ }^{8}$ Google Maps [accessed November 11, 2014].

${ }^{9}$ Google Earth [accessed November 11, 2014].
} 
- Pursuing opportunities with vendors and contractors to address and incentivize GHG emission reductions and petroleum use reductions

- Implementing strategies and accommodations for transit, travel, training, and conferences that actively reduce carbon emissions associated with commuting and travel by agency staff

- Meeting GHG emissions reductions associated with other federal government sustainability goals

- Implementing innovative policies and practices that address agency-specific Scope 3 GHG emissions. ${ }^{10}$

Because of the large number of vehicles in the federal fleets, there is a substantial opportunity for PHEV and BEV adoption. Federal fleets offer an opportunity as a first market replacement for alternative fuels due to their scale, refueling patterns, and regular vehicle turnover. ${ }^{11}$

This project has the following four defined tasks:

1. Data collection: Coordinate with the fleet manager to collect data on agency fleet vehicles. This includes collecting information on the fleet vehicle and installing data loggers on a representative sample of the fleet vehicles to characterize their missions.

2. Data analysis and review: Examine data collected by the loggers and fleet vehicle characteristics to describe typical fleet activity. Incorporate fleet manager's input on introducing PEVs to the agency's fleet.

3. PEV implementation feedback: Provide feedback to fleet personnel and Battelle Energy Alliance, LLC on the selection criteria for replacement PEVs in their specific fleet vehicle missions.

4. Observations and recommendations: Provide actionable information to introduce PEVs into agency fleet operations and assess any related impacts for the facility.

Data collected from vehicles include trip distance, idle time, time between uses, and stop locations. Data collection continues for 30 to 60 days using a non-intrusive data logger, which gathers and transmits information using global positioning satellites and cellular service. The loggers collect data at 1-minute intervals and transmit when an active signal is present.

Fleet managers may use the information supplied in this report to help them identify which vehicles are candidates for replacement by BEVs or PHEVs based on their use. BEVs are preferred because of the greater potential reduction of GHG emissions, fuel cost, and petroleum usage, but they are not likely to be suitable for all vehicle missions.

The information in this report supports a final report to Battelle Energy Alliance, LLC/Idaho National Laboratory and the U.S. Department of Energy. The aggregated results for all agencies' fleets will provide an overview of federal fleets, vehicle missions, vehicle uses, and agencies needs to plan and establish a more systematic method for the adoption of BEVs and PHEVs.

\section{METHODS}

\subsection{Fleet Vehicle Survey}

Agency fleet managers selected fleet vehicles for this study and provided basic information for each vehicle, including its managing agency, home base for the vehicle, contact information, primary vehicle mission, vehicle ownership, fuel type, and odometer reading.

\footnotetext{
${ }^{10} \mathrm{http}: / /$ energy.gov/sites/prod/files/2013/10/f3/eo13514.pdf [accessed February 5, 2014].

${ }^{11}$ Fleet Purchase Behavior: Decision Processes and Implications for New Vehicle Technologies and Fuel, Nesbitt, Sperling, University of California, Davis 2001.
} 
The fleet manager assessed their wide range of vehicles and made selections of high-interest, representative vehicles based on vehicle missions and vehicle type/class. Selection also favored vehicles used at least twice a week. Because data loggers rely on the vehicle's battery power, non-use of the vehicle can result in the vehicle having a depleted battery. Intertek received no reports of depleted batteries during the study at USCG HQ. Ten vehicles were selected, with all having a pool mission.

\subsection{Data Collection}

Individual privacy concerns exist when monitoring vehicle movement with data loggers. Data collection occurs by vehicle identification as identified by Intertek, data logger number, vehicle identification number (VIN), or an agency-assigned vehicle number. Intertek receives no information related to the vehicle operator and provides no raw data to the fleet managers. In this manner, Intertek does not collect, analyze, or report on individual driving habits.

\subsubsection{Data Logger}

Non-intrusive data loggers, produced by InTouchMVC ${ }^{12}$ and depicted in Figure 3, were inserted into the vehicle's onboard diagnostic port to collect and transmit the relevant data. Installation of the data logger and manual recording of information about the vehicle tying the logger and vehicle together in the data, typically takes less than 5 minutes. Once installed and activated (during vehicle use), the data loggers collect vehicle information once every minute during vehicle operation and transmit by cellular communication to the data center.

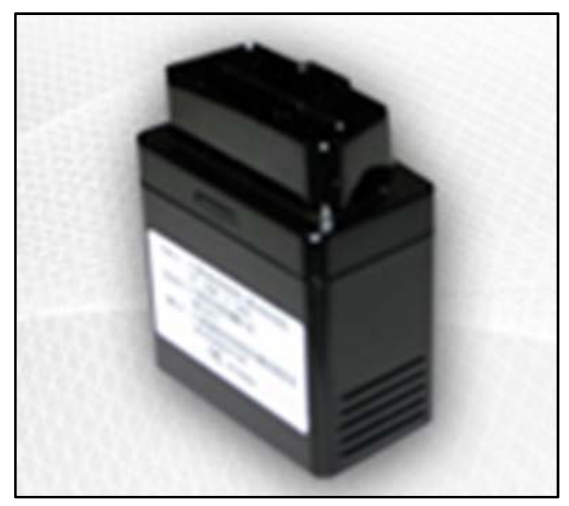

Figure 3. InTouchMVC data logger.

Intertek maintains the data logger's connectivity and verifies data transmission weekly. Missing data (reported as "null" values) are frequently the result of lost global positioning system reception, logger device removal, or extended periods in regions with insufficient cellular reception. Intertek filters the vehicle and data logger information if these null values present a significant impact on the data collected and no resolution is possible. This report also identifies the statistics on this validation process.

USCG HQ requested and installed 10 data loggers into the selected fleet vehicles. The agency removed and shipped the data loggers to Intertek at the conclusion of the data collection period.

\subsubsection{Data Captured}

Data consist of key-on events, key-off events, and position updates logged every minute while the vehicle is keyed-on. InTouchMVC converted these data points into records of trip events, stop events, and idle events.

From these data points, the following information was available for evaluation:

- $\quad$ Trip start and stop time and location

${ }^{12}$ www.intouchmvc.com [accessed January 10, 2014] 
- Trip distance and duration

- Idle start time, location, and duration

- Stop start time, location, and duration.

\subsection{Data Analysis}

\subsubsection{Definitions}

Figure 4 illustrates a vehicle outing, which is comprised of trips, stops, and idle events, that may occur during one day or over several days. The following list provides a definition of these terms:

1. Outing: An outing is the combination of trips and stops that begin at the home base and includes all travel until the vehicle returns home.

2. Trip: A trip begins with a key-on event and ends with the next key-off event.

3. Vehicle stop: A vehicle stop includes a key-off/key-on event pair.

4. Idle time: Idle time is the amount of time a vehicle spends stationary after a key-on event when the vehicle is not moving for a period of 3 minutes or longer.

5. Trip travel time: Trip travel time is the amount of time required to complete a trip, excluding stops but including idle time.

Definitions of additional analysis and survey terms are as follows:

1. Operating shift: Fleet manager-defined period worked.

2. Study days: Days during which the data loggers are connected.

3. Vehicle days: Study days during which a vehicle is used.

4. Null values: Data record unusable for analysis for various reasons.

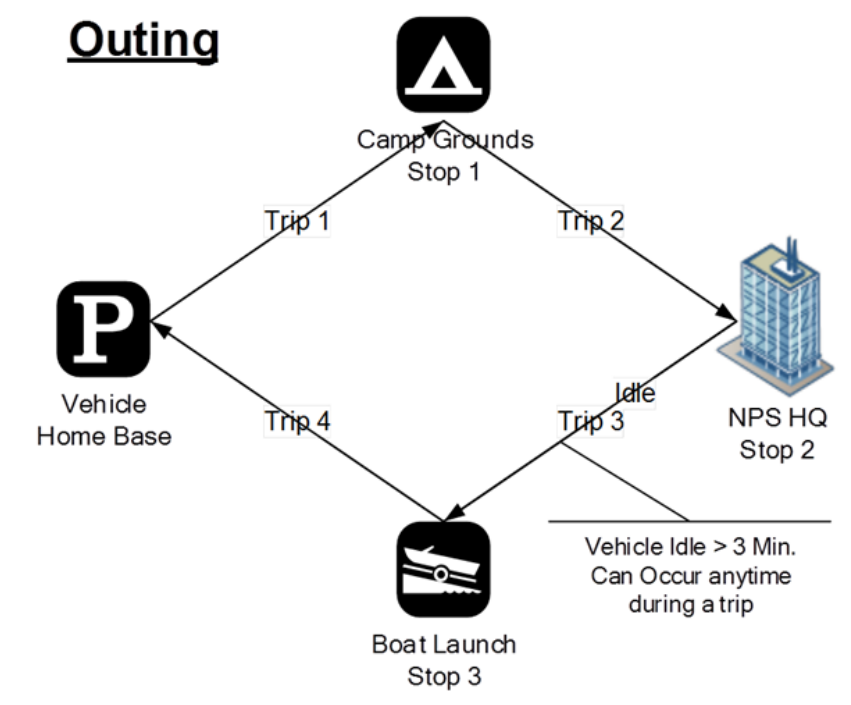

Figure 4. Vehicle outing.

\subsubsection{Data Evaluation}

Processing the data involves removal of null values and aggregation by different spatial and temporal scales. Aggregation was by day, by trip, and by outing to produce figures showing the patterns of use. Aggregation by vehicle mission followed to characterize use for the agency fleet. Section 5 presents these 
results. Data were extrapolated to provide overall fleet usage and benefit analysis when fleet information was provided. Section 6 presents these benefits. Intertek observations are included in Section 7.

Statistical data analysis uses Microsoft ${ }^{\circledR}$ Excel and Tableau ${ }^{\circledR}$ software. Frequency distributions summarize travel behavior of each vehicle and vehicle mission during the study period. Rounding of the tables and figures are to three significant digits.

\section{VEHICLES}

\subsection{Vehicle Missions}

The vehicle mission is an important characteristic in the fleet study. Information used to define the vehicle mission includes the vehicle's configuration, vehicle use, classification per 40 CFR Part 600.31582 and the Environmental Protection Agency (EPA), the participating agency use, and generally assumed vehicle use. Based on gathered fleet information, Intertek has established the following seven mission/vehicle categories for analysis (depicted in Figure 5).

1. Pool vehicles: A pool vehicle is any automobile (other than the low-speed vehicles identified below) manufactured primarily for use in passenger transportation, with not more than 10 passengers.

2. Enforcement vehicles: Vehicles specifically approved in an agency's appropriation act for use in apprehension, surveillance, police, or other law enforcement work. This category also includes site security vehicles, parking enforcement, and general use, but the vehicles are capable of requirements to support enforcement activities. Appendix A provides further definition.

3. Support vehicles: Vehicles assigned to a specific work function or group to support the mission of that group. Vehicles are generally passenger vehicles or light-duty pickup trucks and may contain after-market modifications to support the mission.

4. Transport vehicles: Light, medium, or heavy-duty trucks used to transport an operator and tools or equipment of a non-specific design or nature. The vehicle's uses include repair, maintenance, or delivery.

5. Specialty vehicles: Vehicles designed to accommodate a specific purpose or mission (such as ambulances, mobile cranes, and handicap controls).

6. Shuttles/buses: Vehicles designed to carry more than 12 passengers and further outlined in 49 CFR 532.2.

7. Low-speed vehicle: Vehicles that are legally limited to roads with posted speed limits up to $45 \mathrm{mph}$ and that have a limited load-carrying capability.

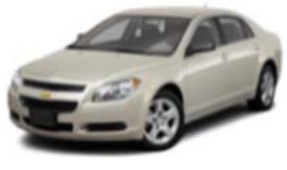

Pool Vehicle

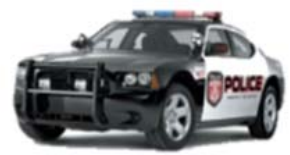

Enforcement Vehicle

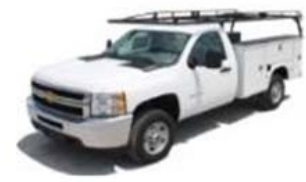

Support Vehicle

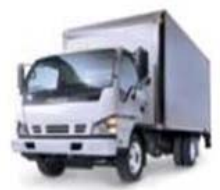

Transport Vehicle

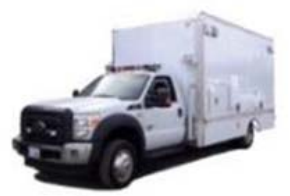

Specialty Vehicle

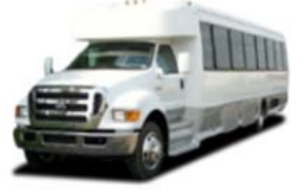

Shuttle / Bus

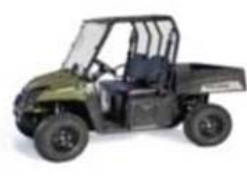

Low Speed

Vehicles

Figure 5. Vehicle missions. 


\subsection{Alternative Fuel Vehicles}

As the operating agency, USCG HQ has a unique opportunity to plan for the adoption of BEVs and PHEVs, along with planning for the supporting infrastructure. The adoption of PHEVs and BEVs is a primary goal of the General Services Administration (GSA) and supports the directives previously referenced.

As GSA increases its certification of PHEVs and BEVs, agencies can plan for vehicle replacement through GSA for passenger vehicles and trucks. Table 1 presents the replacement requirements for fleet vehicles. Note that both the age and mileage requirements need to be met in order for the vehicle to qualify for replacement, except where noted as "or."

Table 1. GSA vehicle replacement requirements.

\begin{tabular}{cccc} 
& GSA Vehicle Replacement Requirements ${ }^{13}$ & \\
& Fuel Type & Years & Miles \\
\hline Passenger vehicles & Gasoline or & 3 & 36,000 \\
& Alternative Fuel & 4 & 24,000 \\
& Vehicle & 5 & Any mileage \\
& & Any age & 75,000 \\
& Hybrid & 5 & Any miles \\
Light trucks 4 x 2 & Speed BEV & 6 & Any miles \\
& Non-diesel & 7 & 65,000 \\
& Diesel & 8 or & 150,000 \\
Light trucks 4 x 4 & Hybrid & 7 & Any mileage \\
& Non-diesel & 7 or & 60,000 \\
& Diesel & 8 or & 150,000 \\
& Hybrid & 7 & Any mileage \\
\hline
\end{tabular}

\subsection{Battery Electric Vehicle and Plug-In Hybrid Electric Vehicle Benefits/Challenges}

BEVs are fully powered by the battery energy storage system available onboard the vehicle. The Nissan Leaf is an example of a BEV. Because the BEV has no other energy source for propulsion, the range, power requirements, and mission of the needed vehicle factor greatly in purchasing decisions. Maximizing BEV capabilities typically requires batteries more than an order of magnitude larger in capacity than the batteries in hybrid electric vehicles.

PHEVs obtain their power from at least two energy sources. The typical PHEV configuration uses a battery and an ICE that is powered by either gasoline or diesel. PHEV designs differ between manufacturers. All have a charge-depleting (CD) mode where the battery is depleted of its stored energy to propel the vehicle and a charge-sustaining (CS) mode (or extended-range mode) that is entered after $\mathrm{CD}$ mode is complete where the battery and the ICE work together to provide propulsion. The state of charge of the battery is maintained between set limits. Some PHEVs' operation in CD mode is purely electric while others employ the engine to supplement the battery power during the initial battery depletion to a set state of charge (usually below 50\%).

\subsubsection{Battery Electric Vehicle Benefits/Challenges}

EPA identifies the following benefits of BEVs: ${ }^{14}$

\footnotetext{
${ }^{13}$ http://www.gsa.gov/graphics/fas/VehicleReplacementStandardsJune2011Redux.pdf [accessed January 10, 2014].
} 
- Energy efficient: Electric vehicles convert about 59 to $62 \%$ of the electrical energy from the grid to power at the wheels, whereas conventional gasoline vehicles only convert about 17 to $21 \%$ of the energy stored in gasoline to power at the wheels.

- Environmentally friendly: PEVs emit no tailpipe pollutants, although the power plant producing the electricity may emit them. Electricity from nuclear, hydro, solar, or wind-powered plants causes no air pollutants.

- Performance benefits: Electric motors provide quiet, smooth operation and exhibit maximum torque at zero and low speeds, while also requiring less maintenance than ICEs.

- Reduce energy dependence: Electricity is a domestic energy source.

The EPA also identifies challenges associated with BEVs, including the following:

- Driving range: Most BEVs can only travel about 100 to 200 miles (or less) before recharging, whereas gasoline vehicles can often travel over 300 miles before refueling and some much further.

- Recharge time: Fully recharging the battery pack can take 4 to 8 hours. With a high-power direct current (DC) fast charger (DCFC), restoration from a depleted state to $80 \%$ capacity can take approximately 30 minutes.

- Battery cost: The large battery packs are expensive and may need to be replaced one or more times.

- Bulk and weight: Battery packs are heavy and take up considerable vehicle space.

\subsubsection{Plug-in Hybrid Electric Vehicle Benefits/Challenges}

EPA identifies the following benefits of PHEVs: ${ }^{15}$

- Less petroleum use: PHEVs are expected to use about 40 to $60 \%$ less petroleum than conventional vehicles. Because electricity is produced primarily from domestic resources, PHEVs reduce dependence on oil.

- Fewer emissions: PHEVs are expected to emit fewer GHG emissions than conventional vehicles, but as with BEVs, the difference depends largely on the type of power plant supplying the electricity.

- Higher vehicle costs, lower fuel costs: PHEVs will likely cost $\$ 1,000$ to $\$ 7,000$ more than comparable non-PHEVs. Fuel will cost less because electricity is much cheaper than gasoline, but the fuel savings depends on how much of the driving is done on the off-board electrical energy.

- Recharging takes time: Recharging the battery typically takes several hours. However, PHEVs do not have to be plugged in to be driven. They can be fueled solely with gasoline, but will not achieve maximum range, fuel economy, or fuel savings without charging.

- Measuring fuel economy: Because a PHEV can operate on electricity alone, gasoline alone, or a mixture of the two, EPA provides a fuel economy estimate for gasoline-only operation (CS mode), electric-only operation (all-electric CD mode), or combined gasoline and electric operation (blended CD mode).

In most cases, the PEV retail cost is higher than a non-PEV model. This incremental purchase cost may be a fleet budget challenge; however, many original equipment manufacturers (OEMs) have offered incentives to encourage the use and adoption of BEVs and PHEVs. Some OEMs have recently reduced the vehicle cost, while also increasing vehicle range. Additionally, federal and state incentives have increased the attractiveness of purchasing a PEV. A common assumption is that increasing PEV sales will result in a reduction in this incremental purchase cost and a positive feedback loop will ensue.

\footnotetext{
${ }^{14}$ http://www.fueleconomy.gov/feg/evtech.shtml [accessed December 27, 2013].

${ }^{15}$ http://www.fueleconomy.gov/feg/phevtech.shtml [accessed July 19, 2013].
} 


\subsection{Plug-In Electric Vehicle Availability}

GSA provides a summary of light and medium-duty passenger vehicles available for lease or purchase through the GSA portal, ${ }^{16}$ although not all BEVs and PHEVs currently on the market are 'certified' to be GSA replacements. Vehicles not on the GSA list of 'certified' vehicles require an agency to self-certify a functional need or provide alternative measures for exemptions. Table 2 summarizes the vehicles that may be suitable replacements and are certified replacements through GSA. Note that the "CD/CS" column provides the EPA fuel economy values for CD and CS modes. The fuel economy of CD mode is provided in units of miles-per-gallon-of-gasoline-equivalent (MPGe). This metric allows for the electricity consumption during CD mode to be compared with fuel consumption during CS mode (or against conventional vehicles). The Nissan Leaf and Mitsubishi i-MiEV are not included in the alternative fuel guide for 2014, but they have appeared in previous guides.

Replacement is dependent on vehicle configuration characteristics and the vehicle mission. Further evaluation related to vehicle purpose, mission follows in Section 5.

Tables 3 through 6 provide summaries of PHEVs and BEVs either currently available or near commercialization in both passenger cars and pickup trucks, but do not appear on the GSA 'certified' vehicle list. These vehicles may qualify for use by the agency through demonstrating a functional need.

Table 2. GSA certified PEVs.

\begin{tabular}{lcccc}
\multicolumn{1}{c}{ Make/Model } & GSA Class & Type & CD/CS & GSA Incremental Price \\
\hline Chevrolet Volt & Sedan, Subcompact & PHEV & $98 \mathrm{MPGe} / 37 \mathrm{mpg}$ & $\$ 17,087.18$ \\
Ford C-MAX & Sedan, Subcompact & PHEV & $100 \mathrm{MPGe} / 38 \mathrm{mpg}$ & $\$ 14,899.52$ \\
Energi & & & \\
Ford Focus Electric & Sedan, Subcompact & BEV & $110 \mathrm{MPGe} / 99 \mathrm{mpg}$ & $\$ 16,573.09$ \\
Ford Fusion Energi & Sedan, Compact & PHEV & $100 \mathrm{MPGe} / 38 \mathrm{mpg}$ & $\$ 19,289.99$ \\
\hline
\end{tabular}

Note that EPA differs in vehicle class. EPA identifies the Volt as a compact, the C_MAX Energi as a midsize, the Fusion Energi as a midsize, and the Focus as a compact. ${ }^{17}$

Table 3. OEM PHEV cars and availability.

\begin{tabular}{llc}
\multicolumn{1}{c}{ Make } & \multicolumn{1}{c}{ Model } & Model Year \\
\hline Audi & A3 eTron PHEV & 2015 (estimate) \\
Chevrolet & Volt & 2011 \\
Honda & Accord PHEV & 2014 \\
Toyota & Prius PHEV & 2012 \\
Volvo & V60 Plug-in & 2016 (estimate) \\
BMW & i3 with range extender & 2014 \\
\hline
\end{tabular}

Table 4. OEM BEV cars and availability.

\begin{tabular}{llc}
\multicolumn{1}{c}{ Make } & \multicolumn{1}{c}{ Model } & Model Year \\
\hline BMW & i3 & 2014 \\
Chevrolet & Spark EV & 2014 \\
Fiat & 500e & 2013(California only) \\
Ford & Focus Electric & 2012 \\
\hline
\end{tabular}

${ }^{16} \mathrm{http} / /$ www.gsa.gov/portal/content/104224 [accessed March 6, 2014].

${ }^{17} \mathrm{http}$ ://www.fueleconomy.gov/feg/Find.do?action=sbs\&id=34130 [accessed August 1, 2014]. 


\begin{tabular}{llc}
\hline \multicolumn{1}{c}{ Make } & \multicolumn{1}{c}{ Model } & Model Year \\
\hline Honda & Fit EV & 2013 \\
Kia & Soul EV & 2014 (estimate) \\
Mercedes-Benz & B-Class ED & 2015 (estimate) \\
Nissan & Leaf & 2011 \\
smart & ED & 2014 \\
Tesla & Model S & 2012 \\
Tesla & Model X & 2015 (estimate) \\
Volkswagen & Golf & 2015 (estimate) \\
Volvo & C30 Electric & 2016 (estimate) \\
\hline
\end{tabular}

Table 5. OEM PHEV trucks, vans, and availability.

\begin{tabular}{llc}
\multicolumn{1}{c}{ Make } & \multicolumn{1}{c}{ Model } & Model Year \\
\hline Land Rover & Range Rover Sport & 2016 (estimate) \\
Mitsubishi & Outlander PHEV & 2015 (estimate) \\
Via & VTRUX VR300 & 2013 \\
\hline
\end{tabular}

Table 6. OEM BEV trucks, vans, and availability

\begin{tabular}{lll} 
Make & Model & Model Year \\
Nissan & eNV200 & 2015 (estimate) \\
Toyota & RAV4 EV & $\begin{array}{l}2013 \text { (California only - } \\
\text { elsewhere 2015 estimate) }\end{array}$ \\
\hline
\end{tabular}

As further indication of the expanding market for PEVs, companies are offering after-market vehicle upgrades involving the addition of plug-in capabilities to OEM vehicles. For example, Echo Automotive headquartered in Scottsdale, Arizona offers a "...low-cost, bolt-on, plug-in hybrid system that can quickly be installed on new or existing fleet vehicles to increase fuel efficiency and decrease operating costs - all without affecting the OEM power train or requiring costly infrastructure." ${ }^{\prime 18}$ Options such as this company's conversions might be of benefit to the USCG HQ fleet vehicles for which no replacement PEV is currently available.

\subsection{Plug-In Electric Vehicle Charging}

Refueling electric vehicles presents some challenges and some opportunities not encountered when refueling petroleum-fueled vehicles. Recharging the battery of a PHEV follows the same methodology as that for BEVs. This section provides basic information on recharging PEVs.

\subsubsection{Electric Vehicle Supply Equipment Design}

4.5.1.1 Charging Components. Electric vehicle supply equipment (EVSE) stations deliver electric power from the utility to the applicable charge port on the vehicle. Figure 6 illustrates the primary components of a typical alternating current (AC) Level 2 EVSE unit.

The electric utility delivers AC current to the charging location. The conversion from AC to the DC electricity necessary for battery charging can occur either on or off board the vehicle. Section 4.5.1.2 provides further explanation of the different EVSE configurations. For onboard conversion, AC current flows through the PEV inlet to the onboard charger. The charger converts AC to the DC current required

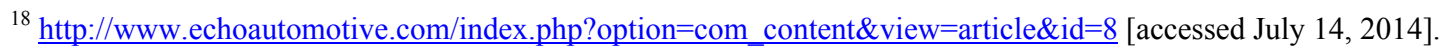


to charge the battery. A connector attached to the EVSE inserts into a PEV inlet to establish an electrical connection to the PEV for charging and information/data exchange. Off-board conversion, also known as DC charging, proceeds in a similar manner except that the AC to DC conversion occurs in a charger that is off board the vehicle and, thus, bypasses any onboard charger. For both $\mathrm{AC}$ and $\mathrm{DC}$ charging, the PEV's battery management system on board the vehicle controls the battery rate of charge, among other functions. All current PEVs have an onboard charger; some BEVs (but no PHEVs currently) accommodate DC charging.

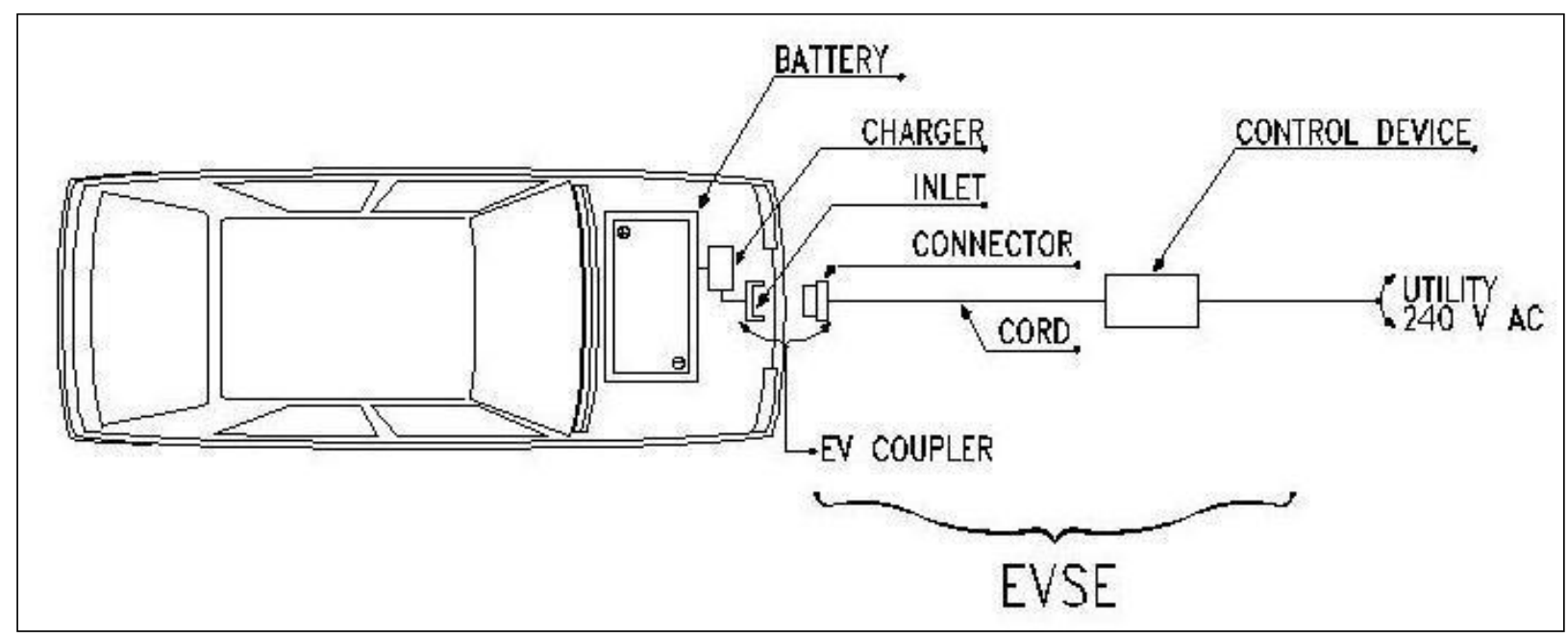

Figure 6. AC Level 2 charging diagram. ${ }^{19}$

4.5.1.2 Charging Configurations and Ratings. The Society of Automotive Engineers standardized the requirements, configurations, and equipment followed by most PEV suppliers in the United States in the J1772 Standard. Figure 7 summarizes these attributes and the estimated recharge times. Actual recharge times depend on the onboard equipment, including the charger, battery, and battery management system.

Most PEV manufacturers supply an AC Level 1 cord set with the vehicle, which provides sufficient capabilities for some drivers, but often provides an emergency backup capability because of the long recharge times. AC recharging capabilities found in the public arena more typically are AC Level 2. Figure 8 depicts a typical J1772-compliant inlet and connector for both AC Levels 1 and 2.

The J1772 standard also identifies requirements for DC charging. For PEVs that accept both AC and DC inputs, the Society of Automotive Engineers approved a single connector and inlet design. Figure 9 shows this connector, which is colloquially known as the J1772 "combo connector."

Some BEVs introduced in the United States prior to the approval of the J1772 standard for DC charging employ the CHAdeMO (designed in Japan) standard for connector and inlet design. Figure 10 shows this connector. EVSE units that are either J1772-compliant or CHAdeMO-compliant are both known as DCFCs.

The presence of the two separate standards for DC charging presents challenges for vehicle owners to ensure the EVSE accessed provides the appropriate connector for their vehicle inlet. Not all PEV suppliers include DC charging options. BEV suppliers have provided DC inlets where PHEV suppliers have not, because the rapid recharging provides opportunities for expanded vehicle range with minimal operator wait times. PHEV operators can rely on the gasoline drive in the event they deplete the vehicle's battery; at present, no PHEV on the market or near commercialization has DC charging capability

${ }^{19}$ http://www.theevproject.com/downloads/documents/Electric\%20Vehicle\%20Charging\%20Infrastructure\%20Deployment $\% 20$ Guidelines\%20for\%20the\%20Greater\%20Phoenix\%20Area\%20Ver\%203.2.pdf [accessed January 15, 2014]. 
(although the Mitsubishi Outlander PHEV is rumored to be offering DC charging capability as an option). It is noted that DC Level 1 and DC Level 2 charging are commonly combined and labeled DCFC.

\begin{tabular}{|c|c|c|c|}
\hline \multicolumn{4}{|c|}{ SAE Charging Configurations and Ratings Terminology } \\
\hline \multirow{5}{*}{$\begin{array}{l}\text { AC level } 1 \\
\left(\text { SAE } J 1772^{m+1}\right)\end{array}$} & PEV includes on-board charger & \multirow[t]{5}{*}{${ }^{*}$ DC Level 1} & EVSE includes an off-board charger \\
\hline & $\begin{array}{l}120 \mathrm{~V}, 1.4 \mathrm{~kW} @ 12 \mathrm{amp} \\
120 \mathrm{~V}, 1.9 \mathrm{~kW} @ 16 \mathrm{amp}\end{array}$ & & $200-450 \mathrm{~V} \mathrm{DC}$, up to $36 \mathrm{~kW}(80 \mathrm{~A})$ \\
\hline & Est. charge time: & & Est. charge time ( $20 \mathrm{~kW}$ off-board charger): \\
\hline & PHEV: $7 \mathrm{hrs}$ (SOC* $-0 \%$ to full) & & PHEV: $22 \mathrm{~min}$. (SOC* - 0\% to $80 \%$ ) \\
\hline & BEV: $17 \mathrm{hrs}$ (SOC $-20 \%$ to full) & & BEV: $1.2 \mathrm{hrs}$. (SOC $-20 \%$ to $100 \%)$ \\
\hline \multirow[t]{11}{*}{$\begin{array}{l}\text { AC level } 2 \\
\text { (SAE J1772 }\end{array}$} & $\begin{array}{l}\text { PEV includes on-board charger (see below for different } \\
\text { types) }\end{array}$ & \multirow[t]{6}{*}{ *DC Level 2} & EVSE includes an off-board charger \\
\hline & $240 \mathrm{~V}$, up to $19.2 \mathrm{~kW}(80 \mathrm{~A})$ & & $200-450 \mathrm{~V} \mathrm{DC}$, up to $90 \mathrm{~kW}(200 \mathrm{~A})$ \\
\hline & Est. charge time for $3.3 \mathrm{~kW}$ on-board charger & & Est. charge time ( $45 \mathrm{~kW}$ off-board charger): \\
\hline & PEV: 3 hrs (SOC* $-0 \%$ to full) & & PHEV: $10 \mathrm{~min}$. (SOC* $-0 \%$ to $80 \%$ ) \\
\hline & BEV: 7 hrs (SOC $-20 \%$ to full) & & BEV: $20 \mathrm{~min}$. (SOC $-20 \%$ to $80 \% 6$ ) \\
\hline & Est. charge time for $7 \mathrm{~kW}$ on-board charger & & \\
\hline & PEV: 1.5 hrs (SOC* $-0 \%$ to full) & \multirow[t]{6}{*}{${ }^{*}$ DC Level 3 (TBD) } & EVSE includes an off-board charger \\
\hline & BEV: 3.5 hrs (SOC $-20 \%$ to full) & & $200-600 \mathrm{~V} \mathrm{DC}$ (proposed) up to $240 \mathrm{~kW}(400 \mathrm{~A})$ \\
\hline & Est. charge time for $20 \mathrm{~kW}$ on-board charger & & Est. charge time ( $45 \mathrm{~kW}$ off-board charger): \\
\hline & PEV: $22 \mathrm{~min}$. (SOC* $-0 \%$ to full) & & BEV (only): $<10 \mathrm{~min}$. (SOC* $-0 \%$ to $80 \% 6$ ) \\
\hline & BEV: $1.2 \mathrm{hrs}$ (SOC $-20 \%$ to full) & & \\
\hline •AC Level 3 (TBD) & $>20 \mathrm{~kW}$, single phase and 3 phase & & \\
\hline \multicolumn{4}{|c|}{$\begin{array}{l}\text { "Not finalized } \\
\text { Voltages are nominal configuration voltages, not coupler ratings } \\
\text { Rated Power is at nominal configuration operating voltage and coupler rated current } \\
\text { Ideal charge times assume } 90 \% \text { efficient chargers, } 150 \mathrm{~W} \text { to } 12 \mathrm{~V} \text { loads and no balancing of Traction Battery Pack }\end{array}$} \\
\hline \multicolumn{4}{|c|}{$\begin{array}{l}\text { Notes: } \\
\text { 1) BEV ( } 25 \mathrm{kWh} \text { usable pack size) charging always starts at } 20 \% \mathrm{SOC} \text {, faster than } \\
100 \%\end{array}$} \\
\hline
\end{tabular}

Figure 7. Society of Automotive Engineers charging configurations and ratings terminology. ${ }^{20}$

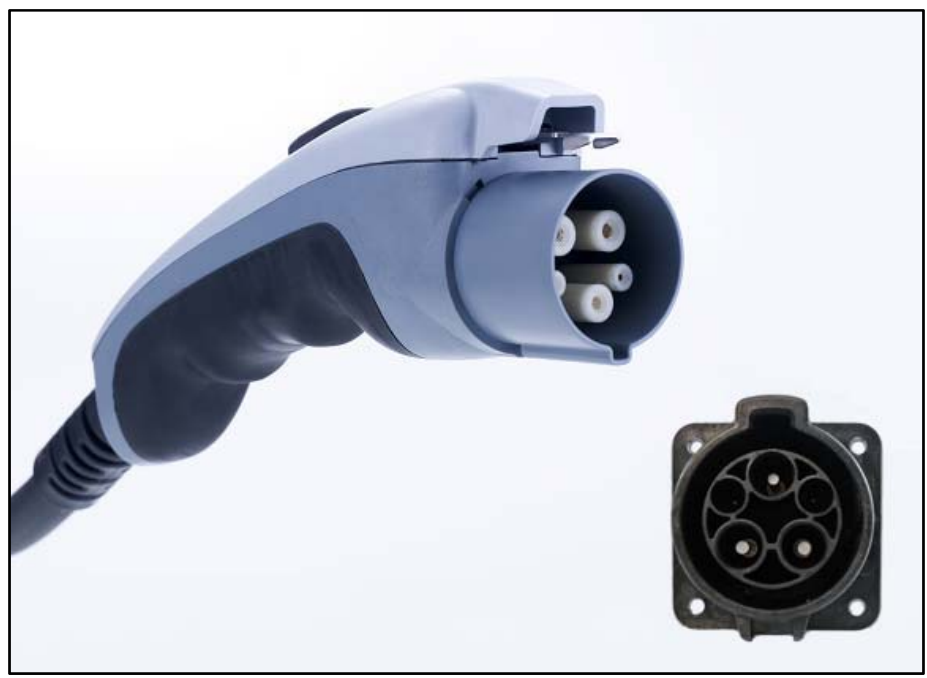

Figure 8. J1772 connector and inlet. ${ }^{21}$

${ }^{20} \mathrm{http}: / /$ www.sae.org/smartgrid/chargingspeeds.pdf [accessed January 15, 2014].

${ }^{21}$ http://carstations.com/types/j09 [accessed January 15, 2014.] 

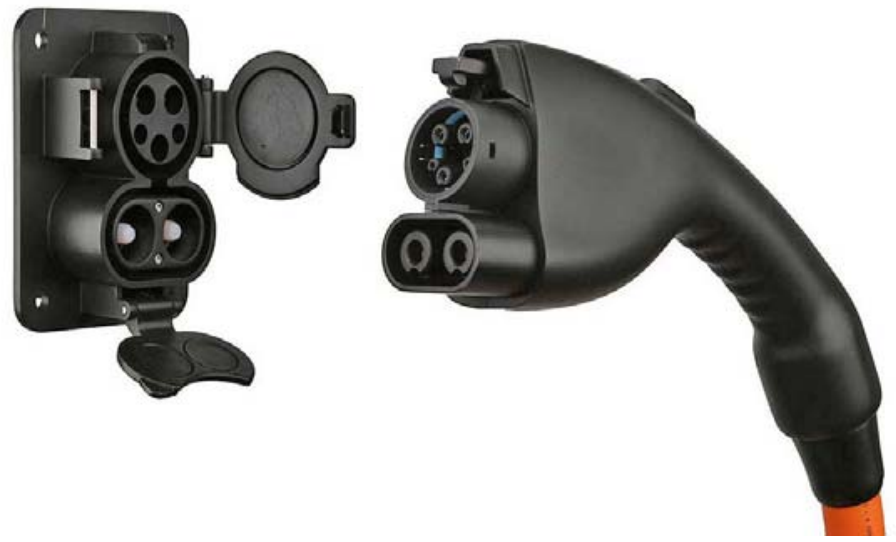

Figure 9. J1772-compliant combo connector. ${ }^{22}$

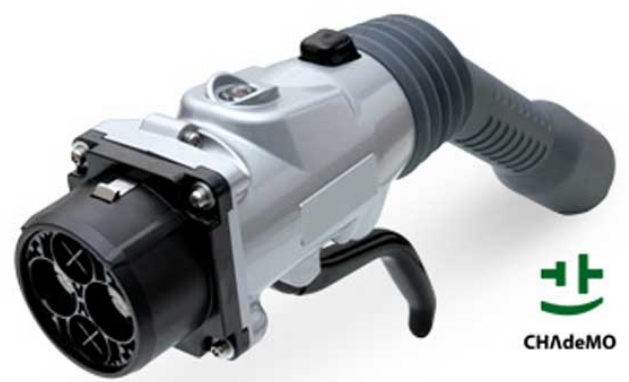

Figure 10. CHAdeMO-compliant connector. ${ }^{23}$

Because the battery of a BEV is typically much larger than that of a PHEV, recharge times are longer (see Figure 7). BEVs that see daily mileage near the limits of the advertised range do better when recharged using AC Level 2 EVSE or DCFC, because AC Level 1 recharge times are usually extensive. PHEVs, on the other hand, generally can use AC Level 1 EVSE for overnight charging to ensure a fully charged battery at the start of daily use. AC Level 2 EVSE units provide greater range in the shortest amount of time when intermediate or opportunity charging. DCFC provides the fastest recharge capability for those vehicles equipped with DCFC inlets.

\subsubsection{Electric Vehicle Supply Equipment Stations}

AC Level 2 charging is the predominant rating of publicly accessible EVSE because of its wide acceptance by auto manufacturers and recharge times that are faster than AC Level 1 charging. Purchase and installation costs are more manageable than DCFCs and less space is required. There are several manufacturers of AC Level 2 equipment and the agency should review brands for comparison purposes. Figure 11 provides an example of a public AC Level 2 EVSE unit. ${ }^{24}$

DCFCs also are available from several manufacturers. Figure 12 illustrates one such charger. ${ }^{25}$ This particular charger uses the CHAdeMO connector standard.

\footnotetext{
${ }^{22}$ http://www.zemotoring.com/news/2012/10/sae-standardizes-j1772-fast-dc-charging-up-to-100-kw [accessed January 15, 2014].

${ }^{23}$ https://radio.azpm.org/p/azspot/2012/5/10/1632-electric-cars/ [accessed January 15, 2014].

${ }^{24}$ www.eaton.com/ [accessed January 29, 2014].

${ }^{25}$ http://evsolutions.avinc.com/products/public_charging/public_charging_b [Accessed April 16, 2014]
} 


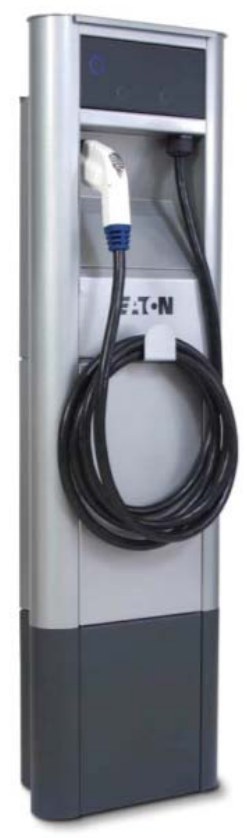

Figure 11. Public AC Level 2 EVSE.

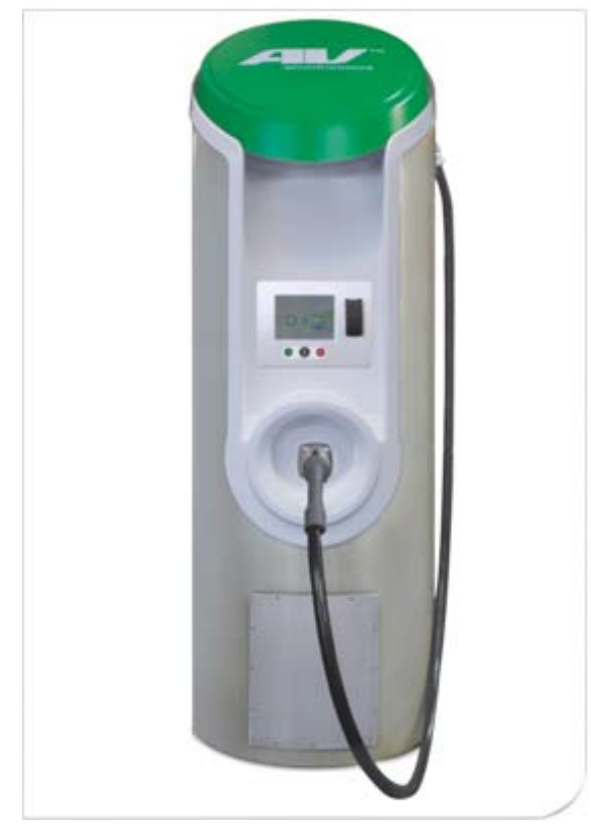

Figure 12. Public DCFC unit.

In general, installation costs are higher for DCFC because of the higher voltage requirements and the inclusion of the AC to DC converter and other safety and design features. Costs for both types are highly dependent on site characteristics such as distance to the nearest power source, asphalt or concrete cutting and repair, conduit requirements, and payment systems, if any.

Payment and equipment control systems included by some suppliers provide the potential for use by privately owned vehicles for a fee, but can allow agency fleet vehicle use without direct payment. These systems also allow for accurate record keeping of vehicle charging requirements. 


\section{U.S. Coast Guard Headquarters Springfield, Ballenger Creek Fleet Evaluation}

\subsection{Survey Results}

Ten vehicles were included in the study at USCG HQ. All 10 vehicles have a pool mission. Table 7 presents a summary of these vehicles and Table 8 provides details of the monitored vehicles.

Table 7 . Vehicle study summary.

\begin{tabular}{|c|c|c|c|c|c|c|c|c|c|c|c|}
\hline Mission & $\begin{array}{c}\text { Sedan } \\
\text { Compact }\end{array}$ & $\begin{array}{c}\text { Sedan } \\
\text { Midsize }\end{array}$ & $\begin{array}{l}\text { Sedan } \\
\text { Large }\end{array}$ & SUV & $\begin{array}{l}\text { Mini } \\
\text {-van }\end{array}$ & $\begin{array}{l}\text { Pass } \\
\text { Van }\end{array}$ & $\begin{array}{l}\text { Pickup } \\
\text { or LD } \\
\text { Truck }\end{array}$ & $\begin{array}{c}\text { MD } \\
\text { HD } \\
\text { Truck }\end{array}$ & Bus & Specialty & Total \\
\hline $\begin{array}{l}\text { Pool } \\
\text { Support } \\
\text { Law Enforce. } \\
\text { Transport } \\
\text { Bus } \\
\text { Specialty }\end{array}$ & 4 & 1 & 1 & & 4 & & & & & & 10 \\
\hline Total & 4 & 1 & 1 & & 4 & & & & & & 10 \\
\hline
\end{tabular}

Table 8. Detailed USCG HQ vehicle index.

\begin{tabular}{ccccccc}
\hline Log & Fleet Vehicle Id & Make & Model & Year & EPA Class & Mission \\
\hline 9 & G41-3130G & Chevrolet & Uplander & 2008 & Minivan & Pool \\
10 & G10-6597D & Pontiac & G6 & 2008 & Sedan - Compact & Pool \\
11 & G11-1871K & Chevrolet & Impala & 2010 & Sedan - Large & Pool \\
12 & G10-6592D & Pontiac & G6 & 2008 & Sedan - Compact & Pool \\
13 & G41-4430L & Dodge & Caravan & 2011 & Minivan & Pool \\
14 & G10-6567D & Pontiac & G6 & 2008 & Sedan - Compact & Pool \\
15 & G41-4397L & Dodge & Grand Caravan & 2010 & Minivan & Pool \\
16 & G41-3785K & Dodge & Caravan & 2010 & Minivan & Pool \\
17 & G12-0290L & Chevrolet & Malibu & 2011 & Sedan - Midsize & Pool \\
18 & G10-6590D & Pontiac & G6 & 2008 & Sedan - Compact & Pool \\
\hline
\end{tabular}

Appendix B provides the analysis of each individual vehicle included in this study. Grouping the vehicles by mission creates an aggregated view of mission requirements to provide observations related to PEV replacement.

\subsection{Data Validity}

USCG HQ data collection took place from February through April 2012. Vehicle data sheets (presented in Appendix B) detail the collected data for each vehicle, including specific dates the logger provided data.

Of the data collected, validation occurred for $97.7 \%$, while null values exist for the balance.

\subsection{U.S. Coast Guard Headquarters Pool Vehicles Evaluation}

\subsubsection{Survey and Site Information}

Pool vehicles are typically light-duty motor vehicles for use in passenger transportation, with not more than 10 passengers. Pool missions can vary by agency, location, and jurisdiction; however, they 
typically utilize sedans, minivans, vans, or small pickup trucks and typically do not carry specific cargo or equipment.

Incorporation of BEVs and/or PHEVs into the pool mission is a definite possibility. Pool vehicles used for shorter trips or outings qualify for BEV or PHEV replacement, while other pool vehicle activities that are associated with longer trips may require PHEV capabilities.

\subsubsection{Summary for Pool Vehicles}

Appendix B provides the vehicle data sheets for each of the pool vehicles monitored. This section aggregates data for all pool vehicles for USCG HQ. Table 9 summarizes pool travel during the study period for those days in which the vehicle was driven. Vehicle use occurred primarily between 0800 and 1600 hours daily. The vehicles were driven 16,978 miles, logged 914 hours of operation, and idled 253 hours during the study period.

Table 9. USCG HQ pool vehicles travel summary.

\begin{tabular}{|c|c|c|c|c|}
\hline \multicolumn{5}{|c|}{ Pool Vehicles Travel Summary } \\
\hline & $\begin{array}{c}\text { Per Day } \\
\text { Average/Peak }\end{array}$ & $\begin{array}{c}\text { Per Outing } \\
\text { Average/Peak }\end{array}$ & $\begin{array}{c}\text { Per Trip } \\
\text { Average/Peak }\end{array}$ & Total \\
\hline Travel Distance (Miles) & $37.1 / 395.6$ & 29.9/1,045.0 & $8.3 / 252.7$ & 16,978 \\
\hline Travel Time (Minutes) & $119.8 / 502.0$ & $96.6 / 1,681.0$ & $26.8 / 359.0$ & 54,888 \\
\hline Idle Time (Minutes) & $33.2 / \mathrm{NA}$ & $26.8 / \mathrm{NA}$ & 7.4/NA & 15,202 \\
\hline
\end{tabular}

\subsubsection{Pool Vehicles Daily Summary}

Figure 13 identifies daily travel distance and time for all pool vehicles. The green line and bars indicate typical electric range on a single charge for a PHEV, while the blue line and bars (including the green bars) indicate the same for a BEV. Figures 14 and 15 show the composite history in distance and time traveled for the pool vehicles.
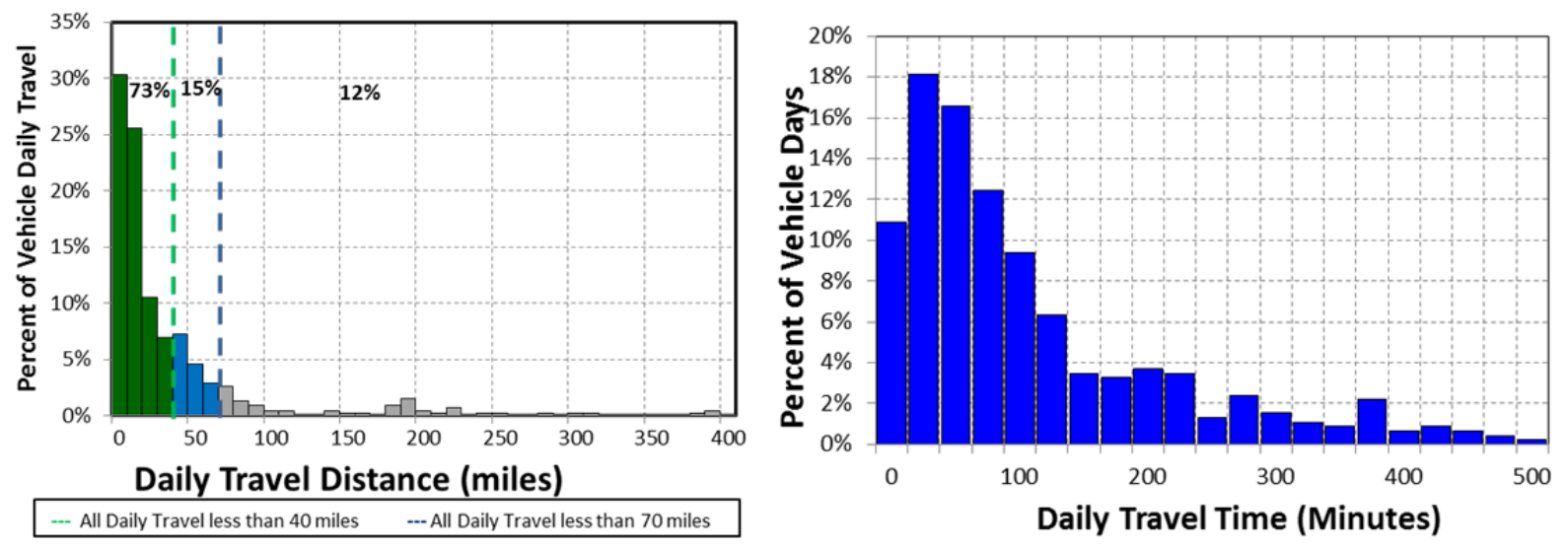

Figure 13. USCG HQ pool vehicle daily travel miles and time (all vehicles).

In the stacked bar charts of Figures 14 and 15, the contribution of each vehicle is indicated by a different color. 


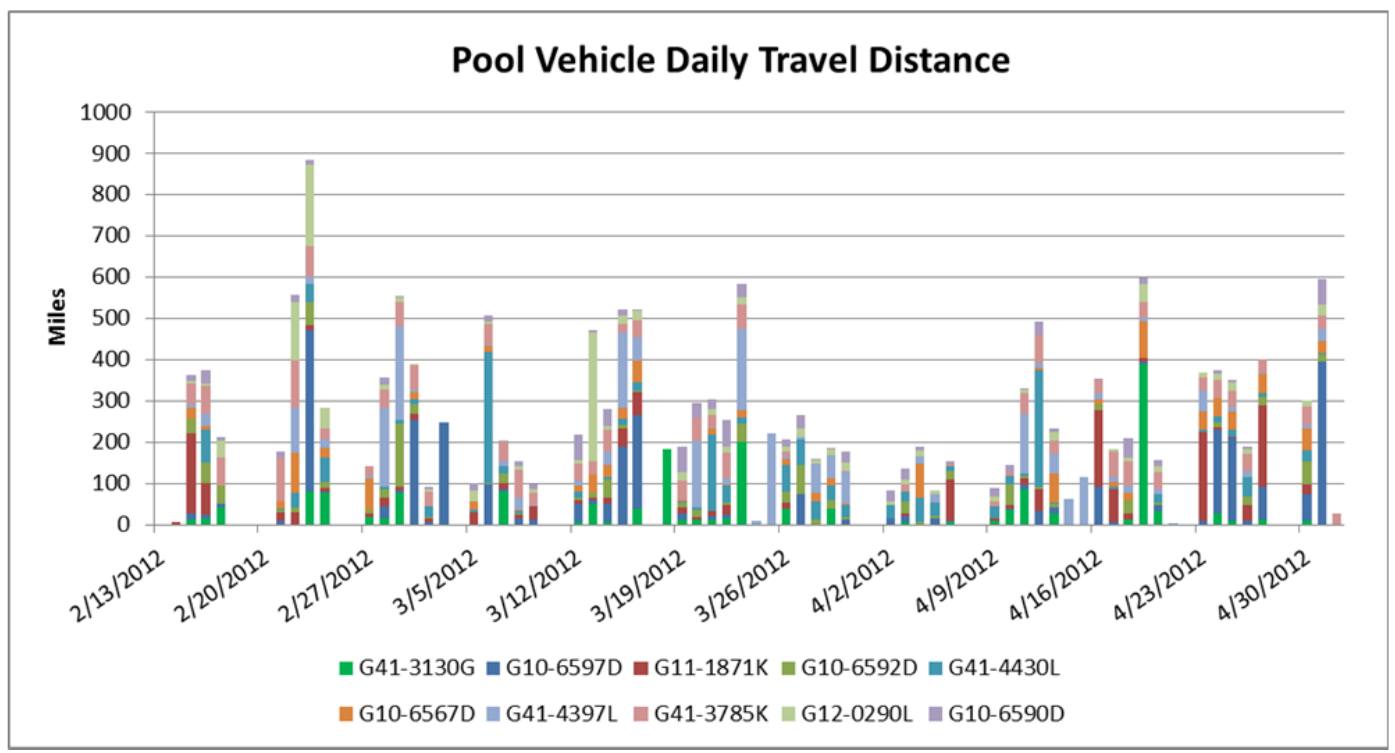

Figure 14. USCG HQ pool vehicle daily travel history (all vehicles).

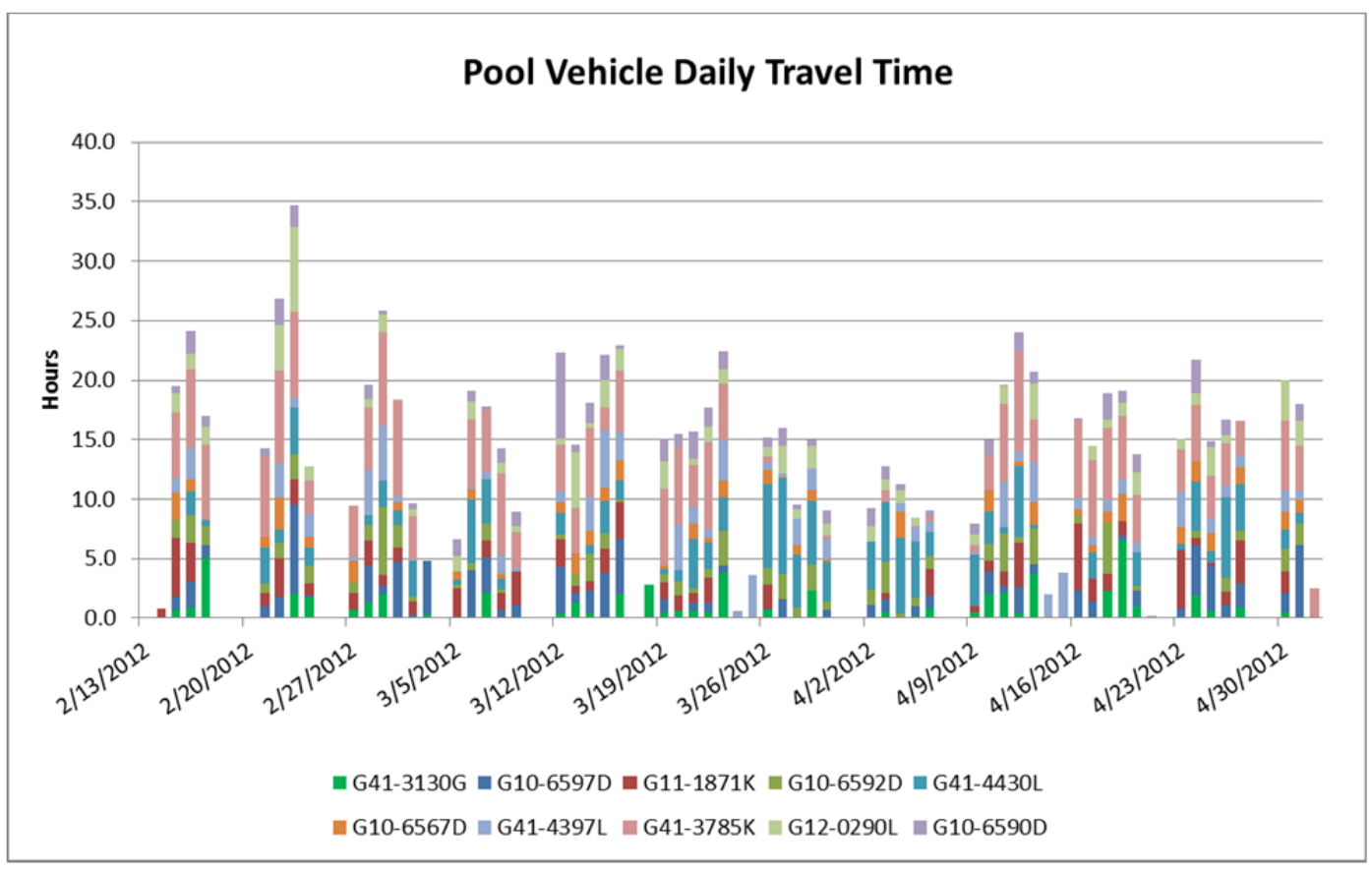

Figure 15. USCG HQ pool vehicles travel time (all vehicles).

When driven, the average travel distance per day for pool vehicles was 37.1 miles. On $88 \%$ of these vehicle days, the daily travel was less than the 70 miles considered to be within the BEV safe range (i.e., while BEV range can vary based on several factors, most BEVs provide at least 70 miles of vehicle range on a single battery charge) and $12 \%$ percent of pool daily travel was greater than 70 miles. Further, $73 \%$ of vehicle travel days were less than the 40 miles considered to be within the CD range of a PHEV.

Figures 14 and 15 show that the vehicles are not used every day, although there are some days when more than one vehicle is in use. All vehicles were utilized more than half of the study period days. Figure 16 displays the summary of use by time of day for all pool vehicles. Figure 17 shows the outing distances traveled, including data for all pool vehicles. 


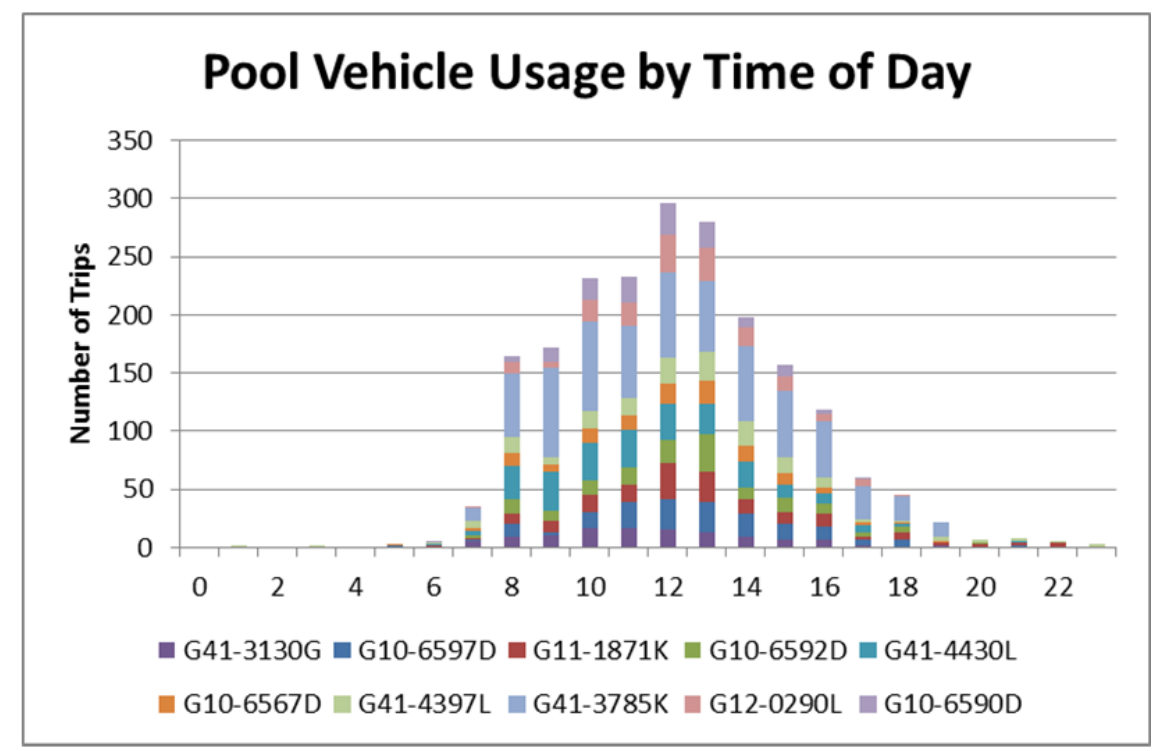

Figure 16. USCG HQ pool vehicles hourly usage.

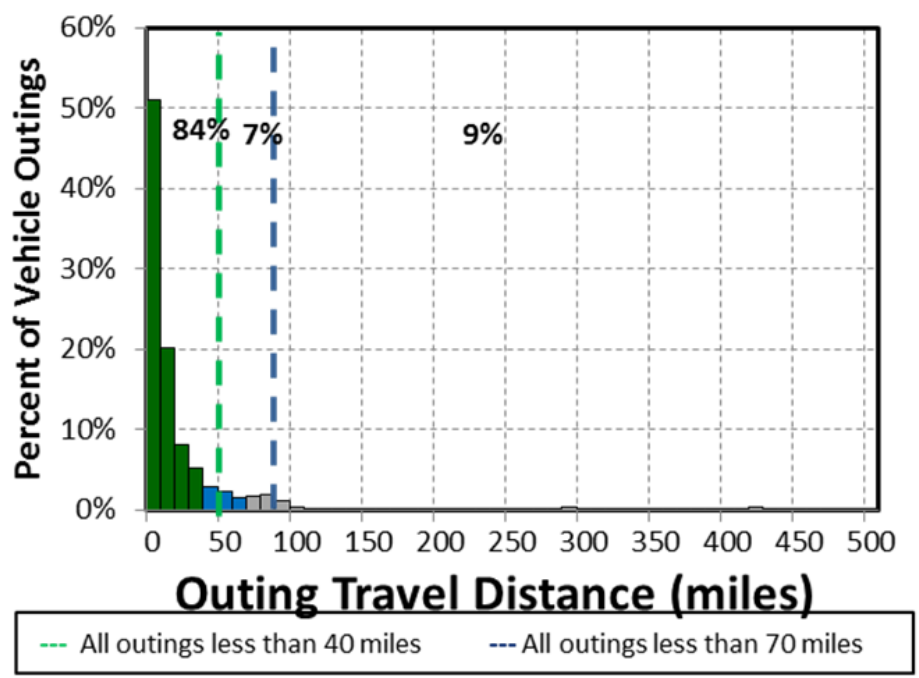

Figure 17. USCG HQ pool vehicle outings. Note: peak outings of 515 and 1,045 miles not shown for clarity of scale.

Appendix B provides the details of each of the pool vehicle's outing travel. The average travel outing for pool vehicles was 29.9 miles. On $91 \%$ of these vehicle outings, the distance traveled was less than the 70 miles considered to be within the BEV safe range and $9 \%$ percent of pool outing travel was greater than 70 miles. Further, 84\% of vehicle travel outings were less than 40 miles considered to be within the CD range of a PHEV. Vehicles G41-3130G, G10-6597D, G11-1871K, G41-4430L, G41-4397L, and G12-0290L had days of travel outings exceeding 100 miles.

\subsubsection{U.S. Coast Guard Headquarters Pool Vehicle Observations/Summary}

There appears to be three choices for USCG HQ in implementing PEVs into the pool fleet. It should be noted that the objective would be to incorporate as many BEVs as possible to realize the advantages of reduced petroleum usage and reduced emissions of GHGs.

1. All BEV fleet: While some BEV manufacturers report vehicle range exceeding 70 miles, Intertek recommends careful evaluation of experienced range to ensure vehicle missions are accomplished. 
Nevertheless, assuming the 70-mile safe range for a BEV, an all-BEV fleet does not appear to be possible due to the length of the daily travel of most vehicles.

2. Mixed BEV/PHEV fleet: Certainly, PHEVs can accomplish the same mission as the current fleet when only considering travel times and distances because the PHEV's gasoline engine can provide motive power when the battery has been depleted. Figure 13 shows that on $73 \%$ of all vehicle travel days, the total daily travel was less than 40 miles, which typically is the maximum distance a PHEV will travel in CD mode. This represents a significant operating cost savings opportunity while retaining the ability to go longer distances when needed. In addition, $84 \%$ of the outings were less than 40 miles and could be completed in CD mode for certain PHEVs if the battery is fully charged prior to the outing.

Meanwhile, $91 \%$ of the outings were within the typical capability of a BEV and EVSE at the home base could provide recharge energy for another outing. A mixed fleet requires fleet manager attention to assign vehicles appropriately for the anticipated use on that day.

Figure 13 also shows $88 \%$ of daily travel was within the typical range of a BEV. This would suggest that $12 \%$ of the fleet could be PHEVs to handle travel greater than 70 miles per day without requiring additional opportunity charging during daytime stops and $88 \%$ of the fleet could be BEVs. The fact that $91 \%$ of the outings were within the range capabilities of a BEV suggest that with additional charging between outings, the BEV could be able to handle more of the daily travel. The pool vehicles averaged 1.6 hours of use daily, suggesting that time is available for additional charging.

However, a more conservative approach in adding BEVs is appropriate because many vehicles are in use at the same time and a higher level of fleet management would be required to ensure BEVs are properly assigned based on their range limitations. Allowing more conservatism in assigning vehicles for the 10 vehicles, it is suggested that five BEVs and five PHEVs could conservatively meet the demand.

3. All PHEV fleet: As noted above, PHEVs can accomplish the same mission as the current fleet when only considering travel times and distances. Replacing all current vehicles with PHEVs only requires an evaluation of the individual vehicle capabilities of currently available PHEVs to meet current pool requirements. All of these 10 pool vehicles have replacement PEVs available. Data show that for a significant number of days, the PHEV will operate in CD mode. The first 40 miles of longer travel days would also be powered by (at least mostly) electricity so that $73 \%$ of all pool vehicle travel would be (again, at least mostly) battery powered with only one charge per day. As above, this represents an opportunity for significant operating cost savings while retaining the ability to go longer distances when needed. Intermediate charging opportunities provide additional benefit, enhancing CD mode. Data show significant charging opportunities throughout the day during stop times.

The vehicle summary shows sufficient time for charging at the base location during the course of the day and additional opportunities at intermediate charging stations are not required. Given the availability of daytime charging, with experience, USCG HQ may find that a greater fraction of BEVs within the pool vehicle fleet may meet their needs.

\subsubsection{U.S. Coast Guard Headquarters Pool Vehicle Charging Needs}

Upon review of these data, Intertek suggests replacement of the 10 vehicles in the studied pool fleet with five BEVs and five PHEVs. No available PHEVs at this writing provide for DCFC nor do the data suggest that this would be a significant benefit for PHEVs in the pool fleet.

As noted above, AC Level 2 overnight charging of BEVs is typical, whereas overnight charging of PHEVs can usually be accomplished with AC Level 1 charging.

Intertek's experience suggests that each vehicle should have an assigned a charging parking space at its home base. Assigned stations require less management attention to ensure completion of overnight charging. BEVs and PHEVs not assigned to these stations also benefit during visits to the location as part of their normal operation. Intertek recommends a minimum of two EVSE at each location to maximize 
charge capability without a significant increase in installation costs. The PHEVs can utilize the AC Level 2 EVSE at the home base during the day to increase the amount of vehicle miles traveled in CD mode.

Figure 18 shows the stop locations of all the monitored vehicles in the local area. This represents the typical service area of these vehicles and indicates that most of the stops occur at the home bases near HQ on Half Street $/ 1^{\text {st }}$ Street $/ 2^{\text {nd }}$ Street or V Street or in the case of G41-3785K on $10^{\text {th }}$ Street.

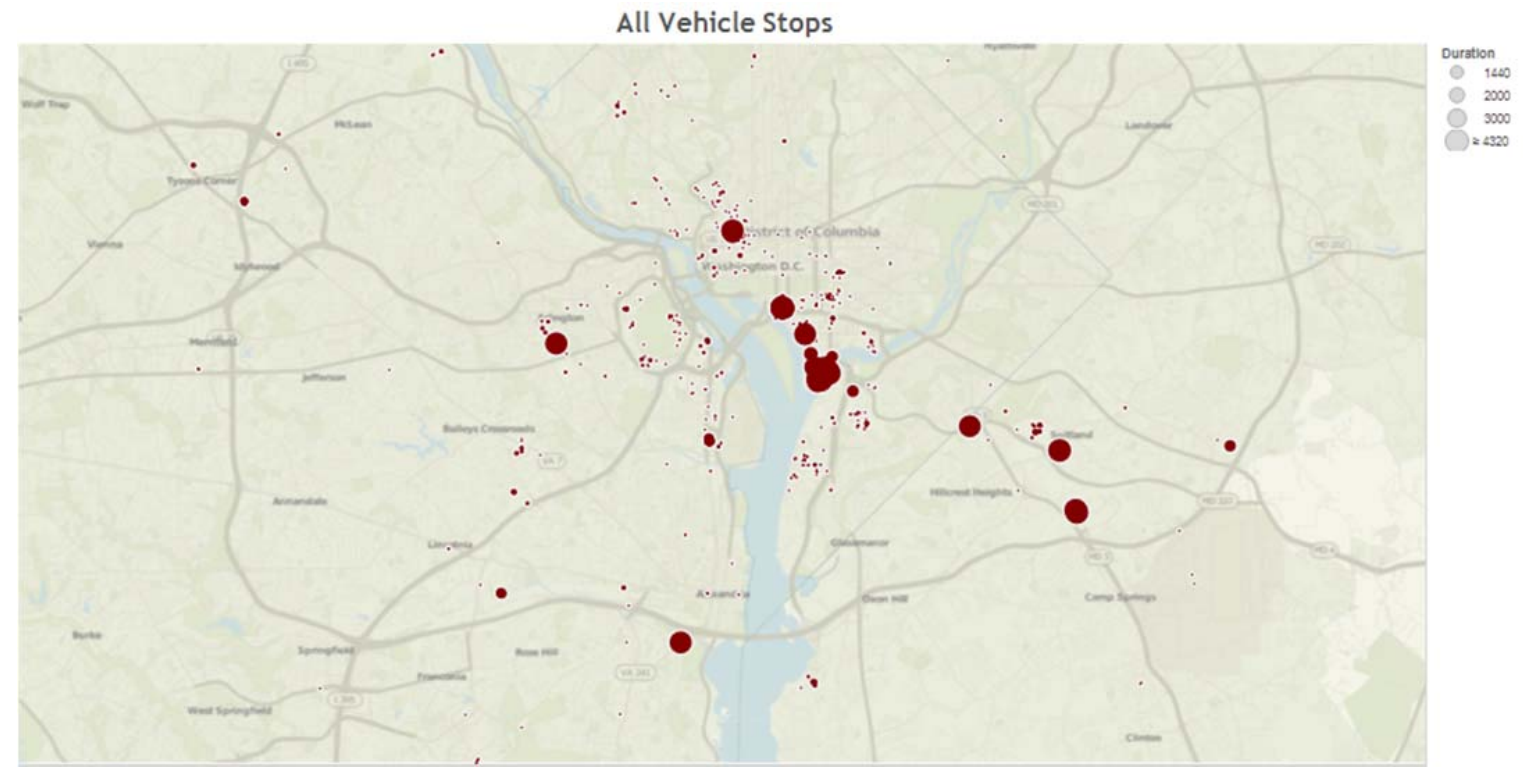

Figure 18. All vehicle local stops.

Figure 19 displays the availability of public charging at the time of this writing for the USCG HQ area. All indicated stations are available to the public and provide AC Level 2 or Level 1 EVSE. Many of these may be located along the traffic routes used by USCG HQ vehicles. PEVs in use by USCG HQ traveling these routes may benefit from the use of public chargers to increase range in CD mode.

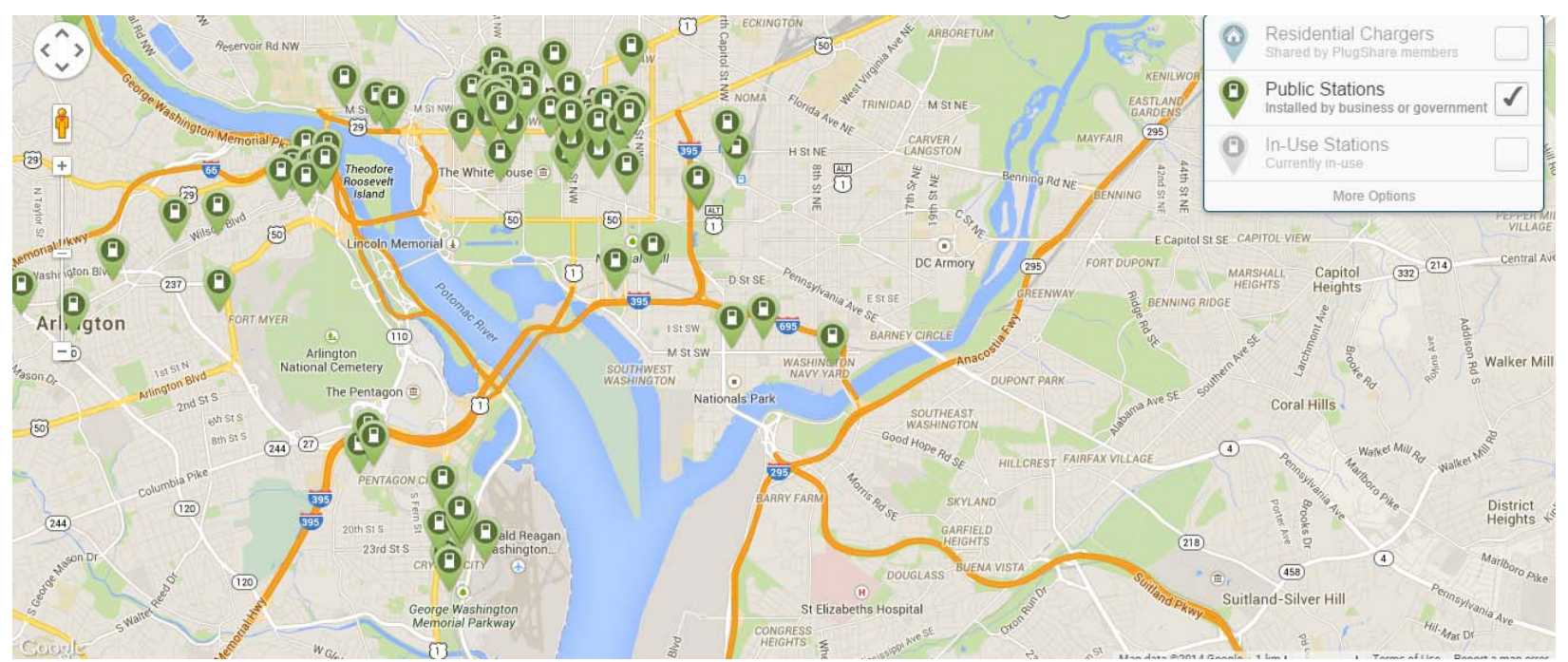

Figure 19. Public EVSE in the USCG HQ region. ${ }^{26}$

${ }^{26}$ http://www.plugshare.com/ [accessed November 19, 2014]. 


\section{GREENHOUSE GAS EMISSIONS AVOIDED AND FUEL COST REDUCTION ANALYSIS}

PEV substitution for an existing conventional vehicle avoids GHG emissions and reduces fuel costs. The GHG emissions avoided occur due to the difference in emissions associated with power plant electricity generation versus fuel combustion that occurs in the engine of a conventional vehicle. This analysis does not account for life-cycle emissions that occur outside of the electricity generation and fuel combustion phases (i.e., materials and resource extraction, production supply-chains, and decommissioning are not accounted for). These phases are beyond the scope of this report due to the significant effort required to conduct an accurate environmental life-cycle assessment for a transportation system in a very specific setting. The analysis used is known as a "tank-to-wheel" analysis rather than a "well-to-wheel" analysis that would include the aforementioned phases. Cost reduction also occurs because the cost of electricity is comparable to the cost of gasoline on a unit of energy basis; however, PEVs are more efficient than conventional ICE vehicles. Because fuel logs were not kept, the mileage accumulated by each vehicle and the extrapolation to annual miles provide one source of annual miles estimates. USCG HQ also provided information related to anticipated annual miles. These are compared to that calculated during the study to identify the source of fuel consumption estimates for the study vehicles.

In order to perform the analysis, EPA fuel economy ratings are used. ${ }^{27}$ Tables 10 and 11 provide these ratings. Ratings for the PHEVs in Table 11 include CD operation. Because these data are estimates, assumptions include the following:

1. PHEVs operate in CD mode only for the percentage of travel less than 40 miles per day. This is reasonable for most daily operations, as described in Section 5. This is conservative because additional charge time between most outings exists. It is also conservative in that the replacement PEV typically will have greater fuel economy when operating in CS mode. BEVs operate in electric mode for $100 \%$ of travel.

2. The energy consumption for the Mitsubishi Outlander is assigned the same value as the RAV4 EV because the EPA has not yet created ratings for this vehicle.

3. Table 11 suggests the PEVs to replace the existing monitored vehicles. See Section 4.4 for vehicle availability.

Annual miles are calculated from the actual miles identified in the study and extrapolated to a full 365-day year. USCG HQ also reported the average annual miles. These annual miles are used for the reduction calculations, because they were averaged over a much longer period. Miles in CD mode are the USCG HQ annual miles times percent of daily travel less than 40 miles for the PHEV replacement and full annual miles for the BEV replacement.

Table 10. U.S. EPA fuel economy ratings of current fleet vehicles.

\begin{tabular}{cccccc}
\hline Vehicle & Logger & Mission & Make \& Model & $\begin{array}{c}\text { Model } \\
\text { Year }\end{array}$ & $\begin{array}{c}\text { Fuel Economy- } \\
\text { Combined (miles/gallon) }\end{array}$ \\
\hline G41-3130G & 9 & Pool & Chevrolet Uplander & 2008 & 19 \\
G10-6597D & 10 & Pool & Pontiac G6 & 2008 & 25 \\
G11-1871K & 11 & Pool & Chevrolet Impala & 2010 & 22 \\
G10-6592D & 12 & Pool & Pontiac G6 & 2008 & 25 \\
G41-4430L & 13 & Pool & Dodge Caravan & 2011 & 20 \\
G10-6567D & 14 & Pool & Pontiac G6 & 2008 & 25 \\
G41-4397L & 15 & Pool & Dodge Grand Caravan & 2010 & 20 \\
\hline
\end{tabular}

${ }^{27}$ http://www.fueleconomy.gov/feg/Find.do?action=sbs\&id=33558 [accessed August 27, 2014] 


\begin{tabular}{cccccc}
\hline Vehicle & Logger & Mission & Make \& Model & $\begin{array}{c}\text { Model } \\
\text { Year }\end{array}$ & $\begin{array}{c}\text { Fuel Economy- } \\
\text { Combined (miles/gallon) }\end{array}$ \\
\hline G41-3785K & 16 & Pool & Dodge Caravan & 2010 & 19 \\
G12-0290L & 17 & Pool & Chevrolet Malibu & 2011 & 26 \\
G10-6590D & 18 & Pool & Pontiac G6 & 2008 & 25 \\
\hline
\end{tabular}

Table 11. U.S. EPA PEV energy consumption assumptions.

\begin{tabular}{cccc}
\hline Vehicle & Mission & Replacement PEV & Wh/mile \\
\hline Uplander & Pool & Mitsubishi Outlander & 440 \\
G6 & Pool & Chevrolet Volt & 350 \\
Impala & Pool & Ford Fusion & 370 \\
G6 & Pool & Ford Focus & 310 \\
Caravan & Pool & Toyota Rav4 & 440 \\
G6 & Pool & Chevrolet Volt & 350 \\
Grand Caravan & Pool & Mitsubishi Outlander & 440 \\
Caravan & Pool & Toyota Rav4 & 440 \\
Malibu & Pool & Nissan Leaf & 300 \\
G6 & Pool & Ford Focus & 310 \\
\hline
\end{tabular}

Table 12 provides a pictorial view of potential replacement PEVs.

Table 12. PEV substitutions for current vehicles.

\begin{tabular}{|c|c|c|c|}
\hline Vehicle Class & $\begin{array}{c}\text { Current Vehicle } \\
\text { Example }\end{array}$ & Replacement PHEV & Replacement BEV \\
\hline \multicolumn{4}{|c|}{ Sedan - Midsize/Large } \\
\hline & Chevrolet Impala & $\begin{array}{l}\text { Ford Fusion Energi } \\
370 \mathrm{Wh} / \mathrm{mi}\end{array}$ & Nissan Leaf $300 \mathrm{Wh} / \mathrm{mi}$ \\
\hline \multicolumn{4}{|l|}{ Sedan - Compact } \\
\hline & Pontiac G6 & $\begin{array}{l}\text { Chevrolet Volt } \\
350 \mathrm{Wh} / \mathrm{mi}\end{array}$ & $\begin{array}{l}\text { Ford Focus BEV } \\
310 \mathrm{Wh} / \mathrm{mi}\end{array}$ \\
\hline \multicolumn{4}{|l|}{ Pickup Truck } \\
\hline & Chevrolet Silverado & $\begin{array}{l}\text { Via Motors VTRUX } \\
475 \mathrm{Wh} / \mathrm{mi}\end{array}$ & $\begin{array}{l}\text { Nissan eNV200 } \\
400 \mathrm{Wh} / \mathrm{mi}\end{array}$ \\
\hline
\end{tabular}




$\begin{aligned} & \text { Pickup Truck } \\ & \text { (alternate) }\end{aligned}$
SUV and Minivan

Calculations provided for GHG emissions and fuel savings include both a total U.S. perspective and for the local area. The electricity generation mix of power plants for the total United States is different from the local mix of generation in the USCG HQ area. Likewise, the national average cost for petroleum fuel is different from the local cost for fuel. This analysis includes both approaches in order to allow for local evaluation and to provide the potential benefit for fleet vehicles in other locations of the United States that may be of interest. The final report summarizing results from all sites studied across the United States from Intertek to Idaho National Laboratory primarily will consider the national figures. For clarity, only the local Washington D.C. figures are shown here. The national figures are included in Appendix C.

For the GHG emissions-avoided portion of the analysis, the GHG emissions (in pounds of carbon dioxide equivalent (which also accounts for other GHGs such as methane and nitrous oxide) $\left(\mathrm{lb}-\mathrm{CO}_{2} e\right.$ ) from combustion of gasoline is $20.1 \mathrm{lb}-\mathrm{CO}_{2} \mathrm{e} /$ gallon. ${ }^{28}$ The U.S. average for GHG emissions for the production of electricity is $1.53 \mathrm{lb}-\mathrm{CO}_{2} \mathrm{e} / \mathrm{kWh}^{29}$

Potomac Electric Power Company (PEPCO) delivers power to the USCG HQ area in Washington D.C. Electricity power-generating companies report emissions to EPA and EPA reports GHG emissions from all plants in the production of electricity. The annual report is available in the Emissions and Generation Resource Integrated Database. The most recent publication is for $2010 .^{30}$ Using the information provided for the PEPCO service territory, emissions for 2010 for the production of electricity were $2.187 \mathrm{lb}-\mathrm{CO}_{2} \mathrm{e} / \mathrm{kWh}$. Note that PEPCO emissions are higher than the national average due to high reliance on coal-fueled generation.

GHG emissions avoided are the GHG emitted by the current vehicle (total annual gallons gasoline $\times$ GHG emissions/gallon) minus the annual GHG emitted by the replacement PEV (total annual $\mathrm{kWh} \times$ GHG emissions/kWh). For the PHEVs, the percentages of outings less than 40 miles are counted for the annual miles saved in CD mode, with the balance of the miles accounted as fueled with gasoline.

Table 13 shows the calculation of annual miles based on the recorded and extrapolated miles in this study. The USCG HQ reported annual miles are also shown for comparison. A replacement vehicle is identified for each vehicle. It is important to note that the analysis conducted above suggests replacement vehicles for the fleet of vehicles rather than necessarily replacing the exact vehicle monitored. The percent of miles in CD mode is $100 \%$ for BEVs because all travel is battery powered. The percent of

\footnotetext{
${ }^{28} \mathrm{http}: / /$ www.theevproject.com/cms-assets/documents/106077-891082.ghg.pdf [accessed 19 July 2013].

${ }^{29} \mathrm{http}: / /$ www.theevproject.com/cms-assets/documents/106077-891082.ghg.pdf [accessed July 19, 2013]

${ }^{30} \mathrm{http} / /$ www.epa.gov/cleanenergy/energy-resources/egrid/ [accessed September 20, 2014]
} 
miles in CD mode for PHEVs is obtained from the daily travel shown in Appendix B. Miles in CD mode is the percentage of USCG HQ-reported annual miles.

Table 13. CD mode miles calculations.

\begin{tabular}{cccccc} 
Vehicle & Replacement & $\begin{array}{c}\text { Study } \\
\text { Calculated } \\
\text { Annual Miles }\end{array}$ & $\begin{array}{c}\text { USCG HQ } \\
\text { Provided Annual } \\
\text { Miles }\end{array}$ & $\begin{array}{c}\text { Percent of } \\
\text { Miles CD } \\
\text { Mode }\end{array}$ & $\begin{array}{c}\text { CD Mode } \\
\text { Miles }\end{array}$ \\
\hline Uplander & Outlander & 8,218 & 6,600 & $72 \%$ & 4,752 \\
G6 & Volt & 13,741 & 7,500 & $69 \%$ & 5,175 \\
Impala & Fusion & 7,832 & 6,000 & $76 \%$ & 4,560 \\
G6 & Focus & 5,041 & 7,500 & $100 \%$ & 7,500 \\
Caravan & Rav4 & 8,702 & 6,000 & $100 \%$ & 6,000 \\
G6 & Volt & 5,346 & 7,200 & $69 \%$ & 4,968 \\
Grand Caravan & Outlander & 11,381 & 5,760 & $68 \%$ & 3,917 \\
Caravan & Rav4 & 9,799 & 6,600 & $100 \%$ & 6,600 \\
Malibu & Leaf & 6,229 & 7,200 & $100 \%$ & 7,200 \\
G6 & Focus & 4,333 & 7,500 & $100 \%$ & 7,500 \\
\hline
\end{tabular}

For the cost-avoided piece of the analysis, fuel cost assumptions are $\$ 2.853$ per gallon of regular gasoline for the United States and \$3.083 in Washington D.C. ${ }^{31}$ Electrical cost are $0.0984 \$ / \mathrm{kWh}$ for the United States and $0.1190 \$ / \mathrm{kWh}$ in Washington D.C. ${ }^{32}$ Therefore, fuel costs savings are the current vehicle's calculated annual gasoline cost (total annual gallons gasoline $\times$ cost/gallon) minus the electricity cost (total annual $\mathrm{kWh} \times$ cost $/ \mathrm{kWh}$ ) of the replacement PEV traveling the same distance.

The miles calculated above for CD mode yields the estimates for yearly GHG emissions avoided and fuel cost reductions. The results of this analysis (shown in Table 14) demonstrate that the substitution of a conventional ICE vehicle with a PEV can reduce the GHG emissions and fuel costs dramatically. The table also shows the percentage reduction in GHG emissions and fuel costs for ease of comparison. For example, if the Chevrolet Volt replaces the Pontiac G6, Vehicle G10-6567D, a 5\% reduction in GHG emissions in the area occurs. The G6 travels 7,200 miles per year, but the battery of the Volt could power $69 \%$ of those miles. The $\mathrm{G} 6$ traveling 4,968 miles per year produces 3,994 $\mathrm{lb}-\mathrm{CO}_{2} \mathrm{e} / \mathrm{year}$, whereas the Volt produces 3,802 lb- $\mathrm{CO}_{2} \mathrm{e} /$ year for that same distance for a reduction of $192 \mathrm{lb}-\mathrm{CO}_{2} \mathrm{e} / \mathrm{year}$.

Table 14 shows the high potential benefit in the reduction of GHG emissions in the local USCG HQ area. In addition, the fuel cost reduction potential benefit is also significant due to the low cost of power. Because of the higher $\mathrm{CO}_{2} \mathrm{e}$ emissions from PEPCO generation sources than the national average, GHG savings in the Washington D.C. area are small. However, the reliance on electricity for fuel for these vehicles provides significant fuel cost savings.

Table 14. Greenhouse gas emissions avoidance and fuel cost reduction analysis summary.

\begin{tabular}{|c|c|c|c|c|c|}
\hline Mission & $\begin{array}{c}\text { Replacement } \\
\text { Model }\end{array}$ & $\begin{array}{l}\text { Extrapolated Local } \\
\text { Yearly } \mathrm{CO}_{2} \mathrm{e} \text { Avoided } \\
\left(\mathrm{lb}-\mathrm{CO}_{2} \mathrm{e} / \text { year }\right)\end{array}$ & $\%$ reduction & $\begin{array}{c}\text { Extrapolated } \\
\text { Local Yearly Fuel } \\
\text { Cost Reduction }\end{array}$ & $\%$ reduction \\
\hline Pool & Outlander & 454 & $9 \%$ & $\$ 522$ & $68 \%$ \\
\hline Pool & Volt & 199 & $5 \%$ & $\$ 423$ & $66 \%$ \\
\hline Pool & Fusion & 476 & $11 \%$ & $\$ 438$ & $69 \%$ \\
\hline
\end{tabular}




\begin{tabular}{lccccc} 
Pool & Focus & 945 & $16 \%$ & $\$ 648$ & $70 \%$ \\
Pool & Rav4 & 256 & $4 \%$ & $\$ 611$ & $66 \%$ \\
Pool & Volt & 192 & $5 \%$ & $\$ 406$ & $66 \%$ \\
Pool & Outlander & 167 & $4 \%$ & $\$ 399$ & $66 \%$ \\
Pool & Rav4 & 631 & $9 \%$ & $\$ 725$ & $68 \%$ \\
Pool & Leaf & 842 & $15 \%$ & $\$ 597$ & $70 \%$ \\
Pool & Focus & 945 & $16 \%$ & $\$ 648$ & $70 \%$ \\
& Total & $\mathbf{5 , 1 0 9}$ & $\mathbf{1 0 \%}$ & $\mathbf{\$ 5 , 4 1 7}$ & $\mathbf{6 8 \%}$ \\
\hline
\end{tabular}

\section{OBSERVATIONS}

Intertek appreciates the opportunity to present the results of this evaluation. Observations for possible follow-up action include the following:

\section{Observation \#1:}

Implementation: USCG HQ can move forward in the near future with replacement of pool vehicles with PEVs as current budget and vehicle replacement schedules allow. All of the vehicle types studied in this report are candidates for immediate replacement.

\section{Observation \#2:}

Fleet Inventory: A more thorough examination of the quantities and types of fleet vehicles within each usage category may be beneficial to quantify the potential for replacement by PEVs. While Intertek suggests a mix of BEVs and PHEVs, a more refined look may be possible. In addition, this study did not look at the full fleet in detail and other fleet vehicle categories, such as those with support, specialty, enforcement, or transport missions.

\section{Observation \#3:}

Vehicle Replacement Plan: Development of a detailed vehicle replacement plan could be beneficial. This plan would include cost and schedule for vehicle replacement. A more detailed survey and calculation of the use of the fleet vehicles (such as vehicle parking locations, age of vehicle, expected replacement time, expected replacement costs, GSA vehicle costs, EVSE cost, total life costs, and EVSE installation costs) provide support to this replacement plan. A more refined estimate for reduced GHG emissions, petroleum usage reduction, and fuel cost savings flow from this detailed plan.

\section{Observation \#4:}

Infrastructure Planning: In conjunction with the replacement plan, evaluation of the USCG HQ sites for placement of PEV charging infrastructure could be beneficial. Intertek has significant experience in this area and such plans will consider not only fleet vehicle charging needs, but also the convenience that charging infrastructure provides employees and visitors. This planning also considers the existing facility electrical distribution system. Vehicle home base considerations factor into the ratio of PEVs to EVSE units to maintain all vehicles at operational readiness. Charging stations at USCG HQ may also provide an opportunity for charging by employees and the public. 


\section{Appendix A Definitions}

Alternative fuel

City fuel economy (MPG)

Conventional fuel

Daily travel

Diesel fuel

E85

Electric vehicle

Ethanol-fueled vehicle

Federal vehicle standards

Government motor vehicle

Gross vehicle weight rating

GSA fleet
An alternative fuel means any fuel other than gasoline and diesel fuels, such as methanol, ethanol, and gaseous fuels (40 CFR 86.1803-01). A fuel type other than petroleum-based gasoline or diesel as defined by the Energy Policy Act (examples include ethanol, methanol, compressed natural gas, propane, and electrical energy).

City fuel economy means the city fuel economy determined by operating a vehicle (or vehicles) over the driving schedule in the federal emission test procedure or determined according to the vehicle-specific 5-cycle or derived 5-cycle procedures (40 CFR 600.001).

A petroleum-based fuel (examples include gasoline and diesel fuel).

The sum of daily trips and stops in one day.

Diesel means a type of engine with operating characteristics significantly similar to the theoretical diesel combustion cycle. The non-use of a throttle during normal operation is indicative of a diesel engine (49 CFR 86-1803).

Ethanol fuel blend of up to $85 \%$ denatured ethanol fuel and gasoline or other hydrocarbons by volume.

Electric vehicle means a motor vehicle that is powered solely by an electric motor drawing current from a rechargeable energy storage system, such as from storage batteries or other portable electrical energy storage devices, including hydrogen fuel cells, provided that

(1) The vehicle is capable of drawing recharge energy from a source off the vehicle, such as residential electric service

(2) The vehicle must be certified to the emission standards of Bin \#1 of Table S04-1 in § 86.1811-09(c)(6)

(3) The vehicle does not have an onboard combustion engine/generator system as a means of providing electrical energy (40 CFR 86-1803).

Ethanol-fueled vehicle-means any motor vehicle or motor vehicle engine that is engineered and designed to be operated using ethanol fuel (i.e., a fuel that contains at least $50 \%$ ethanol $\left(\mathrm{C}_{2} \mathrm{H}_{5} \mathrm{OH}\right)$ by volume) as fuel (40 CFR 86.1803-01).

The document that establishes classifications for various types and sizes of vehicles, general requirements, and equipment options. It is issued annually by the GSA Vehicle Acquisition and Leasing Service's Automotive Division.

Any motor vehicle that the government owns or leases. This includes motor vehicles obtained through purchase, excess, forfeiture, commercial lease, or GSA fleet lease.

Gross vehicle weight rating (GVWR) means the value specified by the vehicle manufacturer as the maximum design loaded weight of a single vehicle (e.g., vocational vehicle) (US Government Printing Office 2009)

GSA fleet lease means obtaining a motor vehicle from the General Services Administration fleet (GSA fleet) (41 CFR 102-34). 
Heavy light-duty truck

Highway fuel economy (Hwy MPG)

Hybrid electric vehicle

Idle time

Law enforcement

Light-duty motor vehicle Light-duty truck
Heavy light-duty truck means any light-duty truck rated greater than 6,000 lb GVWR. The light-duty truck 3 (LDT3) and LDT4 classifications comprise the heavy light-duty truck category (40 CFR 86.1803-01).

Highway fuel economy means the highway fuel economy determined either by operating a vehicle (or vehicles) over the driving schedule in the federal highway fuel economy test procedure or determined according to either the vehicle-specific, 5-cycle equation, or the derived 5-cycle equation for highway fuel economy (40 CFR 600.001).

Hybrid electric vehicle means a motor vehicle that draws propulsion energy from onboard sources of stored energy that are both an internal combustion engine or heat engine using consumable fuel and a rechargeable energy storage system (such as a battery, capacitor, hydraulic accumulator, or flywheel), where recharge energy for the energy storage system comes solely from sources on board the vehicle.

Idle time is logged whenever a vehicle idles with the engine running for 3 minutes or longer.

Law enforcement motor vehicle means a light-duty motor vehicle that is specifically approved in an agency-s appropriation act for use in apprehension, surveillance, police, or other law enforcement work or specifically designed for use in law enforcement. If not identified in an agency's appropriation language, a motor vehicle qualifies as a law enforcement motor vehicle only in the following cases:

(1) A passenger automobile having heavy-duty components for electrical, cooling, and suspension systems and at least the next higher cubic inch displacement or more powerful engine than is standard for the automobile concerned

(2) A light truck having emergency warning lights and identified with markings such as "police"

(3) An unmarked motor vehicle certified by the agency head as essential for the safe and efficient performance of intelligence, counterintelligence, protective, or other law enforcement duties

(4) A forfeited motor vehicle seized by a federal agency that subsequently is used for performing law enforcement activities (41 CFR Part 102-34.35).

Any motor vehicle with a GVWR of 8,500 pounds or less (41 CFR 102-34). Light-duty truck means any motor vehicle rated at 8,500 pounds GVWR or less, which has a curb weight of 6,000 pounds or less and, which has a basic vehicle frontal area of 45 square feet or less, which is as follows:

(1) Designed primarily for purposes of transportation of property or is a derivation of such a vehicle

(2) Designed primarily for transportation of persons and has a capacity of more than 12 persons

(3) Available with special features, enabling off-street or off-highway operation and use.

LDT1 means any light light-duty truck up through 3,750-lb loaded vehicle weight.

LDT2 means any light light-duty truck greater than 3,750-lb loaded vehicle weight. 


\section{Light-duty vehicle \\ Low-speed vehicle \\ Light-duty vehicle means a passenger car or passenger car derivative capable of seating 12 passengers or less. \\ Low-speed vehicle means a motor vehicle \\ (1) That is 4-wheeled \\ (2) Whose speed attainable in $1.6 \mathrm{~km}$ (1 mile) is more than 32 kilometers per hour (20 miles per hour) and not more than 40 kilometers per hour (25 miles per hour) on a paved level surface \\ (3) Whose GVWR is less than 1,361 kilograms (3,000 pounds) (49 CFR 571.3 - Definitions).}

Medium-duty passenger vehicle

Model year

$M P G$

$M P G e$

Non-passenger automobile
LDT3 means any heavy light-duty truck up through 5,750-lb adjusted loaded vehicle weight.

LDT4 means any heavy light-duty truck greater than 5,750-lb adjusted loaded vehicle weight (US Government Printing Office 2009)

Medium-duty passenger vehicle means any heavy-duty vehicle (as defined in this subpart) with a GVWR of less than 10,000 pounds that is designed primarily for transportation of persons. The medium-duty passenger vehicle definition does not include any vehicle which

(1) Is an "incomplete truck" as defined in this subpart

(2) Has a seating capacity of more than 12 persons

(3) Is designed for more than 9 persons in seating rearward of the driver's seat

(4) Is equipped with an open cargo area (for example, a pick-up truck box or bed) of 72.0 inches in interior length or more. A covered box not readily accessible from the passenger compartment will be considered an open cargo area for purposes of this definition (US Government Printing Office 2009)

Model year means the manufacturer's annual production period (as determined by the administrator), which includes January 1 of such calendar year; provided that if the manufacturer has no annual production period, the term "model year" shall mean the calendar year (40 CFR 86-1803.01).

"MPG" or "mpg" means miles per gallon. This generally may be used to describe fuel economy as a quantity or it may be used as the units associated with a particular value.

MPGe means miles per gallon equivalent. This generally is used to quantify a fuel economy value for vehicles that use a fuel other than gasoline. The value represents miles the vehicle can drive with the energy equivalent of one gallon of gasoline:

(c) SCF means standard cubic feet

(d) SUV means sport utility vehicle

(e) CREE means carbon-related exhaust emissions [76 FR 39527, July 6, 2011].

A non-passenger automobile means an automobile that is not a passenger automobile or a work truck and includes vehicles described in paragraphs (a) and (b) of 49 CFR 523.5. 
Owning agency

Passenger automobile

Pickup truck

Plug-in hybrid electric vehicle

Vehicle class

Vehicle configuration

Vehicle days

Vehicle home base

Vehicle study period
Owning agency means the executive agency that holds the vehicle title, manufacturer's Certificate of Origin or is the lessee of a commercial lease. This term does not apply to agencies that lease motor vehicles from the GSA fleet (41 CFR Part 102-34.35).

A passenger automobile is any automobile (other than an automobile capable of off-highway operation) manufactured primarily for use in the transportation of not more than 10 individuals (49 CFR 523.4 - Passenger automobile). A sedan or station wagon designed primarily to transport people (41 CFR 102-34).

Pickup truck means a non-passenger automobile, which has a passenger compartment and an open cargo bed (49 CFR 523.2).

PHEV means a hybrid electric vehicle that has the capability to charge the battery from an off-vehicle electric source, such that the off-vehicle source cannot be connected to the vehicle while the vehicle is in motion (40 CFR 86.1803).

The designation of motor vehicle types that include sedans, station wagons, ambulances, buses, and trucks, or different categories of vehicles according to Federal vehicle standards and further defined in 49 CFR 600.315-82.

Vehicle configuration means a unique combination of basic engine, engine code, inertia weight class, transmission configuration, and axle ratio.

The number of days a vehicle was driven or utilized during the (vehicle) study period.

The primary assigned outing beginning and ending parking location for the vehicle.

The time period the vehicle, within the study, has been equipped with a data logger. 


\section{Appendix B \\ USCG HQ Vehicle Data Sheets}

Table B-1. USCG HQ vehicle index.

\begin{tabular}{ccccccc}
\hline Log & Fleet Vehicle Id & Make & Model & Year & EPA Class & Mission \\
\hline 9 & G41-3130G & Chevrolet & Uplander & 2008 & Minivan & Pool \\
10 & G10-6597D & Pontiac & G6 & 2008 & Sedan - Compact & Pool \\
11 & G11-1871K & Chevrolet & Impala & 2010 & Sedan - Large & Pool \\
12 & G10-6592D & Pontiac & G6 & 2008 & Sedan - Compact & Pool \\
13 & G41-4430L & Dodge & Caravan & 2011 & Minivan & Pool \\
14 & G10-6567D & Pontiac & G6 & 2008 & Sedan - Compact & Pool \\
15 & G41-4397L & Dodge & Grand Caravan & 2010 & Minivan & Pool \\
16 & G41-3785K & Dodge & Caravan & 2010 & Minivan & Pool \\
17 & G12-0290L & Chevrolet & Malibu & 2011 & Sedan - Midsize & Pool \\
18 & G10-6590D & Pontiac & G6 & 2008 & Sedan - Compact & Pool \\
\hline
\end{tabular}




\begin{tabular}{|l|l|c|}
\hline & Make/Model/Year & Chevrolet Uplander/2008 \\
\hline EPA Class Size & Minivan \\
\hline Mission & Pool \\
\hline VIN & 1 GNDU23W88D175660 \\
\hline Parking Location & G41-3130G \\
\hline & Fleet Vehicle ID & Gas/E85 St \\
\hline Fuel Type & $16 / 23 / 1912 / 17 / 14$ \\
\hline EPA Label/MPG (City/Hwy/Combined) & $468 / 443$ \\
\hline & EPA GHG Emissions (Grams CO $/$ Mi) & 9 \\
\hline & Study Logger ID & $40 / 76$ \\
\hline
\end{tabular}

\begin{tabular}{|l|c|c|c|c|}
\hline \multicolumn{5}{|c|}{ Vehicle G41-3130G Travel Summary } \\
\hline & $\begin{array}{c}\text { Per Day } \\
\text { Average/Peak }\end{array}$ & $\begin{array}{c}\text { Per Outing } \\
\text { Average/Peak }\end{array}$ & $\begin{array}{c}\text { Per Trip } \\
\text { Average/Peak }\end{array}$ & Total \\
\hline Travel Distance (Miles) & $42.8 / 388.4$ & $40.7 / 515.4$ & $14.3 / 194.8$ & 1,711 \\
\hline Travel Time (Minutes) & $86.0 / 391.0$ & $81.6 / 692.0$ & $28.6 / 184.0$ & 3,429 \\
\hline Idle Time (Minutes) & $13.1 / \mathrm{NA}$ & $12.5 / \mathrm{NA}$ & $4.4 / \mathrm{NA}$ & 523 \\
\hline
\end{tabular}

\begin{tabular}{|c|c|c|c|c|}
\hline \multicolumn{3}{|c|}{ Total Stops } & \multicolumn{2}{c|}{ Stop Duration } \\
\hline $\begin{array}{c}\text { Distance From } \\
\text { Home Base (Miles) }\end{array}$ & Stops & Percentages & Stop Duration (Hours) & Stops \\
\hline Less than 10 & 85 & $68.0 \%$ & Less than 2 & 78 \\
\hline 10 to 20 & 9 & $7.2 \%$ & 2 to 4 & 4 \\
\hline 20 to 40 & 17 & $13.6 \%$ & 4 to 8 & 10 \\
\hline Greater than 40 & 14 & $11.2 \%$ & Greater than 8 & 33 \\
\hline
\end{tabular}

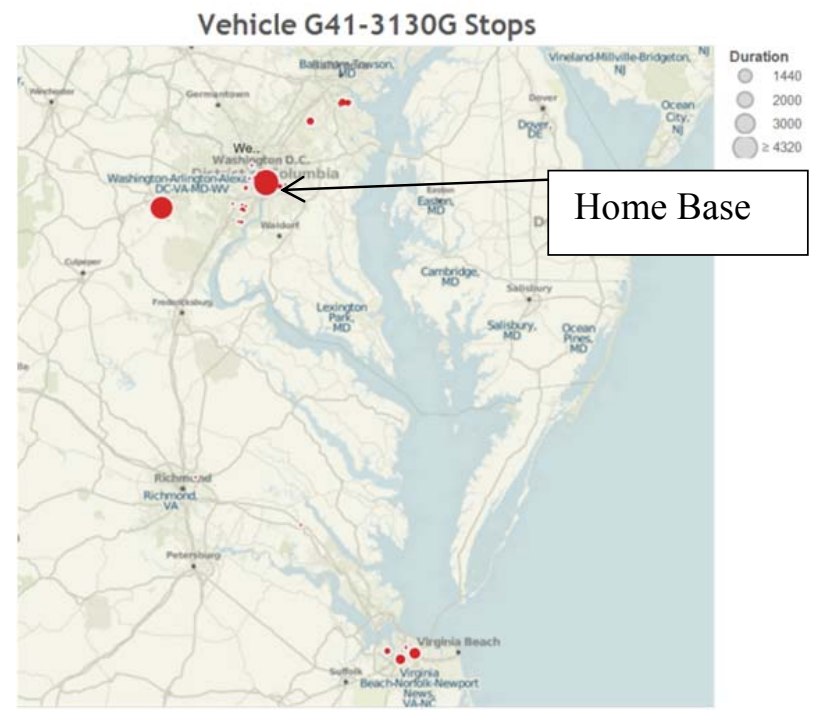

Figure B-1. Vehicle G41-3130G stops.

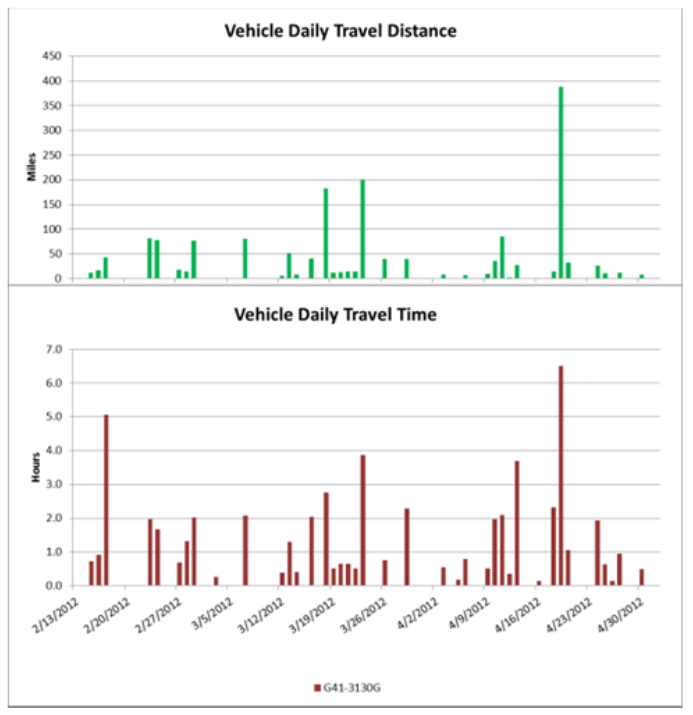

Figure B-2. Vehicle G41-3130G history. 

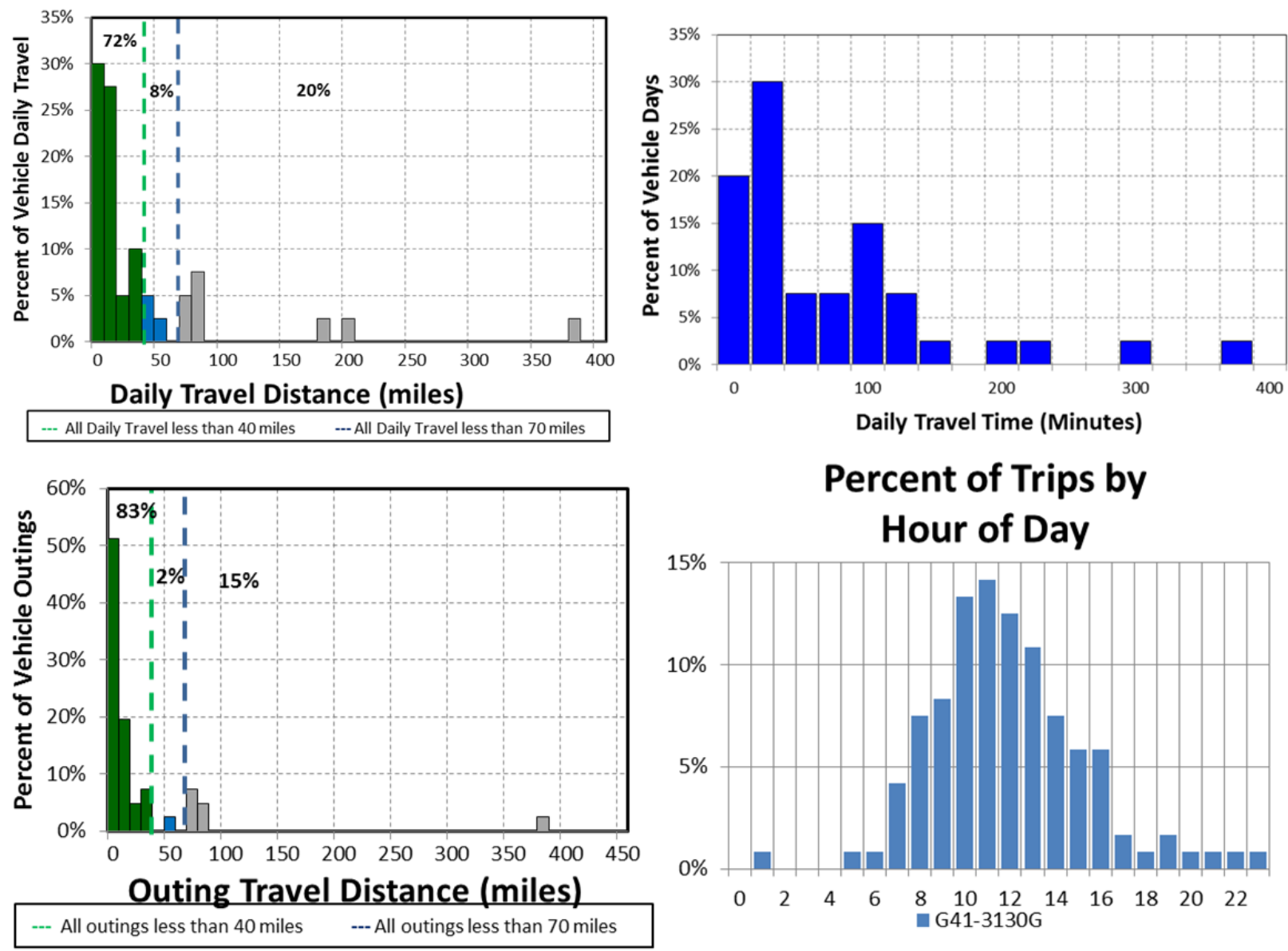

Figure B-3. Vehicle G41-3130G travel graph. Note: peak outing of 515.4 miles not shown for clarity of scale.

\section{Vehicle G41-3130G Observations}

Logger 9 collected data on this vehicle for 40 days of the 76-day study period. Validation occurred on $90.1 \%$ of the input data. USCG HQ reports that this vehicle has a pool mission for administration. This vehicle's data indicate it parks near HQ on Half St $/{ }^{\text {st }} \mathrm{St} / 2^{\text {nd }} \mathrm{St}$ or V St. (Figure B-1 and Google Earth figure to the right).

USCG HQ reports that the vehicle odometer indicated 18,631miles during the study and an annual mileage of 6,600 miles. The vehicle was used on $53 \%$ of the available days, with an average daily usage of 1.4 hours and a peak daily usage of 6.5 hours on the days it was used. The vehicle was used primarily during dayshift hours.

Figure B-3 shows several days of travel exceeding the advertised range of a BEV of approximately 70 miles, with $80 \%$ of daily travel within the BEV range and $85 \%$ of the outings also within this range. Further, $72 \%$ of daily travel and $83 \%$ of outings were within the typically advertised CD mode of 40 miles for PHEVs. The peak outing exceeds the peak daily travel because of an extended several day excursion to Norfolk.

A BEV could not meet the specific daily travel, but a BEV could provide benefits for a significant amount of travel that was local. Thus, a fleet of pool vehicles with this mission could likely contain both BEVs and PHEVs. 


\begin{tabular}{|c|c|c|}
\hline$-e^{2}$ & Make/Model/Year & Pontiac G6/2008 \\
\hline & EPA Class Size & Sedan - Compact \\
\hline 80 & Mission & Pool \\
\hline & VIN & 1G2ZG57B384232236 \\
\hline & Parking Location & $1^{\text {st }} \mathrm{St}$ \\
\hline & Fleet Vehicle ID & G10-6597D \\
\hline & Fuel Type & Gas \\
\hline & EPA Label/MPG (City/Hwy/Combined) & $22 / 30 / 25$ \\
\hline & EPA GHG Emissions (Grams $\mathrm{CO}_{2} / \mathrm{Mi}$ ) & 355 \\
\hline & Study Logger ID & 10 \\
\hline & Total Vehicle Days/Total Study Days & $49 / 78$ \\
\hline
\end{tabular}

\begin{tabular}{|l|c|c|c|c|}
\hline \multicolumn{5}{|c|}{ Vehicle G10-6597D Travel Summary } \\
\hline & $\begin{array}{c}\text { Per Day } \\
\text { Average/Peak }\end{array}$ & $\begin{array}{c}\text { Per Outing } \\
\text { Average/Peak }\end{array}$ & $\begin{array}{c}\text { Per Trip } \\
\text { Average/Peak }\end{array}$ & Total \\
\hline Travel Distance (Miles) & $59.9 / 395.6$ & $94.7 / 1045.0$ & $18.1 / 252.7$ & 2,936 \\
\hline Travel Time (Minutes) & $113.0 / 457.0$ & $178.8 / 1681.0$ & $34.2 / 281.0$ & 5,543 \\
\hline Idle Time (Minutes) & $19.0 / \mathrm{NA}$ & $30.0 / \mathrm{NA}$ & $5.7 / \mathrm{NA}$ & 931 \\
\hline
\end{tabular}

\begin{tabular}{|c|c|c|c|c|}
\hline \multicolumn{3}{|c|}{ Total Stops } & \multicolumn{2}{c|}{ Stop Duration } \\
\hline $\begin{array}{c}\text { Distance From } \\
\text { Home Base (Miles) }\end{array}$ & Stops & Percentages & Stop Duration (Hours) & Stops \\
\hline Less than 10 & 82 & $72.6 \%$ & Less than 2 & 79 \\
\hline 10 to 20 & 2 & $1.8 \%$ & 2 to 4 & 7 \\
\hline 20 to 40 & 8 & $7.0 \%$ & 4 to 8 & 5 \\
\hline Greater than 40 & 21 & $18.6 \%$ & Greater than 8 & 22 \\
\hline
\end{tabular}

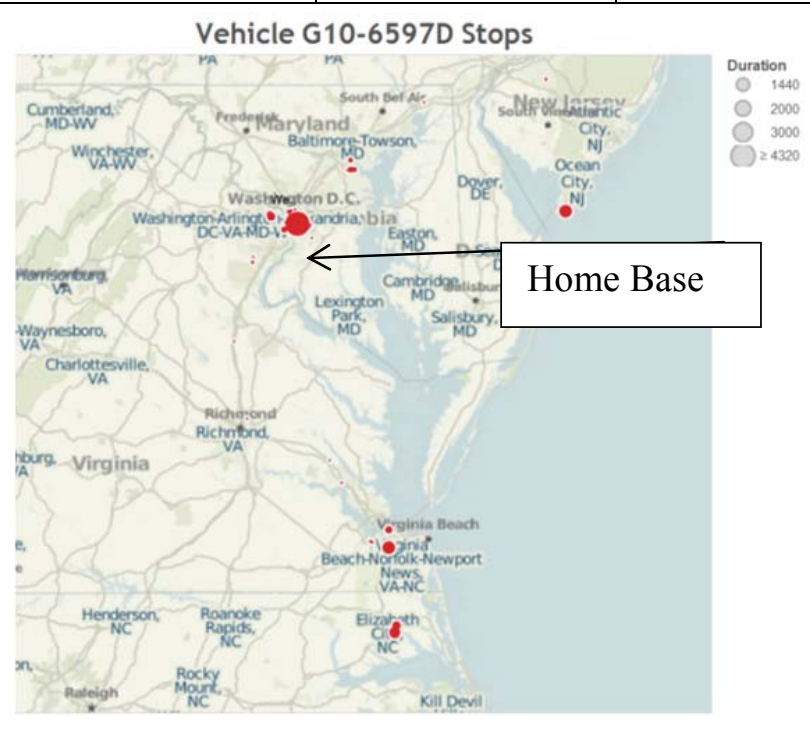

Figure B-4. Vehicle G10-6597D stops.

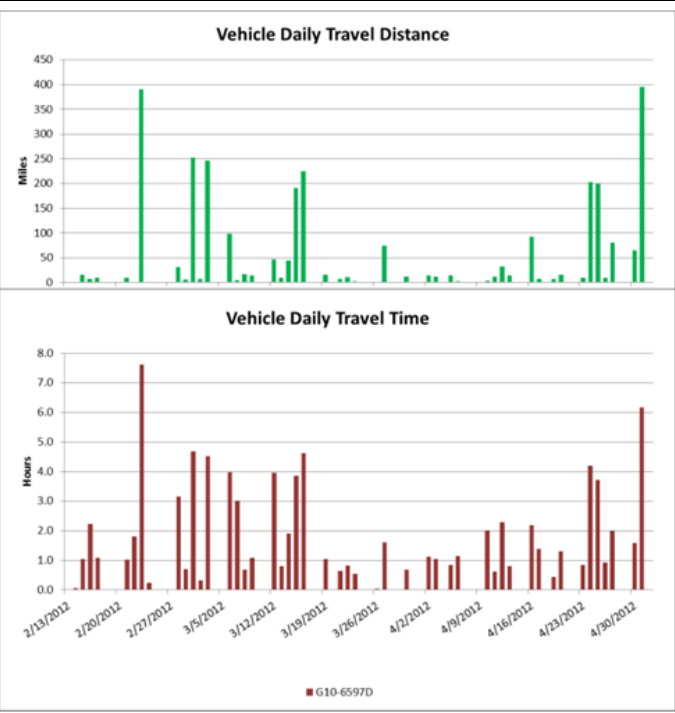

Figure B-5. Vehicle G10-6597D history. 


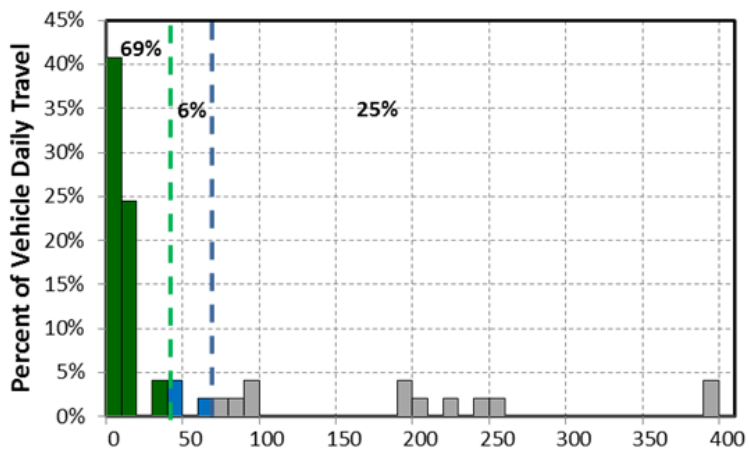

Daily Travel Distance (miles)

-- All Daily Travel less than 40 miles $\quad$---All Daily Travel less than 70 miles

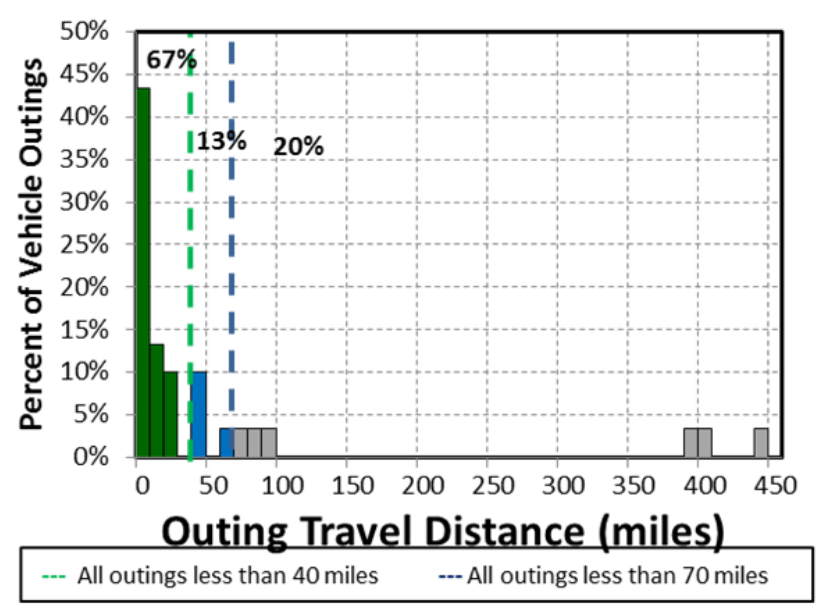

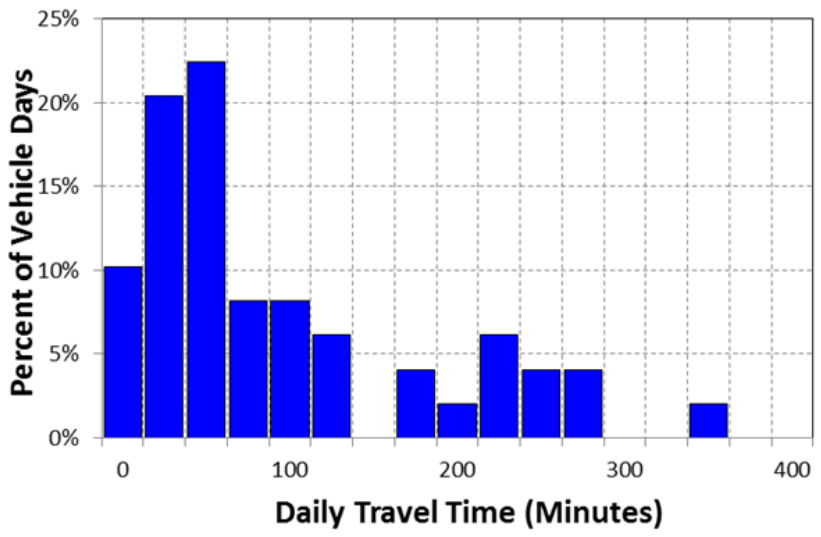

Percent of Trips by Hour of Day

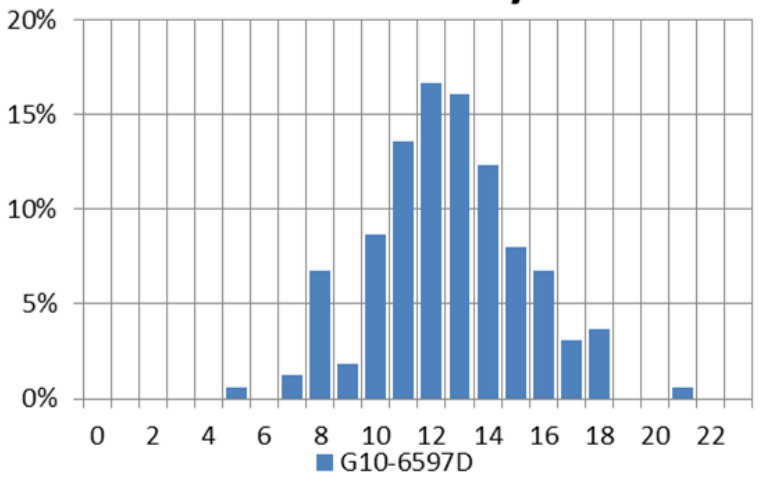

Figure B-6. Vehicle G10-6597D travel graphs. NOTE: peak outing of 1,045 miles not shown for clarity of scale.

\section{Vehicle G10-6597D Observations}

Logger 10 collected data on this vehicle for 49 days of the 78-day study period. Validation occurred on $95.7 \%$ of the input data. USCG HQ reports that this vehicle has a pool mission for administration. This vehicle's data indicate that it parks near HQ on $1^{\text {st }} \mathrm{St} / 2^{\text {nd }} \mathrm{St}$ or V St. (Figure B-4 and the Google Earth figure to the right).

USCG HQ reports that the vehicle odometer indicated 25,875 miles during the study and an annual mileage of approximately 7,500 miles. The vehicle was used on $63 \%$ of the available days, with an average daily usage of 1.9 hours and a peak daily usage of 7.6 hours on the days it was used. The vehicle was used during day shift hours.

Figure B-6 shows that $75 \%$ of the daily travel and $80 \%$ of the outings were within the typically advertised range of a BEV of

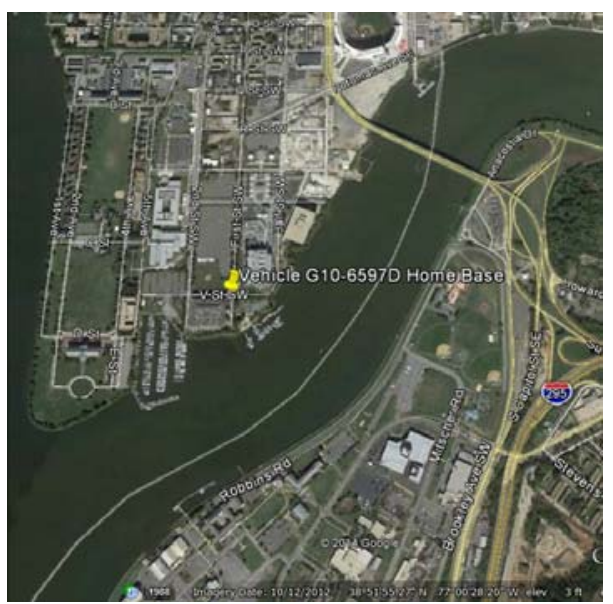
approximately 70 miles. Further, $69 \%$ of daily travel and $67 \%$ of outings were within the typically advertised CD mode of 40 miles for PHEVs. The longest outings occurred on an extended day excursion to North Carolina.

A BEV cannot meet all daily travel because of the long daily distances. A BEV could provide benefits for a significant amount of travel that was local. Thus, a fleet of support vehicles with this mission would likely contain a mix of BEVs and PHEVs. 


\begin{tabular}{|c|c|c|}
\hline 2011 & Make/Model/Year & Chevrolet Impala/2010 \\
\hline $21-4=$ & EPA Class Size & Sedan - Large \\
\hline$\beta=8=$ & Mission & Pool \\
\hline & VIN & 2G1WA5EK6A1264563 \\
\hline & Parking Location & $1^{\text {st }} / 2^{\text {nd }} \mathrm{St}$ \\
\hline & Fleet Vehicle ID & G11-1871K \\
\hline & Fuel Type & Gas/E85 \\
\hline & EPA Label/MPG (City/Hwy/Combined) & $18 / 29 / 22 \quad 14 / 22 / 17$ \\
\hline & EPA GHG Emissions (Grams $\mathrm{CO}_{2} / \mathrm{Mi}$ ) & $404 / 365$ \\
\hline & Study Logger ID & 11 \\
\hline & Total Vehicle Days/Total Study Days & $42 / 77$ \\
\hline
\end{tabular}

\begin{tabular}{|l|c|c|c|c|}
\hline \multicolumn{5}{|c|}{ Vehicle G11-1871K Travel Summary } \\
\hline & $\begin{array}{c}\text { Per Day } \\
\text { Average/Peak }\end{array}$ & $\begin{array}{c}\text { Per Outing } \\
\text { Average/Peak }\end{array}$ & $\begin{array}{c}\text { Per Trip } \\
\text { Average/Peak }\end{array}$ & Total \\
\hline Travel Distance (Miles) & $39.3 / 214.8$ & $55.1 / 469.4$ & $10.5 / 137.2$ & 1,652 \\
\hline Travel Time (Minutes) & $113.0 / 335.0$ & $158.1 / 696.0$ & $30.0 / 147.0$ & 4,742 \\
\hline Idle Time (Minutes) & $34.9 / \mathrm{NA}$ & $48.9 / \mathrm{NA}$ & $9.3 / \mathrm{NA}$ & 1,466 \\
\hline
\end{tabular}

\begin{tabular}{|c|c|c|c|c|}
\hline \multicolumn{2}{|c|}{ Total Stops } & \multicolumn{2}{c|}{ Stop Duration } \\
\hline $\begin{array}{c}\text { Distance From Home } \\
\text { Base (Miles) }\end{array}$ & Stops & Percentages & Stop Duration (Hours) & Stops \\
\hline Less than 10 & 89 & $71.8 \%$ & Less than 2 & 81 \\
\hline 10 to 20 & 3 & $2.4 \%$ & 2 to 4 & 13 \\
\hline 20 to 40 & 8 & $6.5 \%$ & 4 to 8 & 6 \\
\hline Greater than 40 & 24 & $19.3 \%$ & Greater than 8 & 24 \\
\hline
\end{tabular}

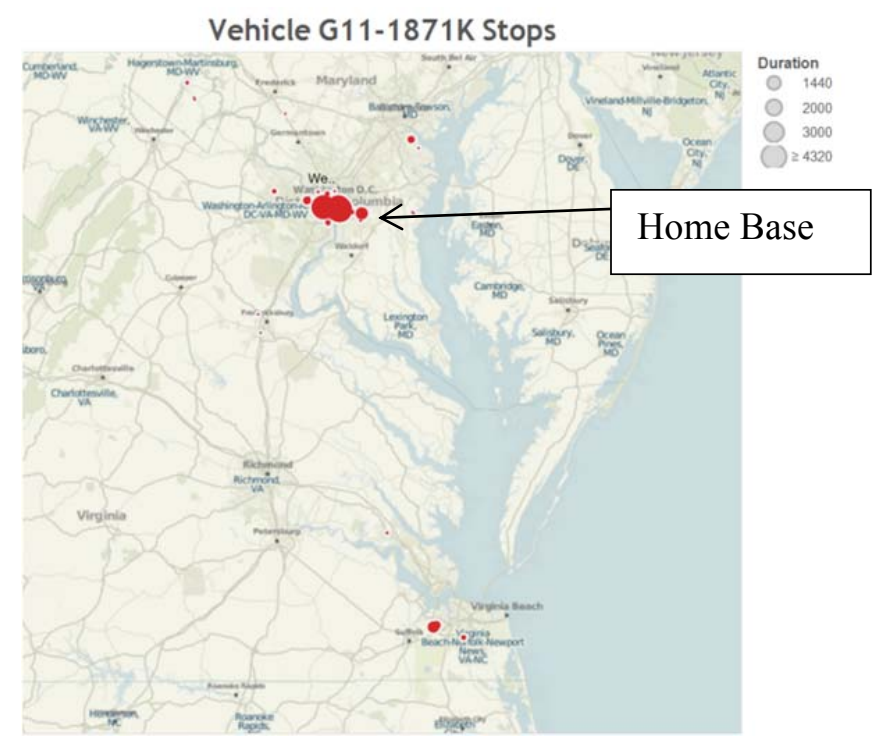

Figure B-7. Vehicle G11-1871K stops.

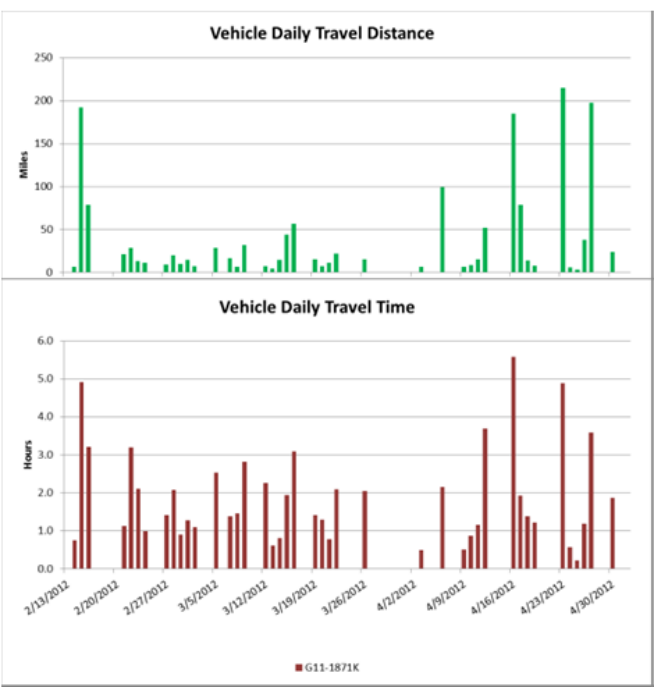

Figure B-8. Vehicle G11-1871K history. 

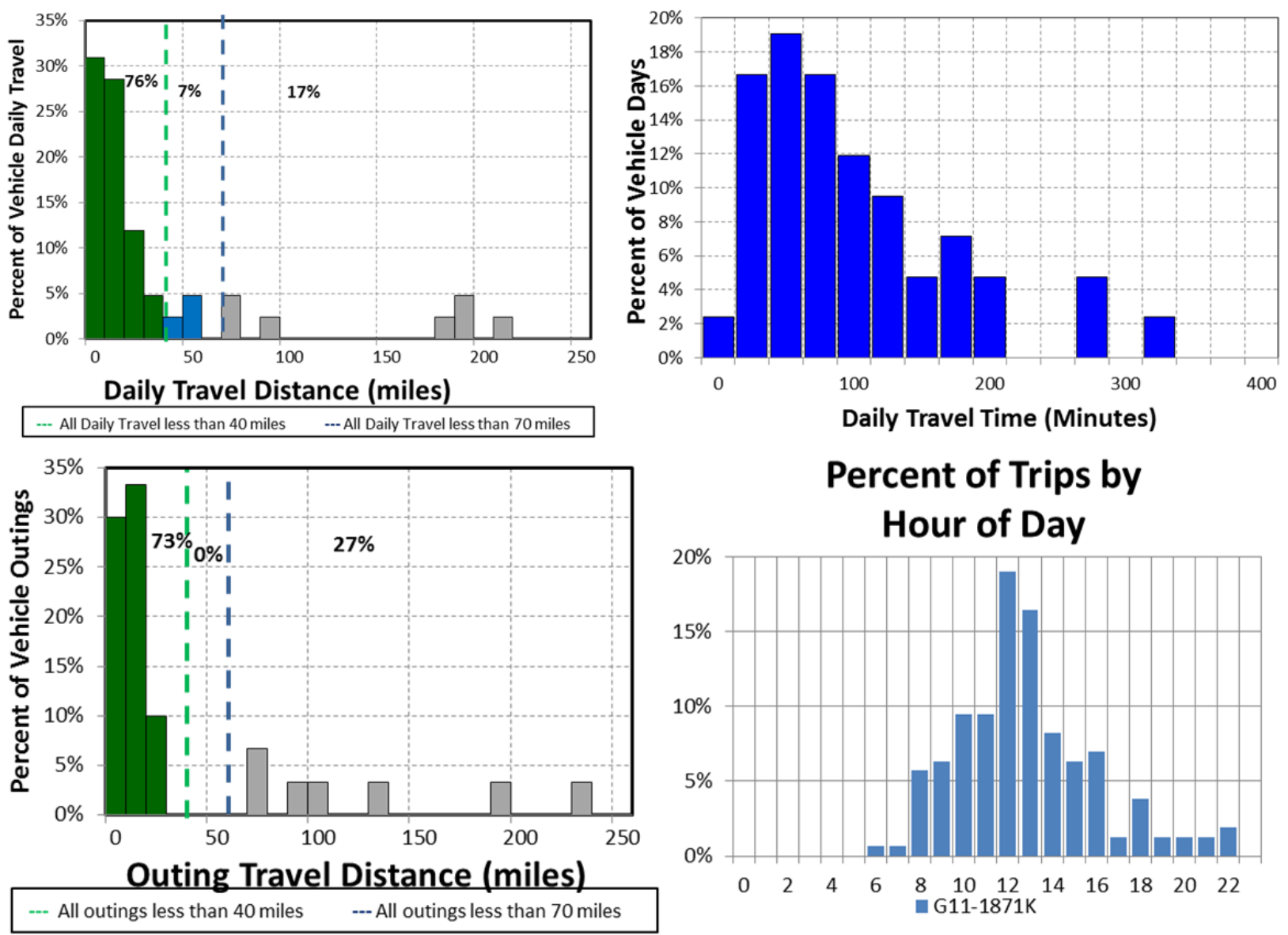

Figure B-9. Vehicle G11-1871K travel graphs. Note: peak outing of 469.4 miles not shown for clarity of scale.

\section{Vehicle G11-1871K Observations}

Logger 11 collected data on this vehicle for 42 days of the 77-day study period. Validation occurred on $98 \%$ of the input data. USCG HQ reports that this vehicle has a pool mission for administration. This vehicle's data indicate it parks near the HQ on $1^{\text {st }} \mathrm{St} / 2^{\text {nd }} \mathrm{St}$ or V St. (Figure B-7 and Google Earth figure to the right).

USCG HQ reports that the vehicle odometer indicated 12,013 miles during the study and an annual mileage of approximately 6,000 miles. The vehicle was used on $55 \%$ of the available days, with an average daily usage of 1.9 hours and a peak daily usage of 5.6 hours on the days it was used. The vehicle was used during typical day shift hours.

Figure B-9 shows $83 \%$ of the daily travel and $73 \%$ outings were

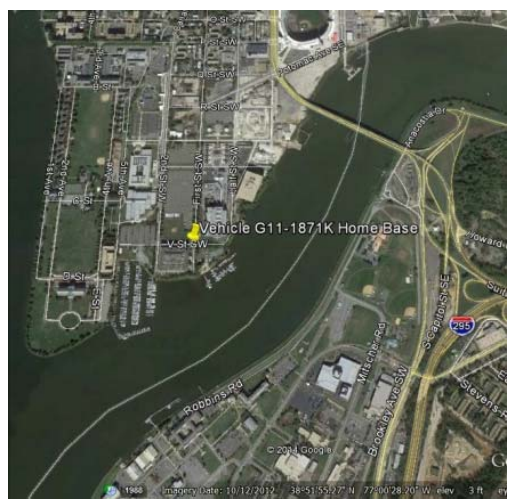
within the typically advertised range of a BEV of approximately 70 miles. Further, $76 \%$ of daily travel and $73 \%$ of outings were within the typically advertised CD mode of 40 miles for PHEVs. The peak outing occurred on a several-day excursion to Chesapeake, VA.

A BEV cannot meet all daily travel because of the long daily distances. A BEV could provide benefits for a significant amount of travel that was local. Thus, a fleet of support vehicles with this mission would likely contain a mix of BEVs and PHEVs. 


\begin{tabular}{|c|c|c|}
\hline 回 & Make/Model/Year & Pontiac G6/2008 \\
\hline$\Delta$ & EPA Class Size & Sedan - Compact \\
\hline 20 & Mission & Pool \\
\hline & VIN & 1G2ZG57B084233344 \\
\hline & Parking Location & $1^{\text {st }} \mathrm{St} / 2^{\text {nd }} \mathrm{St}$ \\
\hline & Fleet Vehicle ID & G10-6592D \\
\hline & Fuel Type & Gas \\
\hline & EPA Label/MPG (City/Hwy/Combined) & $22 / 30 / 25$ \\
\hline & EPA GHG Emissions (Grams $\mathrm{CO}_{2} / \mathrm{Mi}$ ) & 355 \\
\hline & Study Logger ID & 12 \\
\hline & Total Vehicle Days/Total Study Days & $49 / 77$ \\
\hline
\end{tabular}

\begin{tabular}{|l|c|c|c|c|}
\hline \multicolumn{5}{|c|}{ Vehicle G10-6592D Travel Summary } \\
\hline & $\begin{array}{c}\text { Per Day } \\
\text { Average/Peak }\end{array}$ & $\begin{array}{c}\text { Per Outing } \\
\text { Average/Peak }\end{array}$ & $\begin{array}{c}\text { Per Trip } \\
\text { Average/Peak }\end{array}$ & Total \\
\hline Travel Distance (Miles) & $21.7 / 153.4$ & $27.3 / 91.7$ & $7.4 / 48.7$ & 1,064 \\
\hline Travel Time (Minutes) & $84.0 / 344.0$ & $105.6 / 281.0$ & $28.6 / 170.0$ & 4,119 \\
\hline Idle Time (Minutes) & $24.2 / \mathrm{NA}$ & $30.4 / \mathrm{NA}$ & $8.2 / \mathrm{NA}$ & 1,185 \\
\hline
\end{tabular}

\begin{tabular}{|c|c|c|c|c|}
\hline \multicolumn{2}{|c|}{ Total Stops } & \multicolumn{2}{c|}{ Stop Duration } \\
\hline $\begin{array}{c}\text { Distance From } \\
\text { Home Base (Miles) }\end{array}$ & Stops & Percentages & Stop Duration (Hours) & Stops \\
\hline Less than 10 & 98 & $86.7 \%$ & Less than 2 & 69 \\
\hline 10 to 20 & 5 & $4.5 \%$ & 2 to 4 & 13 \\
\hline 20 to 40 & 10 & $8.8 \%$ & 4 to 8 & 5 \\
\hline Greater than 40 & 0 & $0 \%$ & Greater than 8 & 26 \\
\hline
\end{tabular}

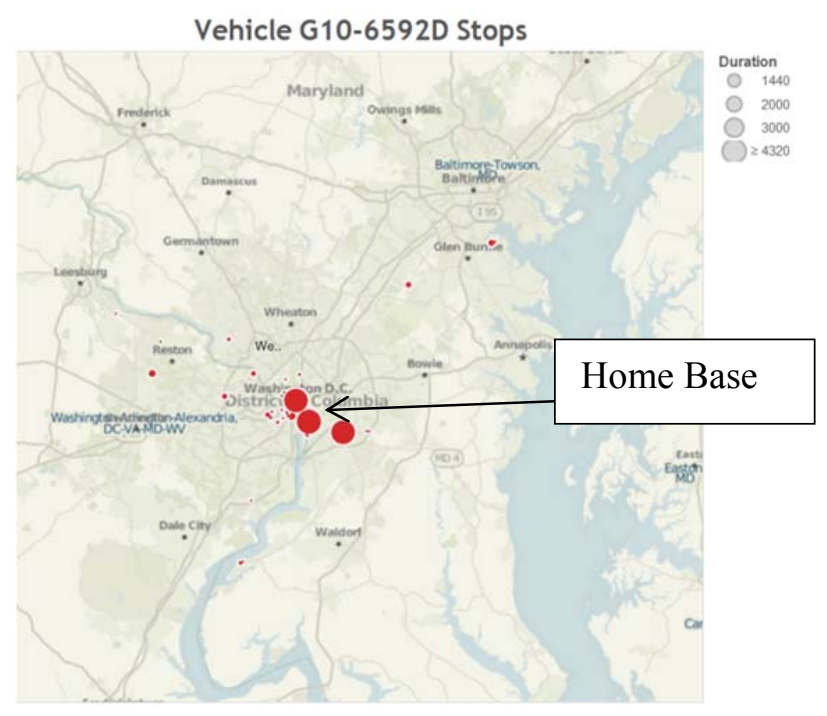

Figure B-10. Vehicle G10-6592D stops.

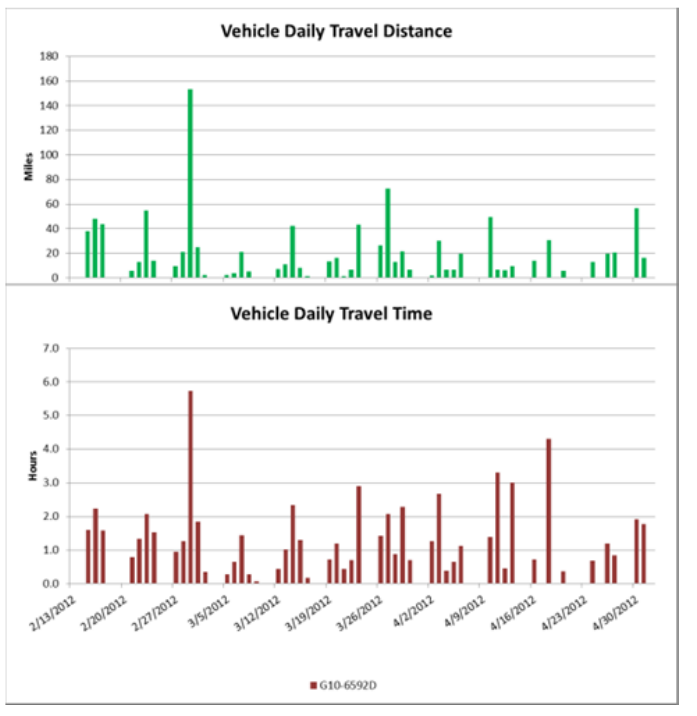

Figure B-11. Vehicle G10-6592D history. 

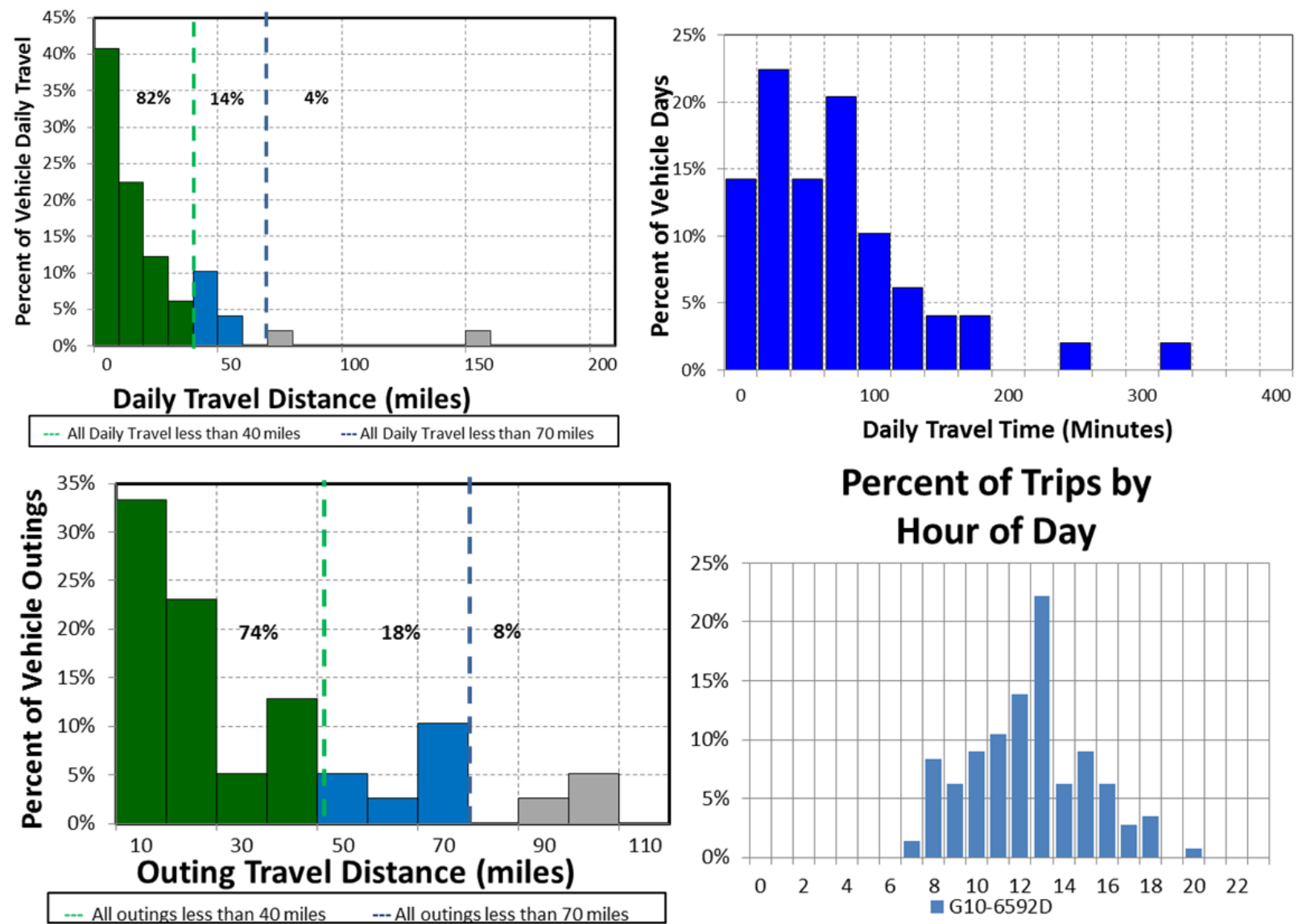

Figure B-12. Vehicle G10-6592D travel graphs.

\section{Vehicle G10-6592D Observations}

Logger 12 collected data on this vehicle for 49 days of the 77-day study period. Validation occurred on $96.8 \%$ of the input data. USCG HQ reports that this vehicle has a pool mission for administration. This vehicle's data indicate it parks near HQ on $1^{\text {st }} \mathrm{St} / 2^{\text {nd }} \mathrm{St}$ or V St. (Figure B-10 and Google Earth figure to the right).

USCG HQ reports that the vehicle odometer indicated 27,426 miles during the study and an annual mileage of approximately 7,500 miles. The vehicle was used on $64 \%$ of the available days, with an average daily usage of 1.4 hours and a peak daily usage of 5.7 hours on the days it was used. The vehicle was used primarily during typical day shift hours.

Figure B-12 shows $96 \%$ of daily travel and $92 \%$ of outings were within the typically advertised range of a BEV of approximately 70 miles. Further, $82 \%$ of daily travel and $74 \%$ of outings were within the typically advertised CD mode of 40 miles for PHEVs.

A BEV cannot meet all daily travel because of the long daily distances. A BEV could provide benefits for a significant amount of travel that was local. Thus, a fleet of support vehicles with this mission would likely contain a mix of BEVs and PHEVs. 
Vehicle G41-4430L

\begin{tabular}{|c|c|c|}
\hline 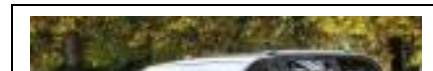 & Make/Model/Year & Dodge Caravan/2011 \\
\hline 9 & EPA Class Size & Minivan \\
\hline 1 & Mission & Pool \\
\hline & VIN & 2D4RN4DG7BR763989 \\
\hline & Parking Location & $1^{\text {st }} \mathrm{St}$ \\
\hline & Fleet Vehicle ID & G41-4430L \\
\hline & Fuel Type & Gas/E85 \\
\hline & EPA Label/MPG (City/Hwy) & $17 / 25 / 20 \quad 12 / 18 / 14$ \\
\hline & EPA GHG Emissions (Grams $\left.\mathrm{CO}_{2} / \mathrm{Mi}\right)$ & 444443 \\
\hline & Study Logger ID & 13 \\
\hline & Total Vehicle Days/Total Study Days & $47 / 76$ \\
\hline
\end{tabular}

\begin{tabular}{|l|c|c|c|c|}
\hline \multicolumn{5}{|c|}{ Vehicle G41-4430L Travel Summary } \\
\hline & $\begin{array}{c}\text { Per Day } \\
\text { Average/Peak }\end{array}$ & $\begin{array}{c}\text { Per Outing } \\
\text { Average/Peak }\end{array}$ & $\begin{array}{c}\text { Per Trip } \\
\text { Average/Peak }\end{array}$ & Total \\
\hline Travel Distance (Miles) & $38.6 / 315.5$ & $23.8 / 315.5$ & $7.6 / 140.9$ & 1,812 \\
\hline Travel Time (Minutes) & $172.0 / 486.0$ & $106.4 / 541.0$ & $33.7 / 176.0$ & 8,083 \\
\hline Idle Time (Minutes) & $68.4 / \mathrm{NA}$ & $42.3 / \mathrm{NA}$ & $13.4 / \mathrm{NA}$ & 3,214 \\
\hline
\end{tabular}

\begin{tabular}{|c|c|c|c|c|}
\hline \multicolumn{2}{|c|}{ Total Stops } & \multicolumn{2}{c|}{ Stop Duration } \\
\hline $\begin{array}{c}\text { Distance From Home } \\
\text { Base (Miles) }\end{array}$ & Stops & Percentages & Stop Duration (Hours) & Stops \\
\hline Less than 10 & 187 & $93.5 \%$ & Less than 2 & 157 \\
\hline 10 to 20 & 0 & $0 \%$ & 2 to 4 & 10 \\
\hline 20 to 40 & 7 & $3.5 \%$ & 4 to 8 & 1 \\
\hline Greater than 40 & 6 & $2.5 \%$ & Greater than 8 & 32 \\
\hline
\end{tabular}

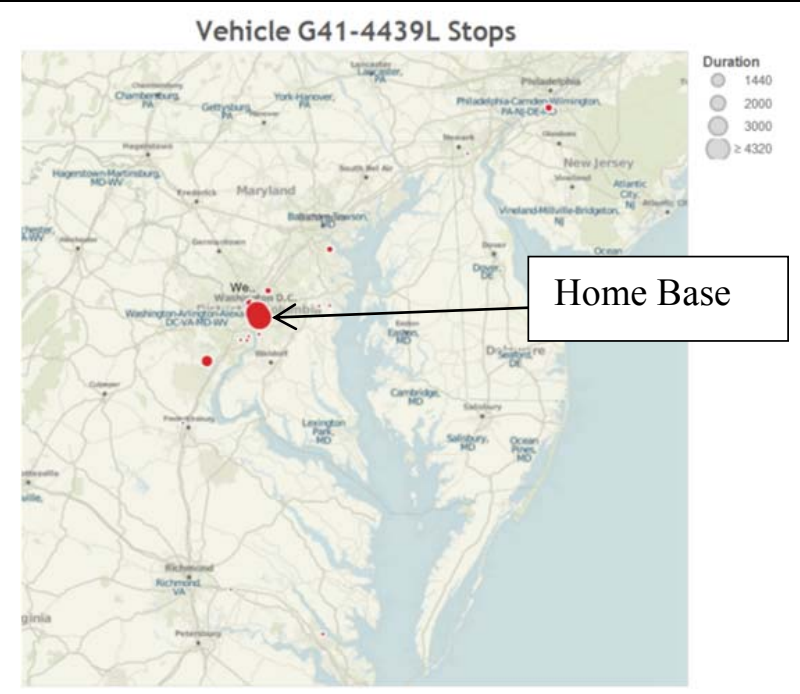

Figure B-13. Vehicle G41-4430L stops.

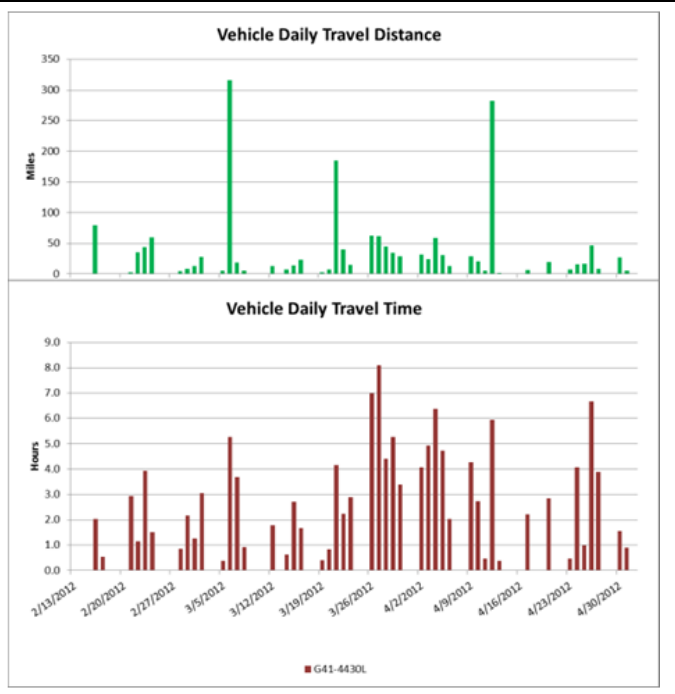

Figure B-14. Vehicle G41-4430L history. 


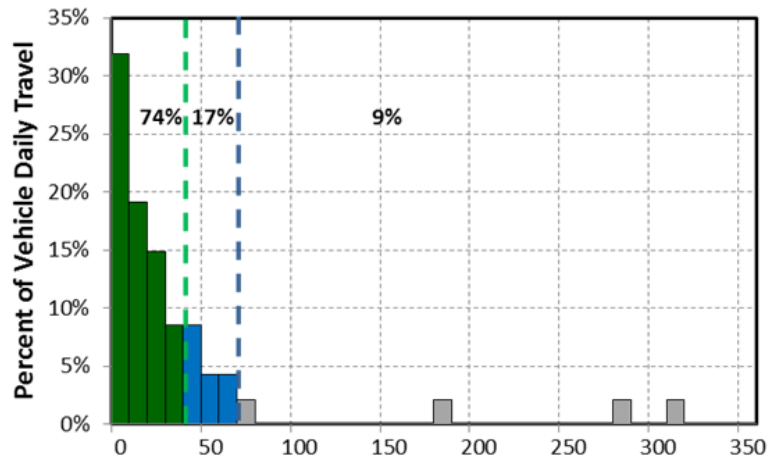

Daily Travel Distance (miles)

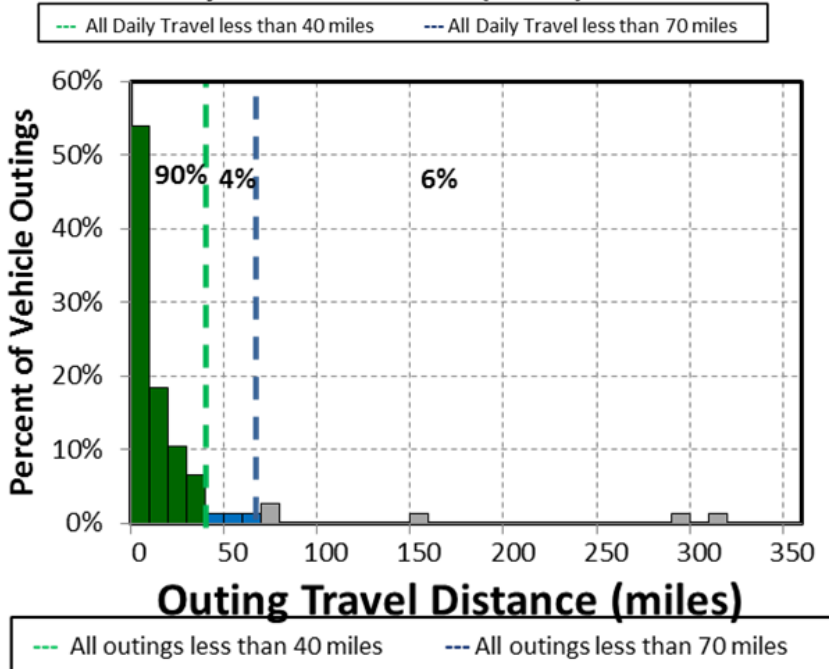

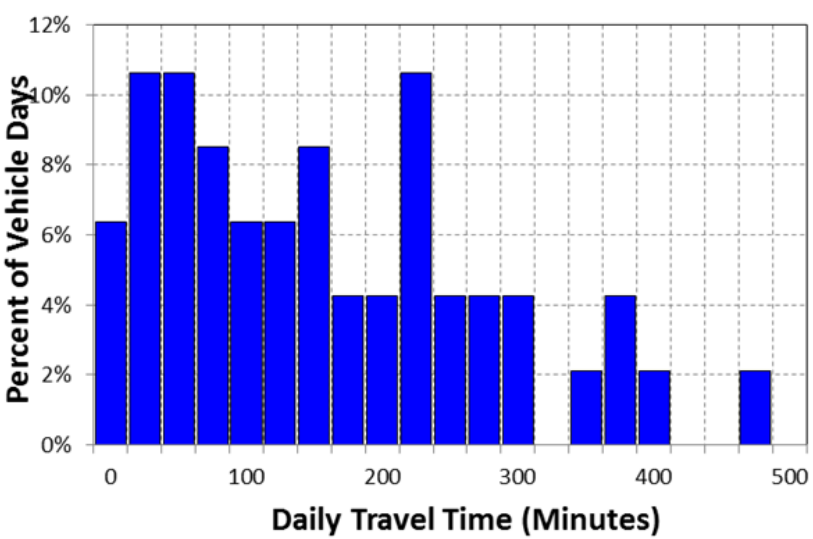

Percent of Trips by Hour of Day

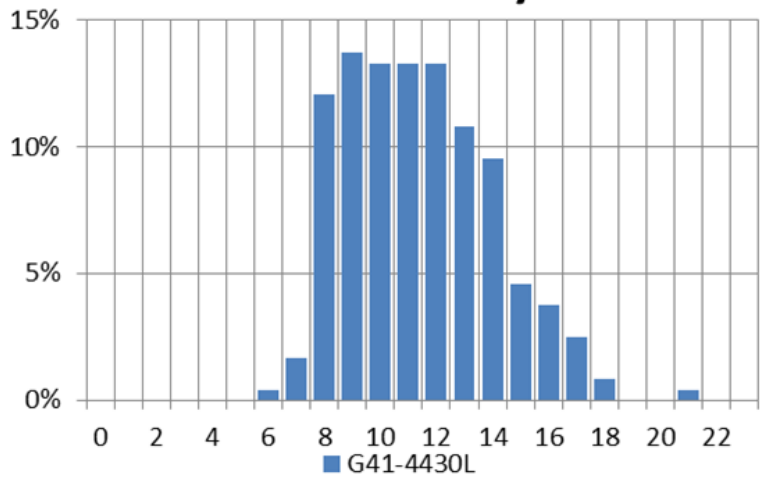

Figure B-15. Vehicle G41-4430L travel graphs.

\section{Vehicle G41-4430L Observations}

Logger 13 collected data on this vehicle for 47 days of the 76-day study period. Validation occurred on $98.0 \%$ of the input data. USCG HQ reports that this vehicle has a pool mission for administration. This vehicle's data indicate it parks near HQ on $1^{\text {st }} \mathrm{St} / 2^{\text {nd }} \mathrm{St}$ or V St (Figure B-13 and Google Earth figure to the right).

USCG HQ reports that the vehicle odometer indicated 2,545 miles during the study and an annual mileage of approximately 6,000 miles. The vehicle was used on $62 \%$ of the available days, with an average daily usage of 2.9 hours and a peak daily usage of 8.1 hours on the days it was used. The vehicle was used primarily during typical day shift hours.

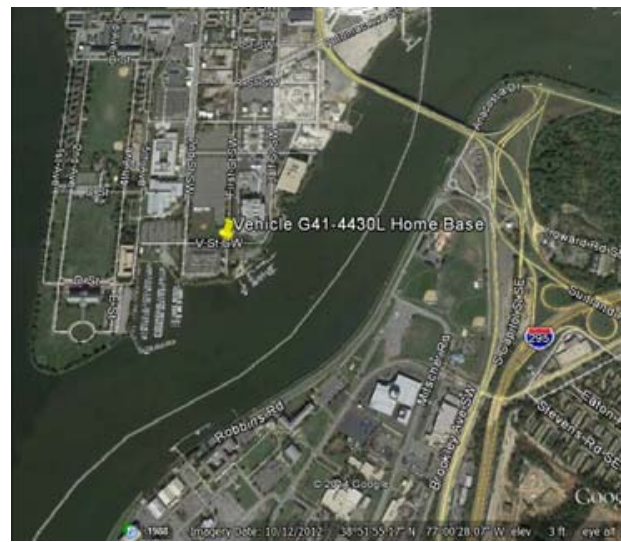

Figure B-15 shows $91 \%$ of daily travel and $94 \%$ of outings were within the typically advertised range of a BEV of approximately 70 miles. Further, $74 \%$ of daily travel and $90 \%$ of outings were within the typically advertised CD mode of 40 miles for PHEVs.

A BEV cannot meet all daily travel because of the long daily distances. A BEV could provide benefits for a significant amount of travel that was local. Thus, a fleet of support vehicles with this mission would likely contain a mix of BEVs and PHEVs. 


\begin{tabular}{|c|c|c|}
\hline$x^{2}$ & Make/Model/Year & Pontiac G6/2008 \\
\hline & EPA Class Size & Sedan - Compact \\
\hline 20 & Mission & Pool \\
\hline & VIN & 1G2ZG57BX84231925 \\
\hline & Parking Location & Half St \\
\hline & Fleet Vehicle ID & G10-6567D \\
\hline & Fuel Type & Gas \\
\hline & EPA Label/MPG (City/Hwy/Combined) & $22 / 30 / 25$ \\
\hline & EPA GHG Emissions (Grams $\mathrm{CO}_{2} / \mathrm{Mi}$ ) & 355 \\
\hline & Study Logger ID & 14 \\
\hline & Total Vehicle Days/Total Study Days & $39 / 77$ \\
\hline
\end{tabular}

\begin{tabular}{|l|c|c|c|c|}
\hline \multicolumn{5}{|c|}{ Vehicle G10-6567D Travel Summary } \\
\hline & $\begin{array}{c}\text { Per Day } \\
\text { Average/Peak }\end{array}$ & $\begin{array}{c}\text { Per Outing } \\
\text { Average/Peak }\end{array}$ & $\begin{array}{c}\text { Per Trip } \\
\text { Average/Peak }\end{array}$ & Total \\
\hline Travel Distance (Miles) & $28.9 / 96.8$ & $24.5 / 96.5$ & $9.8 / 65.6$ & 1,128 \\
\hline Travel Time (Minutes) & $68.0 / 163.0$ & $58.1 / 196.0$ & $23.2 / 95.0$ & 2,671 \\
\hline Idle Time (Minutes) & $12.7 / \mathrm{NA}$ & $10.8 / \mathrm{NA}$ & $4.3 / \mathrm{NA}$ & 495 \\
\hline
\end{tabular}

\begin{tabular}{|c|c|c|c|c|}
\hline \multicolumn{3}{|c|}{ Total Stops } & \multicolumn{2}{c|}{ Stop Duration } \\
\hline $\begin{array}{c}\text { Distance From } \\
\text { Home Base (Miles) }\end{array}$ & Stops & Percentages & Stop Duration (Hours) & Stops \\
\hline Less than 10 & 75 & $77.3 \%$ & Less than 2 & 45 \\
\hline 10 to 20 & 12 & $12.4 \%$ & 2 to 4 & 10 \\
\hline 20 to 40 & 10 & $10.3 \%$ & 4 to 8 & 12 \\
\hline Greater than 40 & 0 & $0 \%$ & Greater than 8 & 30 \\
\hline
\end{tabular}

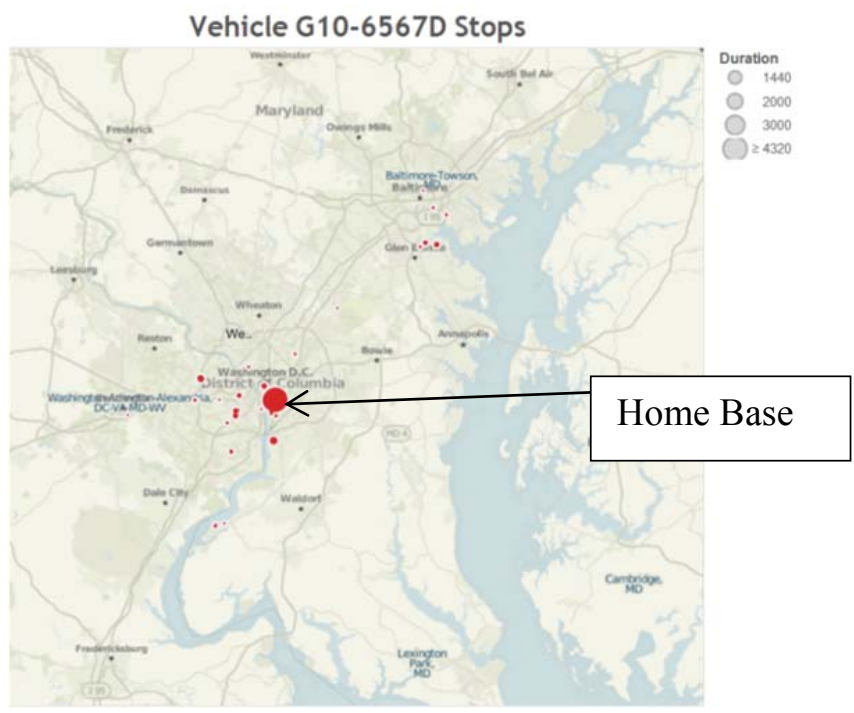

Figure B-16. Vehicle G10-6567D stops.

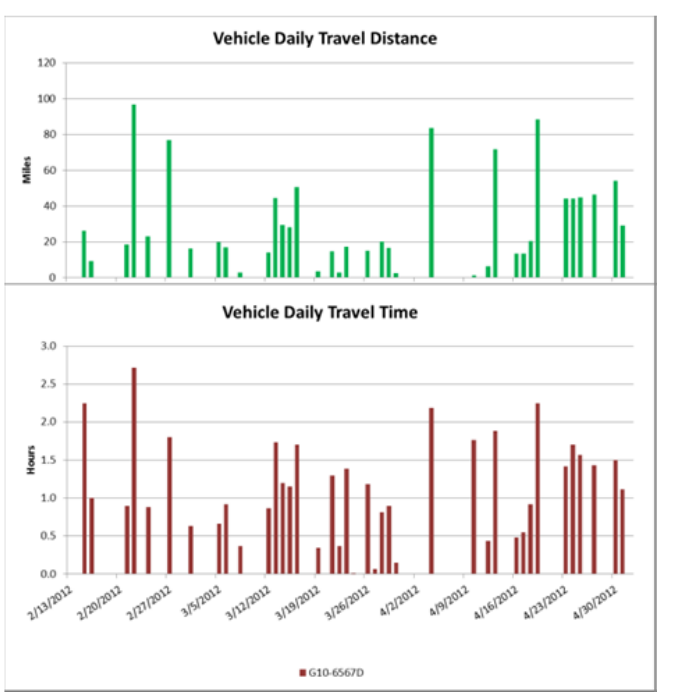

Figure B-17. Vehicle G10-6567D history. 

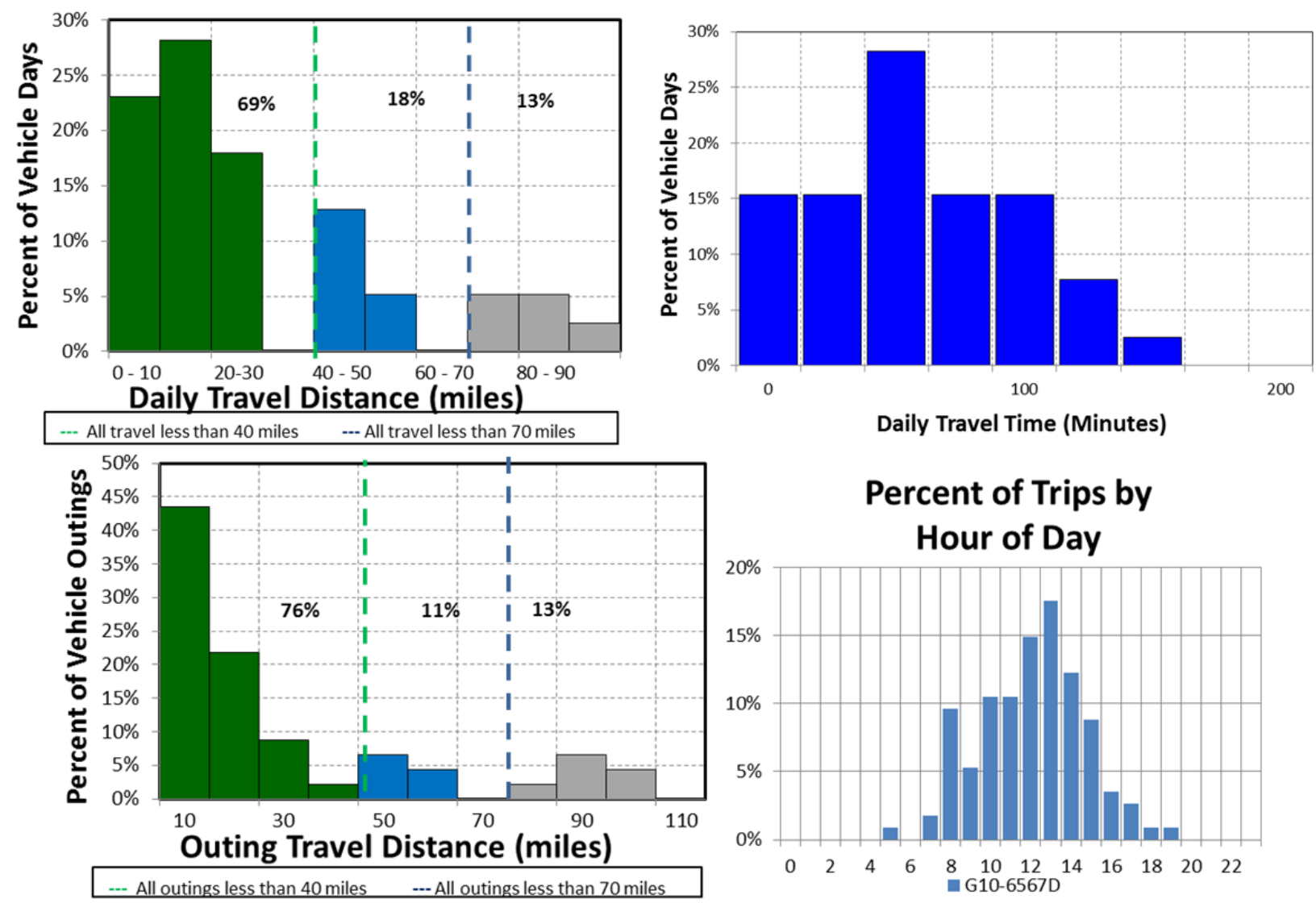

Figure B-18. Vehicle G10-6567D travel graphs.

\section{Vehicle G10-6567D Observations}

Logger 14 collected data on this vehicle for 39 days of the 77 -day study period. Validation occurred on $98.7 \%$ of the input data. USCG HQ reports that this vehicle has a pool mission for administration. This vehicle's data indicate it parks near HQ on Half St (Figure B-16 and Google Earth figure to the right).

USCG HQ reports that the vehicle odometer indicated 17,108 miles during the study and an annual mileage of approximately 4,000 miles. The vehicle was used on $51 \%$ of the available days, with an average daily usage of 1.1 hours and a peak daily usage of 2.7 hours on the days it was used. The vehicle was used during typical day shift hours.

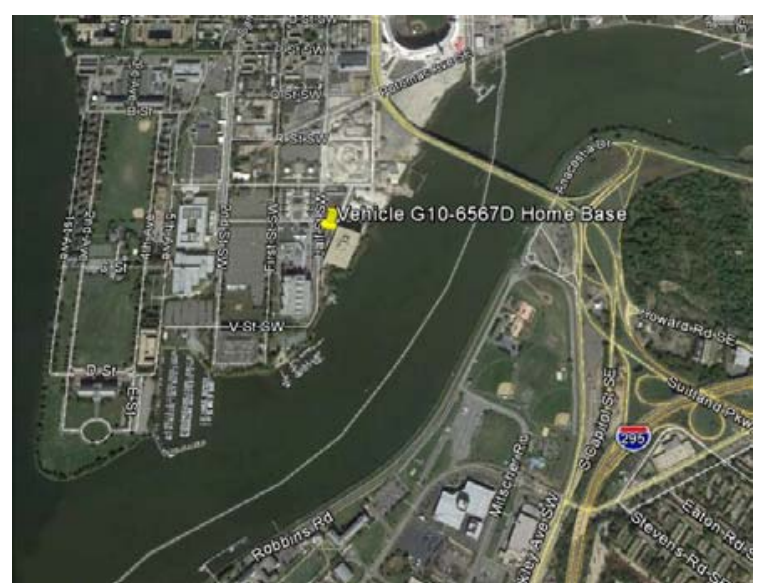

Figure B-18 shows $87 \%$ of daily travel and $87 \%$ of outings were within the typically advertised range of a BEV of approximately 70 miles. Further, $69 \%$ of daily travel and $76 \%$ of outings were within the typically advertised CD mode of 40 miles for PHEVs.

A BEV could not meet all daily travel noted without additional charge opportunities. A BEV could provide benefits for a significant amount of travel that was local. Thus, a fleet of support vehicles with this mission would likely contain a mix of BEVs and PHEVs. 
Vehicle G41-4397L

\begin{tabular}{|c|c|c|}
\hline & Make/Model/Year & Dodge Grand Caravan/2011 \\
\hline & EPA Class Size & Minivan \\
\hline 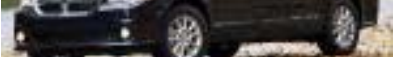 & Mission & Pool \\
\hline 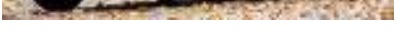 & VIN & 2D4RN4DG3BR763990 \\
\hline & Parking Location & Half St \\
\hline & Fleet Vehicle ID & G41-4397L \\
\hline & Fuel Type & Gas/E85 \\
\hline & EPA Label/MPG (City/Hwy/Combined) & $17 / 25 / 20 \quad 12 / 18 / 14$ \\
\hline & EPA GHG Emissions (Grams $\mathrm{CO}_{2} / \mathrm{Mi}$ ) & $444 / 443$ \\
\hline & Study Logger ID & 15 \\
\hline & Total Vehicle Days/Total Study Days & $50 / 76$ \\
\hline
\end{tabular}

\begin{tabular}{|l|c|c|c|c|}
\hline \multicolumn{5}{|c|}{ Vehicle G41-4397L Travel Summary } \\
\hline & $\begin{array}{c}\text { Per Day } \\
\text { Average/Peak }\end{array}$ & $\begin{array}{c}\text { Per Outing } \\
\text { Average/Peak }\end{array}$ & $\begin{array}{c}\text { Per Trip } \\
\text { Average/Peak }\end{array}$ & Total \\
\hline Travel Distance (Miles) & $47.4 / 226.5$ & $56.4 / 436.7$ & $14.0 / 192.3$ & 2,370 \\
\hline Travel Time (Minutes) & $100.0 / 290.0$ & $118.5 / 1,072.0$ & $29.4 / 185.0$ & 4,975 \\
\hline Idle Time (Minutes) & $20.4 / \mathrm{NA}$ & $24.3 / \mathrm{NA}$ & $6.0 / \mathrm{NA}$ & 1,022 \\
\hline
\end{tabular}

\begin{tabular}{|c|c|c|c|c|}
\hline \multicolumn{3}{|c|}{ Total Stops } & \multicolumn{2}{c|}{ Stop Duration } \\
\hline $\begin{array}{c}\text { Distance From } \\
\text { Home Base (Miles) }\end{array}$ & Stops & Percentages & Stop Duration (Hours) & Stops \\
\hline Less than 10 & 94 & $71.2 \%$ & Less than 2 & 86 \\
\hline 10 to 20 & 1 & $0.8 \%$ & 2 to 4 & 10 \\
\hline 20 to 40 & 17 & $12.9 \%$ & 4 to 8 & 5 \\
\hline Greater than 40 & 20 & $15.1 \%$ & Greater than 8 & 31 \\
\hline
\end{tabular}

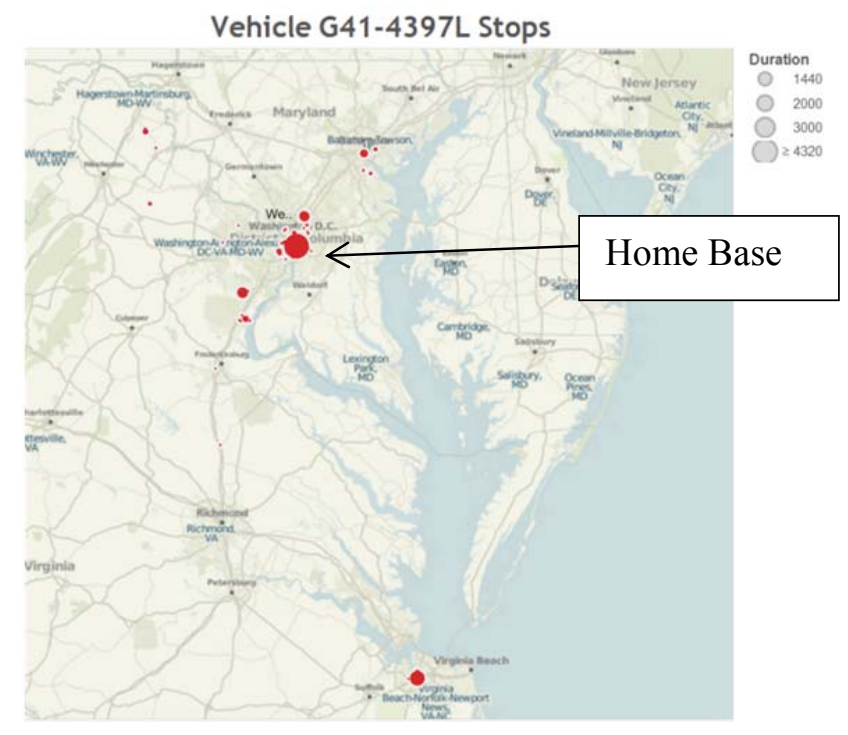

Figure B-19. Vehicle G41-4397L stops.

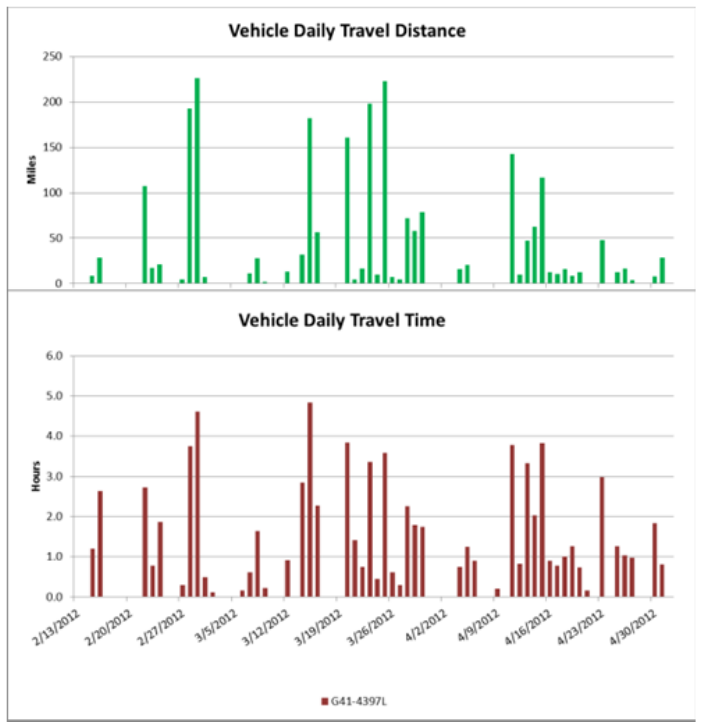

Figure B-20. Vehicle G41-4397L history. 


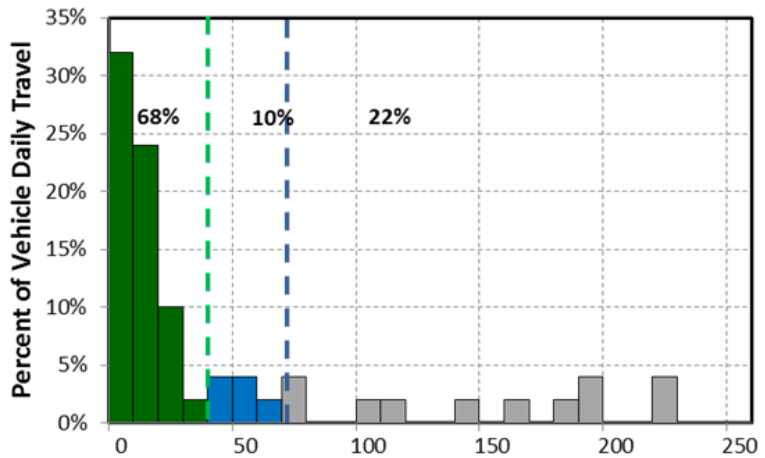

Daily Travel Distance (miles)

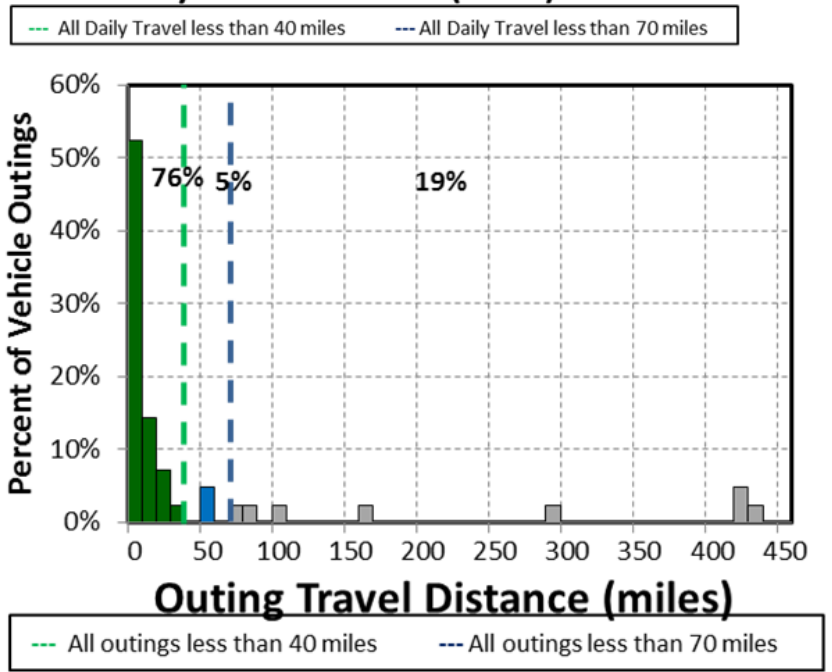

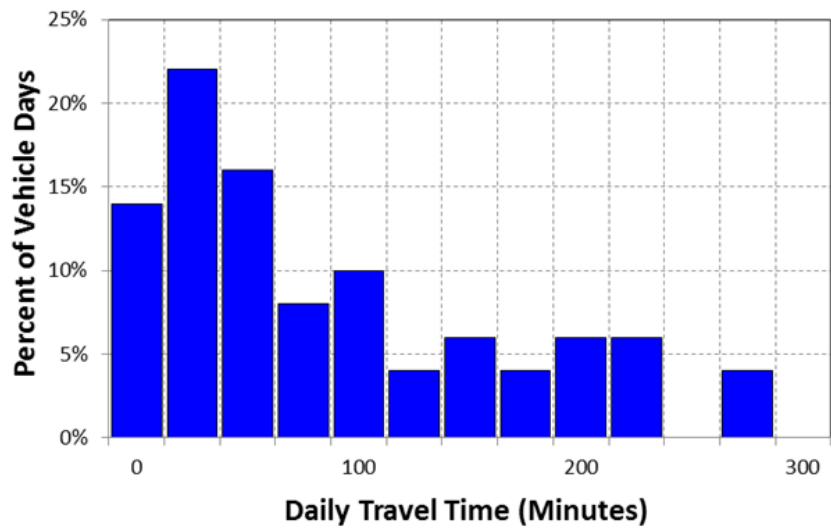

Percent of Trips by Hour of Day

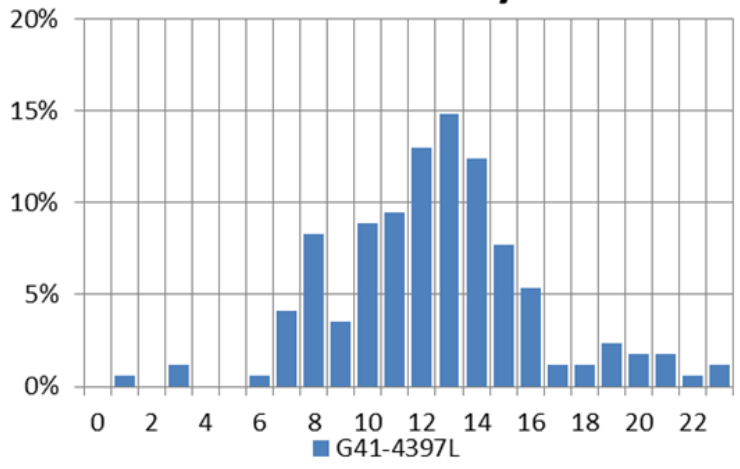

Figure B-21. Vehicle G41-4397L travel graphs.

\section{Vehicle G41-4397L Observations}

Logger 15 collected data on this vehicle for 50 days of the 76-day study period. Validation occurred on $96.9 \%$ of the input data. USCG HQ reports that this vehicle has a pool mission for administration. This vehicle's data indicate it parks near HQ on Half St or $1^{\text {st }} \mathrm{St}$ (Figure B-19 and Google Earth figure to the right).

USCG HQ reports that the vehicle odometer indicated 4,133 miles during the study and an annual mileage of approximately 5,760 miles. The vehicle was used on $66 \%$ of the available days, with an average daily usage of 1.7 hours and a peak daily usage of 4.8 hours on the days it was used. The vehicle was used during typical day shift hours.

Figure B-21 shows $88 \%$ of daily travel and $81 \%$ of outings were

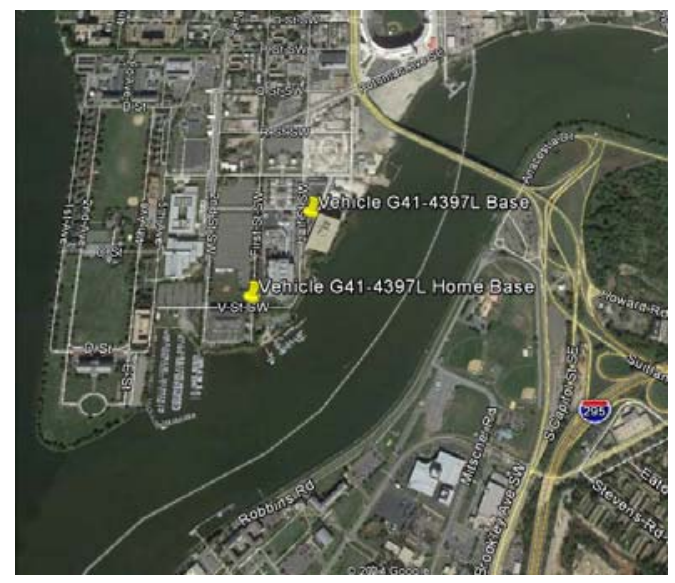
within the typically advertised range of a BEV of approximately 70 miles. Further, $68 \%$ of daily travel and $76 \%$ of outings were within the typically advertised CD mode of 40 miles for PHEVs.

A BEV could not meet all daily travel noted without additional charge opportunities. A BEV could provide benefits for a significant amount of travel that was local. Thus, a fleet of support vehicles with this mission would likely contain a mix of BEVs and PHEVs. 


\section{Vehicle G41-3785K}

\begin{tabular}{|l|l|c|}
\hline & Make/Model/Year & Dodge Caravan/2010 \\
\cline { 2 - 3 } & EPA Class Size & Minivan \\
\hline & Mission & Pool \\
\hline VIN & 2D4RN4DE7AR334848 \\
\cline { 2 - 3 } & Parking Location & $10^{\text {th }} \mathrm{St}$ \\
\hline Fleet Vehicle ID & $\mathrm{G} 41-3785 \mathrm{~K}$ \\
\hline & Fuel Type & Gas/E85 \\
\cline { 2 - 3 } & EPA Label/MPG (City/Hwy/Combined) & $17 / 24 / 1912 / 17 / 13$ \\
\cline { 2 - 3 } & EPA GHG Emissions (Grams CO $/$ Mi) & $468 / 477$ \\
\cline { 2 - 3 } & Study Logger ID & 16 \\
\cline { 2 - 3 } & Total Vehicle Days/Total Study Days & $50 / 78$ \\
\hline
\end{tabular}

\begin{tabular}{|l|c|c|c|c|}
\hline \multicolumn{5}{|c|}{ Vehicle G41-3785K Travel Summary } \\
\hline & $\begin{array}{c}\text { Per Day } \\
\text { Average/Peak }\end{array}$ & $\begin{array}{c}\text { Per Outing } \\
\text { Average/Peak }\end{array}$ & $\begin{array}{c}\text { Per Trip } \\
\text { Average/Peak }\end{array}$ & Total \\
\hline Travel Distance (Miles) & $41.9 / 114.7$ & $10.7 / 85.9$ & $3.2 / 24.2$ & 2,094 \\
\hline Travel Time (Minutes) & $271.0 / 502.0$ & $69.4 / 460.0$ & $20.9 / 145.0$ & 13,537 \\
\hline Idle Time (Minutes) & $83.0 / \mathrm{NA}$ & $21.3 / \mathrm{NA}$ & $6.4 / \mathrm{NA}$ & 4,151 \\
\hline
\end{tabular}

\begin{tabular}{|c|c|c|c|c|}
\hline \multicolumn{2}{|c|}{ Total Stops } & \multicolumn{2}{c|}{ Stop Duration } \\
\hline $\begin{array}{c}\text { Distance From } \\
\text { Home Base (Miles) }\end{array}$ & Stops & Percentages & Stop Duration (Hours) & Stops \\
\hline Less than 10 & 554 & $100 \%$ & Less than 2 & 501 \\
\hline 10 to 20 & 0 & $0 \%$ & 2 to 4 & 6 \\
\hline 20 to 40 & 0 & $0 \%$ & 4 to 8 & 1 \\
\hline 40 to 60 & 0 & $0 \%$ & Greater than 8 & 46 \\
\hline
\end{tabular}

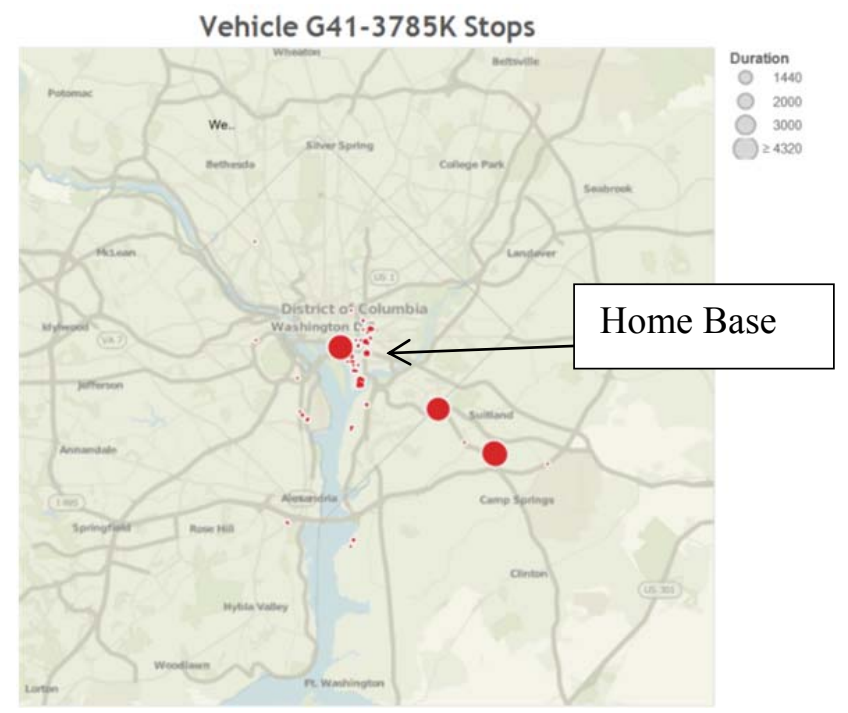

Figure B-22. Vehicle G41-3785K stops.

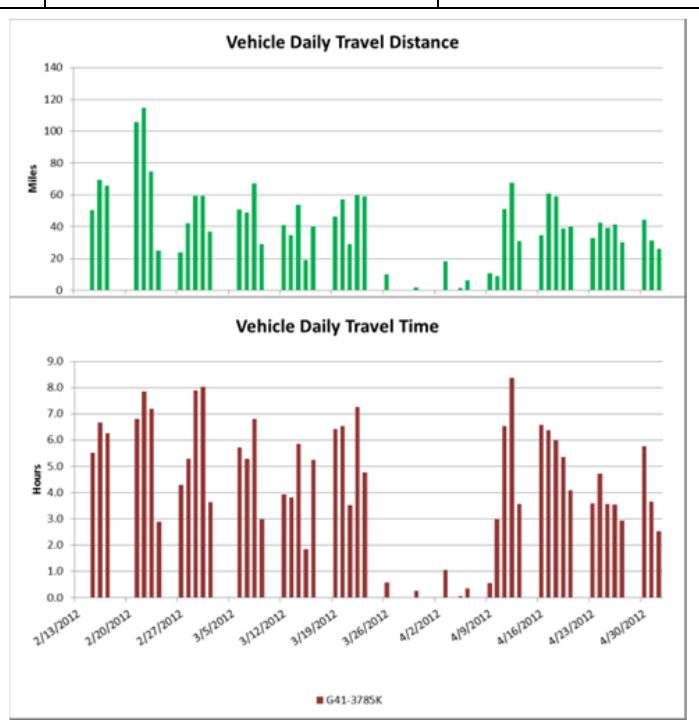

Figure B-23. Vehicle G41-3785K history. 


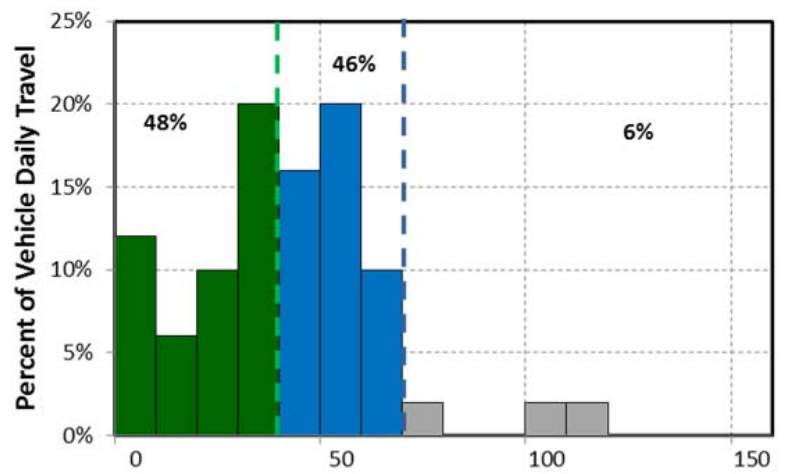

Daily Travel Distance (miles)

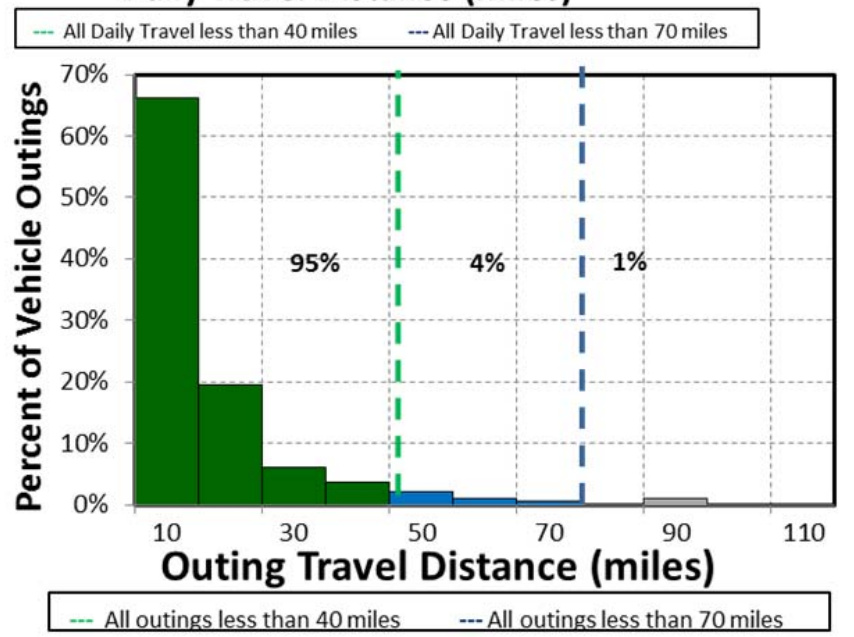

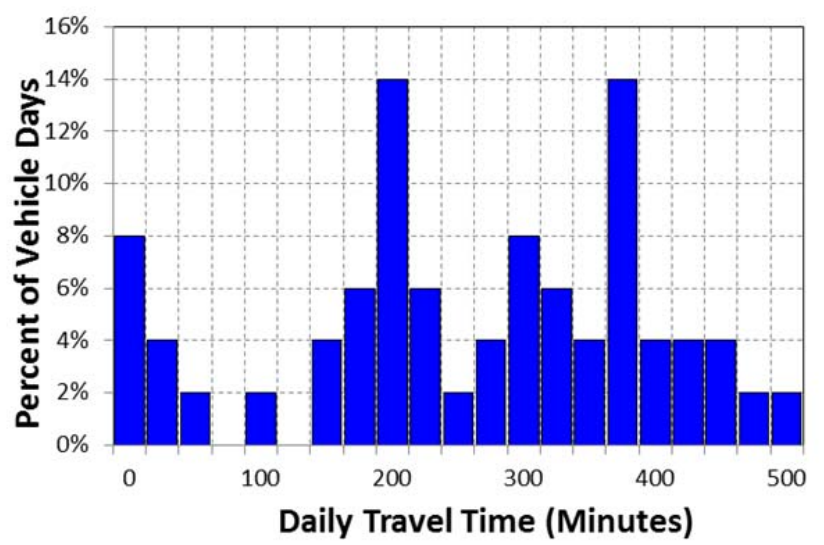

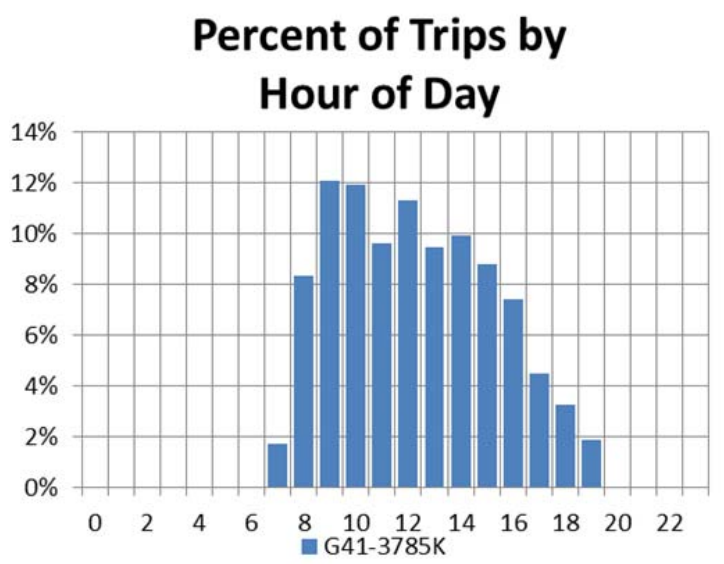

Figure B-24. Vehicle G41-3785K travel graphs.

\section{Vehicle G41-3785K Observations}

Logger 16 collected data on this vehicle for 50 days of the 78 -day study period. Validation occurred on $99.8 \%$ of the input data. USCG HQ reports that this vehicle has a pool mission for administration. This vehicle's data indicate it parks on 10th St (Figure B-22 and Google Earth figure to the right).

USCG HQ reports that the vehicle odometer indicated 12,654 miles during the study and an annual mileage of approximately 6,600 miles. The vehicle was used on $64 \%$ of the available days, with an average daily usage of 4.5 hours and a peak daily usage of 8.4 hours on the days it was used. The vehicle was used during typical day shift hours.

Figure B-24 shows $94 \%$ of daily travel and $99 \%$ of outings were within the typically advertised range of a BEV of

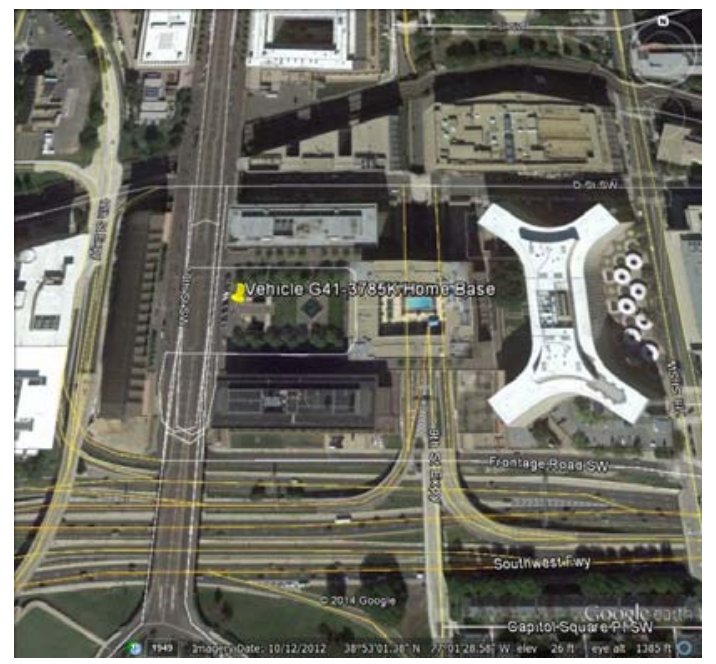
approximately 70 miles. Further, $48 \%$ of daily travel and $95 \%$ of outings were within the typically advertised CD mode of 40 miles for PHEVs.

A BEV could not meet all daily travel noted without additional charge opportunities. A BEV could provide benefits for a significant amount of travel that was local. Thus, a fleet of support vehicles with this mission would likely contain a mix of BEVs and PHEVs. 


\section{Vehicle G12-0290L}

\begin{tabular}{|l|l|c|}
\hline & Make/Model/Year & Chevrolet Malibu/2011 \\
\hline EPA Class Size & Sedan - Midsize \\
\hline Mission & Pool \\
\hline VIN & 1 G1ZA5EU3BF361406 \\
\hline Parking Location & $1^{\text {st }} \mathrm{St}$ \\
\hline Fleet Vehicle ID & $\mathrm{G} 12-0290 \mathrm{~L}$ \\
\hline Fuel Type & $\mathrm{Gas} / \mathrm{E} 85$ \\
\hline EPA Label/MPG $($ City/Hwy/Combined $)$ & $22 / 33 / 2615 / 23 / 18$ \\
\hline & EPA GHG Emissions $(\mathrm{Grams} \mathrm{CO} / \mathrm{Mi})$ & $342 / 345$ \\
\hline & Study Logger ID & 17 \\
\hline & Total Vehicle Days/Total Study Days & $45 / 76$ \\
\hline
\end{tabular}

\begin{tabular}{|l|c|c|c|c|}
\hline \multicolumn{5}{|c|}{ Vehicle G12-0290L Travel Summary } \\
\hline & $\begin{array}{c}\text { Per Day } \\
\text { Average/Peak }\end{array}$ & $\begin{array}{c}\text { Per Outing } \\
\text { Average/Peak }\end{array}$ & $\begin{array}{c}\text { Per Trip } \\
\text { Average/Peak }\end{array}$ & Total \\
\hline Travel Distance (Miles) & $28.8 / 310.0$ & $43.2 / 368.0$ & $8.2 / 155.1$ & 1,297 \\
\hline Travel Time (Minutes) & $94.0 / 428.0$ & $140.6 / 566.0$ & $26.7 / 204.0$ & 4,219 \\
\hline Idle Time (Minutes) & $26.0 / \mathrm{NA}$ & $39.1 / \mathrm{NA}$ & $7.4 / \mathrm{NA}$ & 1,172 \\
\hline
\end{tabular}

\begin{tabular}{|c|c|c|c|c|}
\hline \multicolumn{3}{|c|}{ Total Stops } & \multicolumn{2}{c|}{ Stop Duration } \\
\hline $\begin{array}{c}\text { Distance From } \\
\text { Home Base (Miles) }\end{array}$ & Stops & Percentages & Stop Duration (Hours) & Stops \\
\hline Less than 10 & 98 & $87.4 \%$ & Less than 2 & 83 \\
\hline 10 to 20 & 2 & $1.8 \%$ & 2 to 4 & 6 \\
\hline 20 to 40 & 2 & $1.8 \%$ & 4 to 8 & 3 \\
\hline Greater than 40 & 10 & $9.0 \%$ & Greater than 8 & 20 \\
\hline
\end{tabular}

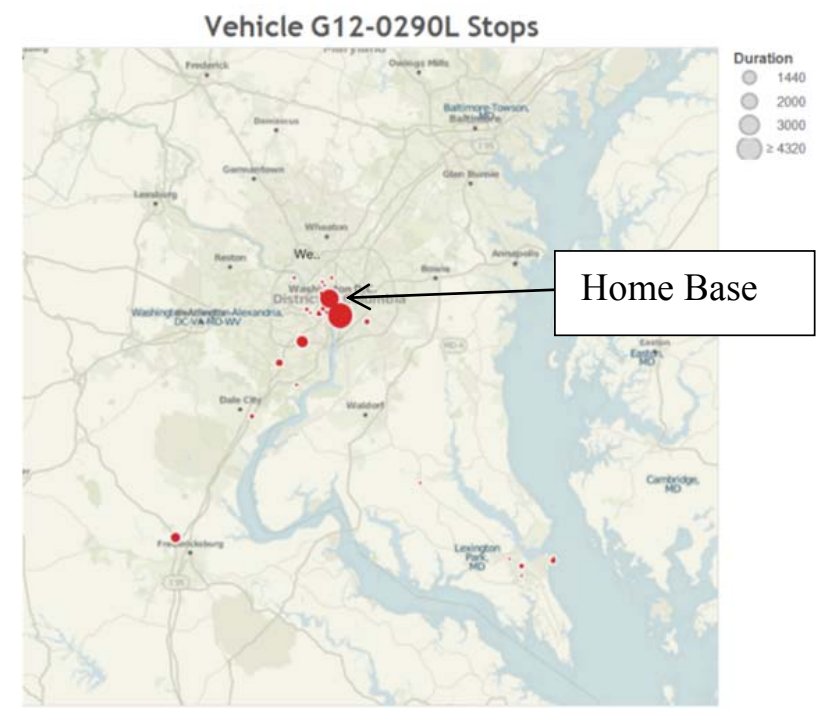

Figure B-25. Vehicle G12-0290L stops.

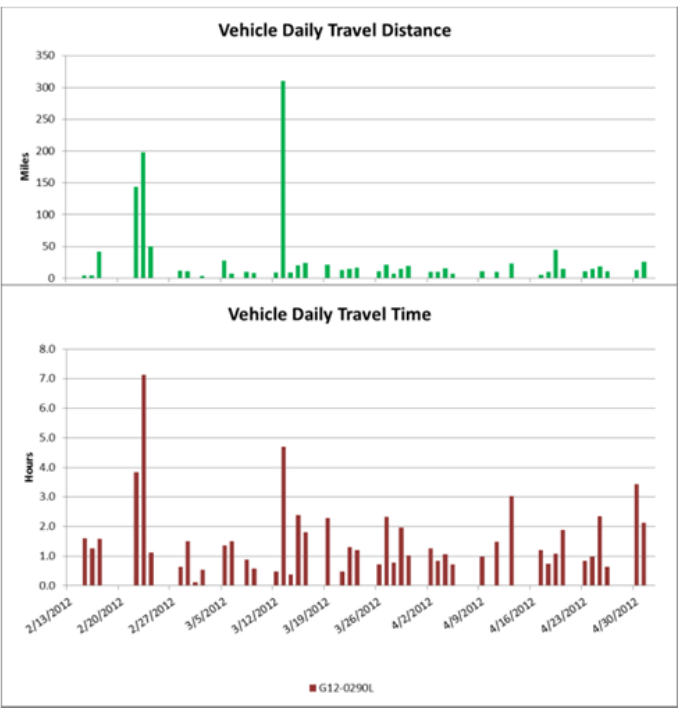

Figure B-26. Vehicle G12-0290L history. 


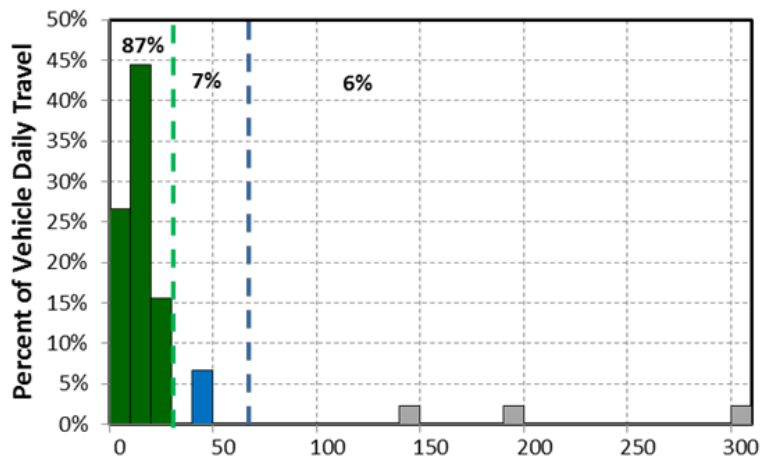

Daily Travel Distance (miles)

--- All Daily Travel less than 40 miles $\quad$---All Daily Travel less than 70 miles

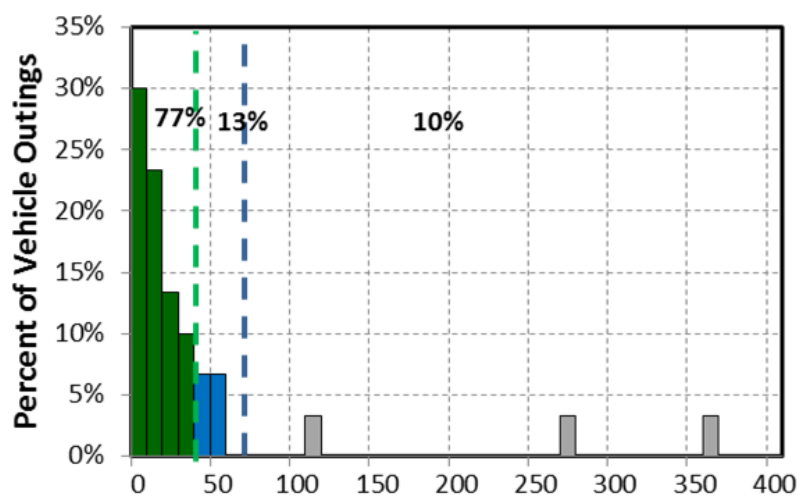

Outing Travel Distance (miles)

--- All outings less than 40 miles ---All outings less than 70 miles

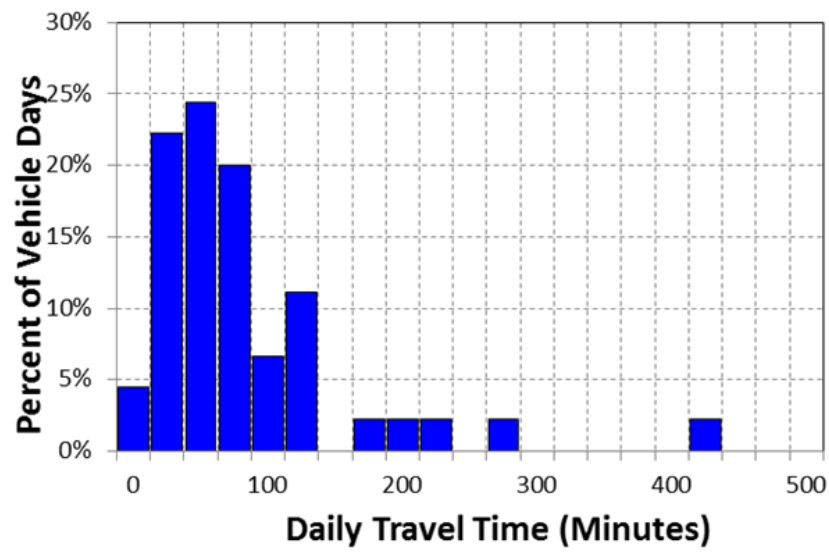

Percent of Trips by Hour of Day

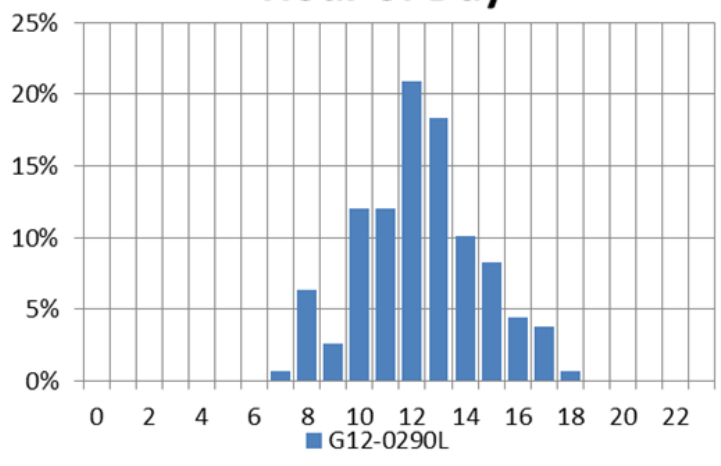

Figure B-27. Vehicle G12-0290L travel graphs.

\section{Vehicle G12-0290L Observations}

Logger 17 collected data on this vehicle for 45 days of the 76-day study period. Validation occurred on $97.4 \%$ of the input data. USCG HQ reports that this vehicle has a pool mission for administration. This vehicle's data indicate it parks near HQ on $1^{\text {st }} \mathrm{St} / 2^{\text {nd }} \mathrm{St}$ or V St (Figure B-25 and Google Earth figure to the right).

USCG HQ reports that the vehicle odometer indicated 5,693 miles during the study and an annual mileage of approximately 7,200 miles. The vehicle was used on $59 \%$ of the available days, with an average daily usage of 1.6 hours and a peak daily usage of 7.1 hours on the days it was used. The vehicle was used during typical day shift hours.

Figure B-27 shows $94 \%$ of daily travel and $90 \%$ of outings were within the typically advertised range of a BEV of approximately 70 miles. Further, $87 \%$ of daily travel and $77 \%$ of outings were within the typically advertised CD mode for PHEVs of 40 miles.

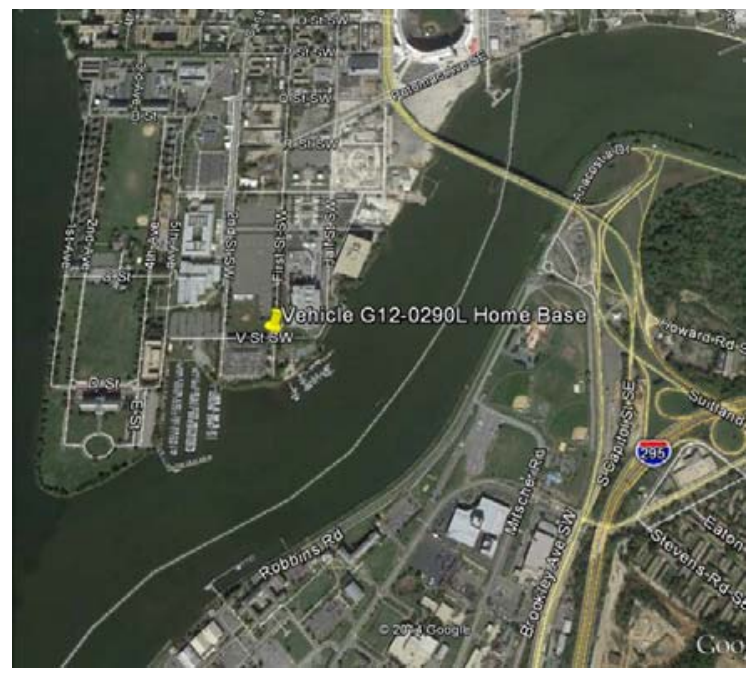

A BEV could not meet all daily travel noted without additional charge opportunities. A BEV could provide benefits for a significant amount of travel that was local. Thus, a fleet of support vehicles with this mission would likely contain a mix of BEVs and PHEVs. 


\begin{tabular}{|l|l|c|}
\hline Make/Model/Year & Pontiac G6/2008 \\
\hline EPA Class Size & Sedan - Compact \\
\hline Mission & Pool \\
\hline VIN & $1 \mathrm{G} 2 \mathrm{ZG} 57 \mathrm{~B} 284232924$ \\
\hline Parking Location & $1^{\text {st }} \mathrm{St}$ \\
\hline Fleet Vehicle ID & $\mathrm{G} 10-6590 \mathrm{D}$ \\
\hline & Fuel Type & $\mathrm{Gas}$ \\
\hline EPA Label/MPG (City/Hwy/Combined) & $22 / 30 / 25$ \\
\hline & EPA GHG Emissions $\left(\mathrm{Grams} \mathrm{CO}_{2} / \mathrm{Mi}\right)$ & 355 \\
\hline & Study Logger ID & 18 \\
\hline & Total Vehicle Days/Total Study Days & $47 / 77$ \\
\hline
\end{tabular}

\begin{tabular}{|l|c|c|c|c|}
\hline \multicolumn{5}{|c|}{ Vehicle G10-6590D Travel Summary } \\
\hline & $\begin{array}{c}\text { Per Day } \\
\text { Average/Peak }\end{array}$ & $\begin{array}{c}\text { Per Outing } \\
\text { Average/Peak }\end{array}$ & $\begin{array}{c}\text { Per Trip } \\
\text { Average/Peak }\end{array}$ & Total \\
\hline Travel Distance (Miles) & $19.4 / 64.8$ & $24.7 / 93.1$ & $6.9 / 34.7$ & 814 \\
\hline Travel Time (Minutes) & $76.0 / 438.0$ & $96.5 / 396.0$ & $26.8 / 359.0$ & 3,570 \\
\hline Idle Time (Minutes) & $22.2 / \mathrm{NA}$ & $28.2 / \mathrm{NA}$ & $7.8 / \mathrm{NA}$ & 1,043 \\
\hline
\end{tabular}

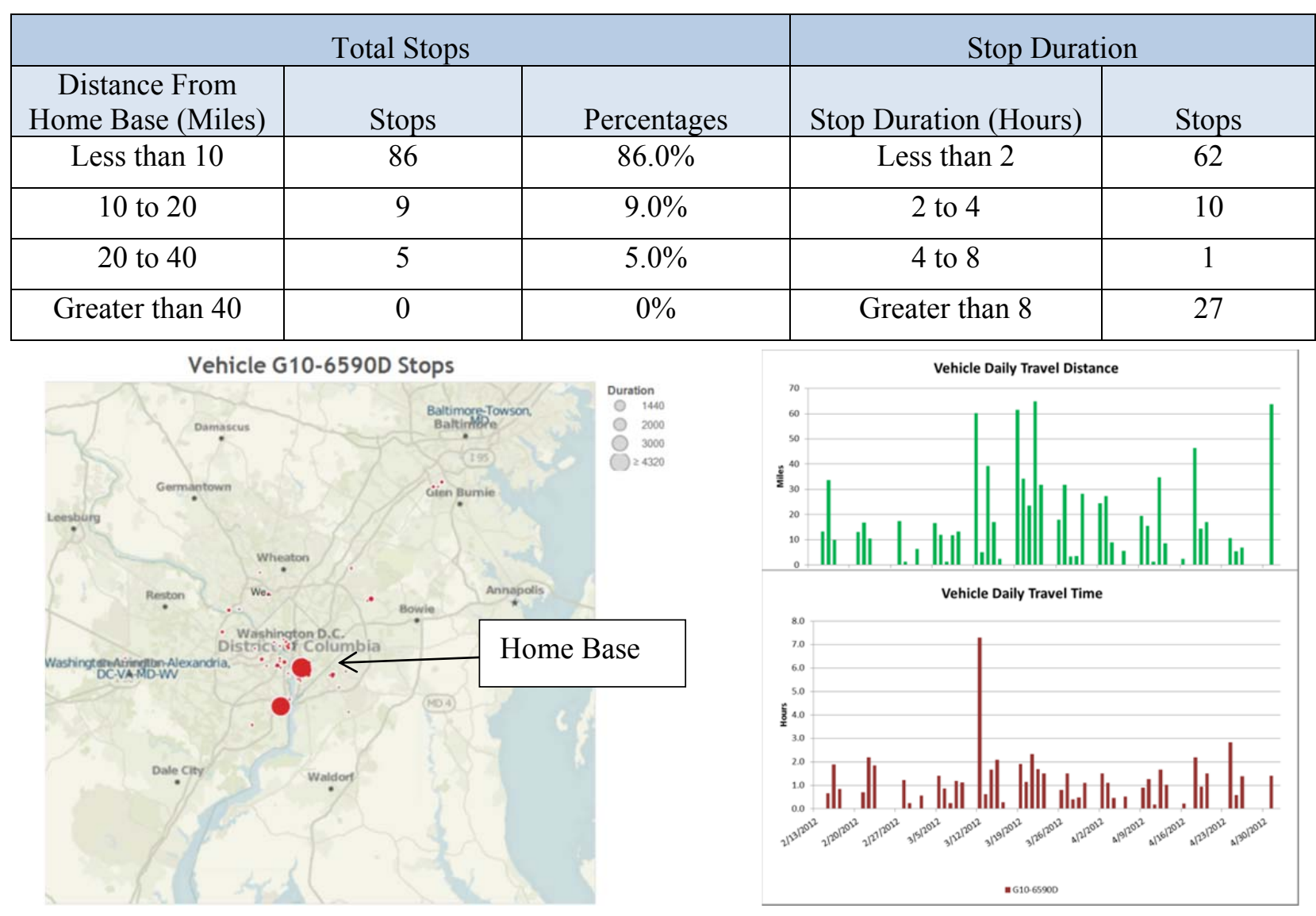

Figure B-28. Vehicle G10-6590D stops.

Figure B-29. Vehicle G10-6590D history. 

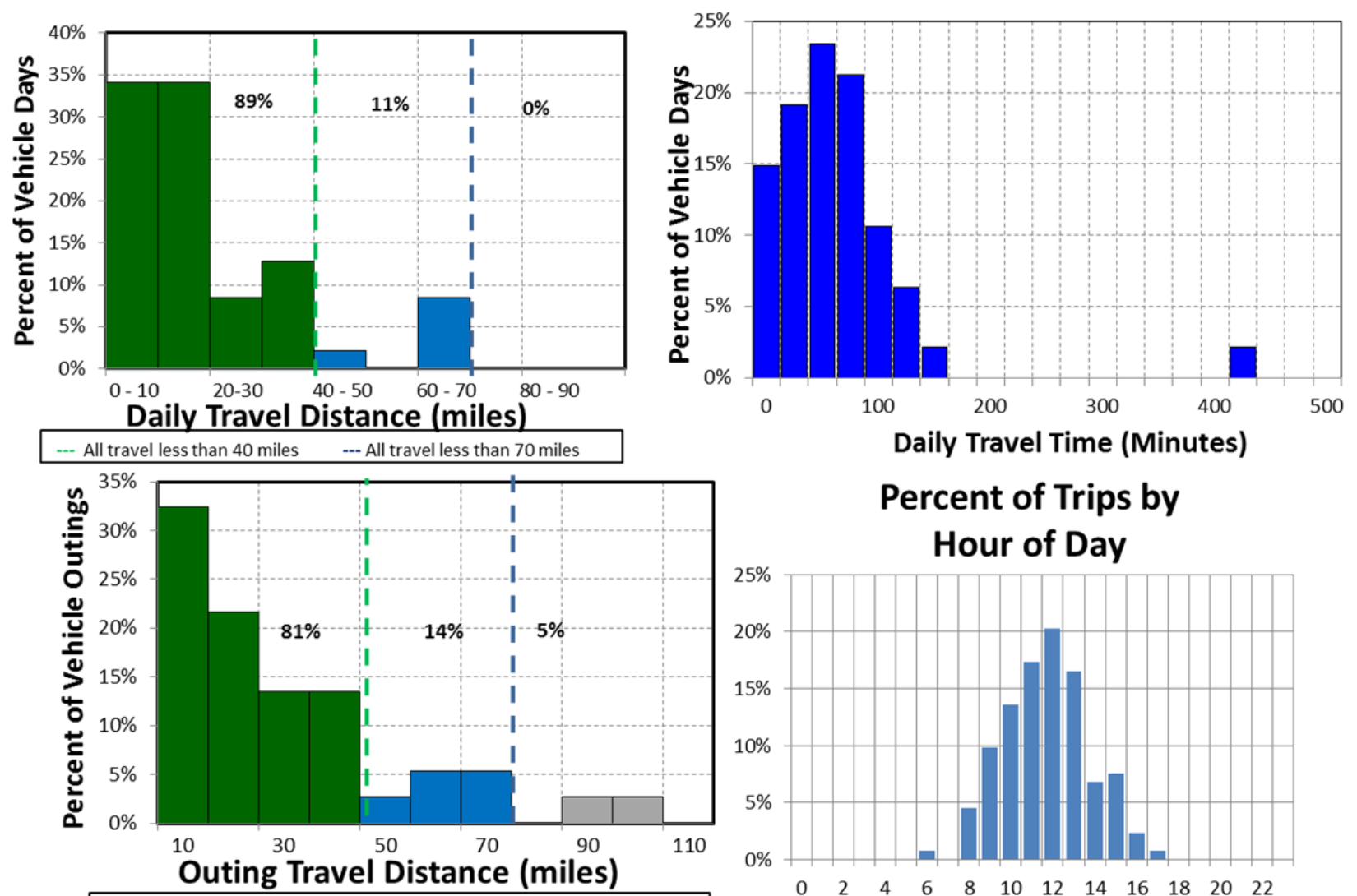

-. All outings less than 40 miles _..-All outings less than 70 miles

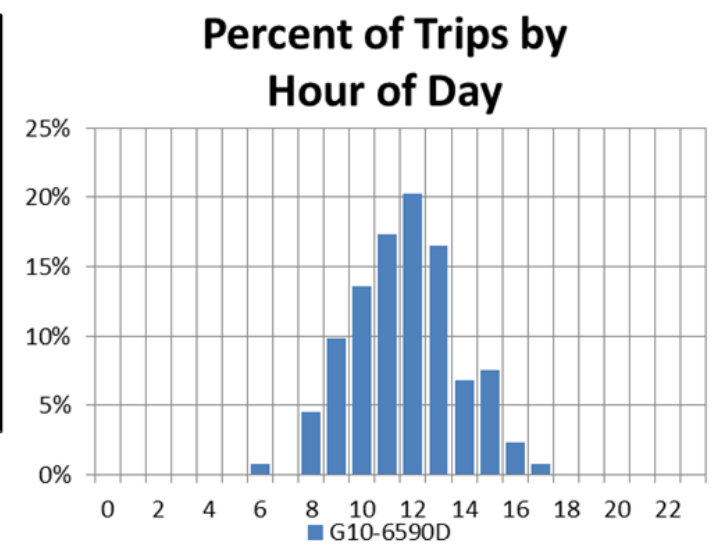

Figure B-30. Vehicle G10-6590D travel graphs.

\section{Vehicle G10-6590D Observations}

Logger 18 collected data on this vehicle for 47 days of the 77 -day study period. Validation occurred on $97.4 \%$ of the input data. USCG HQ reports that this vehicle has a pool mission for administration. This vehicle's data indicate it parks near HQ on $1^{\text {st }} \mathrm{St} / 2^{\text {nd }} \mathrm{St}$ or V St (Figure B-28 and Google Earth figure to the right).

USCG HQ reports that the vehicle odometer indicated 27,159 miles during the study and an annual mileage of approximately 7,500 miles. The vehicle was used on $61 \%$ of the available days, with an average daily usage of 1.3 hours and a peak daily usage of 7.3 hours on the days it was used. The vehicle was used during typical day shift hours.

Figure B-30 shows $100 \%$ of daily travel and $95 \%$ of

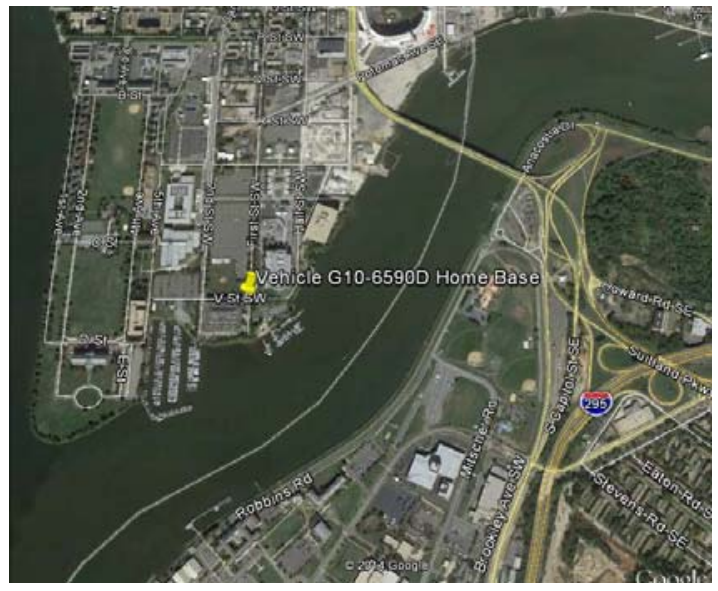
outings were within the typically advertised range of a BEV of approximately 70 miles. Further, $89 \%$ of daily travel and $91 \%$ of outings were within the typically advertised CD mode of 40 miles for PHEVs.

A BEV could meet all daily travel noted without additional charge opportunities. However, a BEV could not meet the occasional overnight away from home outings noted. A BEV would provide benefits for a significant amount of travel that was local. Thus, a fleet of support vehicles with this mission would likely contain a mix of BEVs and PHEVs. 


\section{Appendix C National Fuel Cost and GHG Savings}

Section 5 notes that fuel cost and GHG savings are calculated on a local and a national basis. Local savings are of higher interest to the facility, while national figures are of higher interest in evaluating all sites. Section 5 provides savings on the local level. Table C-1 presents these savings on a national basis for the PEV replacement of monitored vehicles.

Table C-1. Fuel cost and GHG savings on a national basis.

\begin{tabular}{|c|c|c|c|c|c|}
\hline Mission & Replacement Model & $\begin{array}{c}\text { Extrapolated } \\
\text { National Yearly } \\
\mathrm{CO}_{2} \mathrm{e} \mathrm{Avoided} \\
\left(\mathrm{lb}_{-} \mathrm{CO}_{2} \mathrm{e} / \text { year) }\right.\end{array}$ & $\%$ reduction & $\begin{array}{c}\text { Extrapolated } \\
\text { National Yearly } \\
\text { Fuel Cost } \\
\text { Reduction } \\
\end{array}$ & $\%$ reduction \\
\hline Pool & Outlander & 1,828 & $36 \%$ & $\$ 508$ & $71 \%$ \\
\hline Pool & Volt & 1,389 & $33 \%$ & $\$ 412$ & $70 \%$ \\
\hline Pool & Fusion & 1,585 & $38 \%$ & $\$ 425$ & $72 \%$ \\
\hline Pool & Focus & 2,473 & $41 \%$ & $\$ 627$ & $73 \%$ \\
\hline Pool & Rav4 & 1,991 & $33 \%$ & $\$ 596$ & $70 \%$ \\
\hline Pool & Volt & 1,334 & $33 \%$ & $\$ 396$ & $70 \%$ \\
\hline Pool & Outlander & 1,300 & $33 \%$ & $\$ 389$ & $70 \%$ \\
\hline Pool & Rav4 & 2,539 & $36 \%$ & $\$ 705$ & $71 \%$ \\
\hline Pool & Leaf & 2,261 & $41 \%$ & $\$ 578$ & $73 \%$ \\
\hline \multirow[t]{2}{*}{ Pool } & Focus & 2,473 & $41 \%$ & $\$ 627$ & $73 \%$ \\
\hline & Total & 19,172 & $37 \%$ & $\$ 5,264$ & $71 \%$ \\
\hline
\end{tabular}

